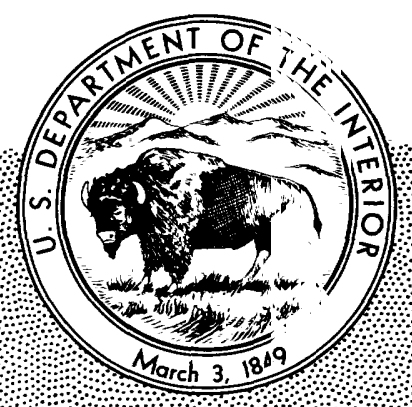

\title{
An Enhanced Digital Line Graph Design
}




\section{AVAILABILITY OF BOOKS AND MAPS OF THE U.S. GEOLOGICAL SURVEY}

Instructions on ordering publications of the U.S. Geological Survey, along with prices of the last offerings, are given in the current-year issues of the monthly catalog "New Publications of the U.S. Geological Survey." Prices of available U.S. Geological Survey publications released prior to the current year are listed in the most recent annual "Price and Availabilit." List." Publications that are listed in various U.S. Geological Survey catalogs (see back inside cover) but not listed in the most recent annual "Price and Availability List" are no longer available.

Prices of reports released to the open files are given in the listing "U.S. Geological Survey Open-File Reports." updated monthly, which is for sale in microfiche from the U.S. Geological Survey. Books and Open-File Reports Section, Federal Center, Box 25425. Denver, CO 80225. Reports released through the NTIS may be obtained by writing to the National Technical Information Service, U.S. Department of Commerce, Springfield. VA 22161; please include NTIS report number with inquiry.

Order U.S. Geological Survey publications by mail or over the counter from the offices given below.

\section{BY MAIL}

\section{Books}

Professional Papers, Bulletins. Water-Supply Papers, Techniques of Water-Resources Investigations. Circulars, publications of general interest (such as leaflets, pamphlets. booklets). single copies of Earthquakes \& Volcanoes. Preliminary Determination of Epicenters, and some miscellaneous reports, including some of the foregoing series that have gone out of print at the Superintendent of Documents. are obtainable by mail from

\section{U.S. Geological Survey, Books and Open-File Reports Federal Center, Box 25425 Denver, CO 80225}

Subscriptions to periodicals (Earthquakes \& Volcanoes and Preliminary Determination of Epicenters $)$ can be obtained ONLY from the

\section{Superintendent of Documents Government Printing Office Washington, D.C. 20402}

(Check or money order must be payable to Superintendent of Documents.)

\section{Maps}

For maps, address mail orders to

\section{U.S. Geolegical Survey, Map Distribution Federal Center, Box 25286 \\ Denver, CO 80225}

Residents of Alaska may order maps from

\author{
Alaska Distribution Section, U.S. Geological Survey \\ New Federal Building - Box 12 \\ 101 Twelfth Ave., Fairbanks, AK 99701
}

\section{OVER THE COUNTER}

\section{Books}

Books of the U.S. Geological Survey are available over the counter at the following U.S. Geological Survey Public Inquiries Offices, all of which are authorized agents of the Superintendent of Documents:

- WASHINGTON, D.C.-Main Interior Pldg.. 2600 corridor, 18th and C Sts., NW.

- DENVER, Colorado--Federal Bldg., Rm. 169. 1961 Stout St.

- LOS ANGELES, California-Federal Bldg., Rm. 7638, 300 N. Los Angeles St.

- MENLO PARK, California-Bldg. 3 (Sto? 533), Rm. 3128, 345 Middlefield Rd.

- RESTON, Virginia-503 National Center, Rm. 1C402, 12201 Sunrise Valley Dr.

- SALT LAKE CITY, Utah-Federal Bldg., Rm. 8105, 125 South State St.

- SAN FRANCISCO, California-Customhouse, Rm. 504, 555 Battery St.

- SPOKANE, Washington-U.S. Courthouse, Rm. 678, West 920 Riverside Ave.

- ANCHORAGE, Alaska-Rm. 101, 4230 University Dr.

- ANCHORAGE, Alaska-Federal Bldg., Pm. E-146. 701 C St.

\section{Maps}

Maps may be purchased over the counter at the U.S. Geological Survey offices where books are sold (all addresses in above list) and at the following U.S. Geological Survey offices:

- ROLLA, Missouri-1400 Independence Rd.

- DENVER, Colorado-Map Distribution, Bldg. 810, Federal Center

- FAIRBANKS, Alaska-New Federal Bldg., 101 Twelfth Ave. 


\title{
An Enhanced Digital Line Graph Design
}

\author{
STEPHEN C. GUPTILL, Editor
}

KENNETH J. BOYKO, MICHAEL A. DOMARATZ, ROBIN G. FEGEAS, HEDY J. ROSSMEISSL, and E. LYNN USERY, Contributing Authors

A feature-based data model for digital spatial data bases that represent geographic phenomenon 


\section{DEPARTMENT OF THE INTERIOR \\ MANUEL LUJAN, Jr., Secretary}

\section{U.S. GEOLOGICAL SURVEY}

Dallas L. Peck, Director

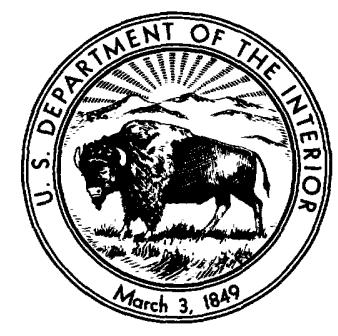

Any use of trade, product, or firm names in this publication is for descriptive purposes only and does not imply endorsement by the U.S. Government

Free on application to the

Books and Open-File Reports Section

U.S. Geological Survey

Federal Center, Box 25425

Denver, CO 80225

\section{Library of Congress Cataloging in Publication Data}

An Enhanced digital line graph design : a feature-based data model for digital spatial data bases that represent geographic phenomenon / Stephen C.

Guptill, editor ; Kenneth J. Boyko ... [et al.].

p. $\mathrm{cm}$.

Includes bibliographical references.

Supt. of Docs. no.: I 19.4/2:1048

1. Digital mapping. I. Guptill, Stephen C. II. Boyko, Kenneth J.

GA139.E54 $1991 \quad 526^{\prime} .0285-$ dc20 


\section{PREFACE}

This circular is the result of several years of work on the part of a number of individuals. Within the National Mapping Division, two groups were established to study aspects of the DLG-E design. The first group, the Data Structures Study Team, consisted of Kenneth J. Boyko, Michael A. Domaratz, Robin G. Fegeas, David Hair, and Stephen C. Guptill. This group developed the basic components of the DLG-E data model and issued a report in November 1987. The second group, the Committee Investigating Cartographic Entities, Definitions, and Standards, was responsible for developing the domain of features for use with DLG-E. This group consisted of Hedy J. Rossmeissl, Michael A. Domaratz, John List, and E. Lynn Usery, with Robert D. Rugg and Stephen C. Guptill as advisors. The first report of this group was issued in November 1987, and a subsequent report was issued in April 1988.

This circular attempts to consolidate the efforts of the two groups. In preparing the circular, various individuals focused their efforts on certain aspects of the work. Kenneth Boyko contributed to the data model activity and was instrumental in developing the representation rules and the example data set. Michael Domaratz, who was a member of both the data structure and the feature definition groups, was invaluable in developing feature representation rules and instance definitions. Robin Fegeas developed major portions of the DLG-E data model and its definitions and prepared the transfer specification and DLG-O+ implementations. Hedy Rossmeissl has been the focus of the feature definition activity and has labored to keep order in the face of chaos. Lynn Usery, now on the faculty of the University of Wisconsin, Madison, contributed to the feature definition methodology using the concept of world views. Although they did not directly contribute to this report, the efforts of David Hair and John List in the predecessor activities are gratefully acknowledged. In addition, Robert Rugg provided valuable assistance in developing the feature definitions by sharing with us his experience in developing the entity and attribute definitions for the "Spatial Data Transfer Standard."

Stephen C. Guptill 



\title{
CONTENTS
}

\author{
Preface III \\ Abstract 1 \\ A new design 1 \\ Overview 1 \\ Evolution of the design 2 \\ Concepts of the DLG-E design 2 \\ Entities and features 3 \\ Objects 3 \\ Mathematical foundation of the spatial objects 4 \\ Attributes 4 \\ Relationships 5 \\ DLG-E data model summary 7 \\ Data model definitions 7 \\ Definition of DLG-E features 9 \\ Background 9 \\ Methodology for identifying features 9 \\ Five views 10 \\ Discussion of views 10 \\ Cover 11 \\ Division 12 \\ Ecosystem 13 \\ Geoposition 13 \\ Morphology 13 \\ Examples of feature objects 13 \\ Building 13 \\ Complex 13 \\ Road 14 \\ Representation of features 14 \\ Feature delineation strategies 14 \\ Rules for feature instances 15 \\ Basic features 15 \\ Named features 15 \\ Modeling constructs 16 \\ Modeling of network flows 16 \\ Vertical feature relationships 16 \\ Use of attributes 16 \\ Use of "underpass" 17 \\ Spatial extent 17
}

Using the model to represent cartographic features 17

Data model implementation 17

Summary and future research 18

Summary 18

Future research 18

Selected references 18

Appendix A: DLG-E features A-1

Appendix B: DLG-E example data set B-1

Appendix C: DLG-E data model implemented within the spatial data transfer specification $\mathbf{C}-\mathbf{1}$ 


\section{FIGURES}

1-4. Diagrams showing:

1. Example of an entity: Roosevelt Bridge in the "real world" 3

2. Examples of objects: Representations of the Roosevelt Bridge 3

3. Logical components of the DLG-E data model 8

4. The five views and associated subviews $\mathbf{1 1}$

\section{TABLES}

1. Domain of attribute values for the attribute "operational status" 4

2. The encoding of attribute values for a feature instance 4

3. Example of attributes of attribute values 5

4. Relationships between the objects of the DLG-E data model $\mathbf{5}$

5. Dimensionality of "underpass" instance from intersection of features $\mathbf{1 7}$ 


\title{
An Enhanced Digital Line Graph Design
}

\author{
Stephen C. Guptill, Editor \\ Kenneth J. Boyko, Michael A. Domaratz, Robin G. Fegeas, \\ Hedy J. Rossmeissl, and E. Lynn Usery, Contributing Authors
}

\section{Abstract}

In response to increasing information demands on its digital cartographic data, the U.S. Geological Survey has designed an enhanced version of the Digital Line Graph, termed Digital Line Graph - Enhanced (DLG-E). In the DLG-E model, the phenomena represented by geographic and cartographic data are termed entities. Entities represent individual phenomena in the real world. A feature is an abstraction of a set of entities, with the feature description encompassing only selected properties of the entities (typically the properties that have been portrayed cartographically on a map). Buildings, bridges, roads, streams, grasslands, and counties are examples of features. A feature instance, that is, one occurrence of a feature, is described in the digital environment by feature objects and spatial objects. A feature object identifies a feature instance and its nonlocational attributes. Nontopological relationships are associated with feature objects. The locational aspects of the feature instance are represented by spatial objects. Four spatial objects (points, nodes, chains, and polygons) and their topological relationships are defined. To link the locational and nonlocational aspects of the feature instance, a given feature object is associated with (or is composed of) a set of spatial objects. These objects, attributes, and relationships are the components of the DLG-E data model.

To establish a domain of features for DLG-E, an approach using a set of classes, or views, of spatial entities was adopted. The five views that were developed are cover, division, ecosystem, geoposition, and morphology. The views are exclusive; each view is a self-contained analytical approach to the entire range of world features. Because each view is independent of the others, a single point on the surface of the Earth can be represented under multiple views. Under the five views, over 200 features were identified and defined. This set constitutes an initial domain of DLG-E features.

Manuscript approved for publication August 29, 1989.

\section{A NEW DESIGN}

\section{Overview}

The U.S. Geological Survey has be.en producing digital cartographic data in its Digital Line Graph (DLG) format for almost a decade. During this time, the tasks for which the data are being used have becom? increasingly diverse, placing information demands on the data that were not planned for in their initial design.

In response to these demands, the Geo'ngical Survey (as both a data supplier and a data user) ha- designed an enhanced version of the Digital Line Graph, termed Digital Line Graph - Enhanced (DLG-E). In simole terms, the DLG-E begins with the topological model ncw used in the Survey's present DLG data structure (USGS, 1987a) and builds a cartographic feature layer upon the topology. Features are the sum of our interpretations of phenomena on or near the Earth's surface. Buildings, 1 idges, roads, streams, grasslands, and counties are exampl is of features. The feature definition is open ended, alloving the definition of additional features of interest. The features are described using objects, attributes, and relationships. In addition, the DLG-E will include data quality information based on the recommendations contained ir "The Spatial Data Transfer Standard" (Spatial Data Trarsfer Standard Technical Review Board, 1990).

Several other major agencies that collect digital cartographic data are also considering (or have implemented) new feature-based spatial data model designs. These agencies include the U.S. Bureau of the Census (Marx, 1986; Kinnear, 1987), U.S. Defense Mapping Agency (Defense Mapping Agency, 1988, F. 99-100), the Institut Géographique National (France) (Bemard and Piquet-Pellorce, 1986; Salgé and Piquet-Pellorce, 1986; and Salgé, written commun., 1989), Landesvermessungamt Nordrhein-Westfalen (West Germany) (Barwinski and Brüggemann, 1986; and Brüggemann, written commun., 1987), and the United Kingdom Ordrance Survey (Haywood, 1988, p. 116). This trend toward featurebased data models signals an evolution in the design of spatial data bases and geographic information systems. 


\section{Evolution of the Design}

One of the demands for change arises from the Survey's major system development activity called Mark II. Mark II will be a digital cartographic production system with the National Digital Cartographic Data Base at its hub. Information in the data base will reflect the data content of the National Mapping Program's standard map series. This information will be periodically revised and new graphic products generated using computerassisted cartographic methods. Maintaining the information required to support these processes is a driving force behind the design of an enhanced data model (Guptill, 1986; Morrison and others, 1987).

Numerous examples of user experiences with the existing DLG data could be cited to support requirements for change. Comments have been made on the restrictive nature of the current DLG attribute coding scheme and data formats. One shortcoming of the existing DLG data is that users cannot identify and retrieve individual real world features by name, such as Broad Brook Stream. At present, named features are not carried in DLG data. The Geographic Names Information System (USGS, 1987b) maintains a data base of named features, but there is little compatibility between the two sets of data. Clearly this deficiency needs to be corrected in any new data model design. Other issues related to flexibility, standardization, and compatibility require changes in data content, geographic coverage, accuracy, and consistency among data categories. Although these issues will be addressed in the specifications for DLG-E data products, they impact the design of the data model.

Additionally, the growing sophistication of geographic information systems (GIS's) and the increasing diversity of applications involving GIS and spatial data are beginning to demand a more flexible and comprehensive model for spatial information. This linkage between GIS capabilities and the need for more advanced data structures has been explored by Goodchild (1987).

Translating requirements into data model/structure/format constructs first requires that these constructs be defined and placed in context. The following framework itemizes levels of data abstraction (based on Peuquet, 1984). These levels can serve as steps in refining a design to meet a set of requirements.

Reality is the total phenomena as they actually exist.

Data reality is an abstraction of reality that includes only those entities thought to be relevant to anticipated needs. It is a definition of the scope of the data.

A data model specifies the sets of components and the relationships among the components pertaining to the specific phenomena defined $t y$ the data reality. A data model is independent of specific systems or data structures that organize and manage the data.

A data structure specifies the logical organization of the components of a data model and th: manner in which relationships among component ${ }^{-}$are to be explicitly defined.

A file structure is a set of rules that specify the logical implementation of a data strusture within computing system environments.

Note that the data model is concerned rith defining components and relationships among those components. The next level, data structuring, is the defining of how these components and relationships are organized in a computing environment. An important point to note is that many different data structures may be generat ${ }^{\circ}$ f from one model. The support of a wide range of user requirements dictates the development of a comprehensive data model.

\section{CONCEPTS OF THE DLG-E DESIGI'}

The underlying philosophy of DLG-E is to "view cartography as an information transfer pro:ess that is centered about a spatial data base which can b: considered, in itself, a multifaceted model of geographic reality" (Guptill and Starr, 1984). DLG-E data form the contents of the spatial data base. The DLG-E featres must be representative of a model of geographic reality.

The process of creating a representation of geographic reality, or more accurately of our conceptualization of reality, is variously referred to as semantic data modeling, knowledge representation, semantic netw'ork description, or, perhaps more broadly, conceptual modeling (the various terms have evolved from work in artificial intelligence and data base management research; see Winston, 1984 , or Brodie and Mylopoulus, 1986). Using the terminology of conceptual modeling, the world is comprehended in terms of conceptual objects or entities, which have associated descriptions and are related to e-ch other in meaningful ways (Borgida, 1986). To expres: these ideas, researchers have developed a modeling framework that includes the concepts listed below (adapted f-om Borgida, 1986, and Borgida and others, 1986):

- A model is described as a collection of object descriptions.

-

Objects in the model correspond to entities in the world. 
- Objects are grouped into classes.

- Every object has zero or more attributes/properties which relate it to other objects.

- Classes are also objects. Classes, therefore, are instances of other classes, sometimes called "metaclasses" and may have their own attributes.

- Attributes can have multiple values.

These modeling concepts have been used in the development of the DLG-E data model.

\section{Entities and Features}

A real world phenomenon that is not subdivided into phenomena of the same kind is termed an entity. For example, a bridge is an entity that exists in the real world. Although it has component parts such as a superstructure and deck, it cannot be divided into components that are, themselves, bridges.

A feature describes a class of entities, defined by a selected set of common attributes and relationships that are properties of the corresponding entities. All of the elements of this set of phenomena are homogeneous with respect to the set of selected common attributes and relationships used to define the feature. Spatial data bases and maps are a collection of spatial and nonspatial information about selected features, attributes of the features, and relationships between the features. All geographic features implicitly have location as a defining attribute.

For example, consider a "bridge." A bridge is one of a number of built-up structures on or near the surface of the Earth. The entity "bridge" is the erected unit in the real world (fig. 1). A bridge may be further defined to be a structure erected over a depression or obstacle to carry traffic. Thus, the feature "bridge" (describing a class of real world entities) is an element of a set of phenomena ("erected structures") with the common attributes of function ("to carry traffic") and location. It also has the common relationship of spanning another feature ("over a depression or obstacle").

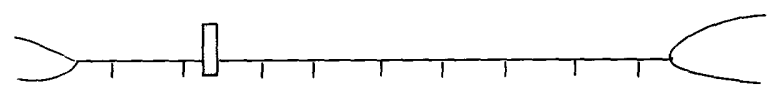

Figure 1. Example of an entity: Roosevelt Bridge in the "real world."

A feature instance is an occurrence of a feature and has a unique set of attribute and relationship values.
Expanding on the bridge example, the featcre instance of a bridge (the Roosevelt Bridge) has unique values for the attributes function (vehicle traffic) and location. It also has unique values for the relationship of passing over another feature (spans the Potomac River).

The resolution, or level of detail, of a domain of defined features may vary between classification schemes created by different organizations. These differences in resolution are due to differences in the set of phenomena and common attributes and relationships use to define the features. For example, one could create "higher resolution" features such as "covered bridge" and "unccvered bridge," which are subsets of the feature "bridge," by modifying the set of phenomena to "an erected enclosed structure" and to "an erected exposed structure," respectively. Conversely, one could create a feature that includes bridge as a member of a superset by modifying the definition to "a structure built to carry traffic." This encompassing feature would include bridges and tunnels as memt ors of the set.

\section{Objects}

Objects, along with their attributes and relationships, describe the characteristics of feature instarces. For the bridge example, the objects on a map graphic might include point, line, and area symbols and associated text. Alternatively, the objects might be a collection of records in a file of digital data (fig. 2).

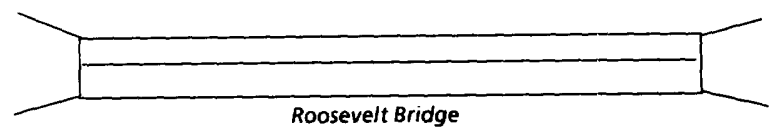

Graphic Object

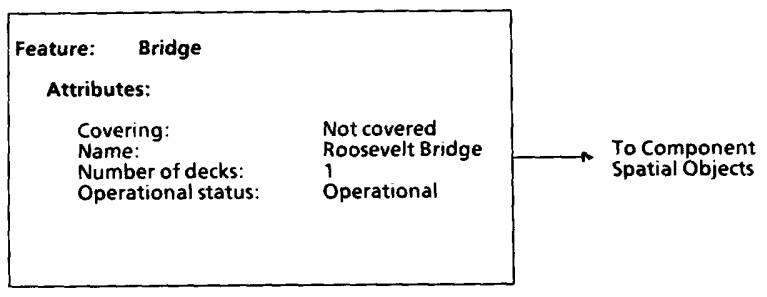

Digital Objects

Figure 2. Examples of objects: representations of the Roosevelt Bridge.

The objects in the digital environment are used to represent both nonlocational and locational aspects of the feature instances. A feature object is an element that identifies the feature instance and its nonlocational attributes. Spatial objects are elements used to represent the location of a feature instance. The spat $a l$ objects are defined for zero-, one-, and two-dimension 11 objects. To be mapped, a feature object must be associated with one or more spatial objects. In a few cases th: location of a 
feature object may be unknown and thus not reference any spatial objects.

\section{Mathematical Foundation of the Spatial Objects}

The objects used to represent the spatial components of the DLG-E data model are formally described using terminology from graph theory. The DLG-E data model uses a directed, planar graph (more precisely a pseudograph) composed of vertices, edges, and faces to describe spatial objects. See, for example, Harary (1969) for an explanation of these terms and the concepts of graph theory.

The graph $G$ consists of a nonempty set $V(G)$ of vertices, where $V$ is a finite set of points in real vector space $R^{2}$ with one point per vertex, together with a prescribed set $E(G)$ of ordered pairs of (not necessarily distinct) vertices of $G$. Each pair $e=(u, v)$ of vertices in $E$ is an edge of $G$, and $e$ is said to join $u$ and $v$. The graph is a plane graph in that the edges intersect only at their vertices (the edges are simple curves). The degree of a vertex $v_{i}$ in graph $G$, denoted deg $v_{i}$, is the number of edges incident with $v_{i}$. The regions defined by the plane graph are called its faces, the unbounded region being called the exterior face.

Synonymous terms exist from geometry and topology and are often seen in the literature. Synonyms that have been used for vertex include point, node, 0 -cell, junction, 0 -simplex, and element; synonyms for edge include line, arc, 1-cell, branch, 1-simplex, and element. Books by Bondy and Murty (1976), Giblin (1977), and Lefschetz (1975) provide additional information on graph theory and topology. Corbett (1979) gives some insights on the topological principles used in cartography.

In order to conform with the terminology used in the proposed Spatial Data Transfer Standard (SDTS), the corresponding terms from SDTS and the mathematical terms described here are given below:

$\begin{array}{ll}\text { SDTS terminology } & \text { Graph theory } \\ & \text { terminology } \\ \text { Point } & \text { Vertex }\left(\operatorname{deg} v_{i}=0\right) \\ \text { Node } & \text { Vertex }\left(\operatorname{deg} v_{i} \geq 1\right) \\ \text { Chain } & \text { Edge } \\ \text { Polygon, topological } & \text { Face }\end{array}$

The SDTS terminology will be used in the remainder of this document. The set of relationships between members of these object classes (point, node, chain, and polygon) is given in "Relationships."

\section{Attributes}

Attributes are the locational and nonlocational characteristics of the entities represented by the objects or of an attribute value. Locational attributes describe an object's geographic position (using $\mathrm{x}, \mathrm{y}$ coordinates, for example) or a geometric characteristic (such as its accuracy). The nonlocational characteristics of an entity include such concepts as its operational status. name, and function. An attribute value is a measurement assigned to an attribute for a feature instance or for (anoth or) attribute value. These measurements are made from one of the four levels of measurement (nominal, ordinal, inter'al, ratio).

A domain of nonlocational attributes is predefined for each feature. In addition, a domain of attribute values is specified for each attribute. An example of an attribute and its domain of attribute values is shown ir table 1 .

Table 1. Domain of attribute values for the attribute "operational status"

Attribute: Operational status

Attribute values:
Abandoned
Dismantled
Operational
Proposed
Under construction
Unknown

For a particular feature instance, appropriate attribute values describing the instance are chosen for each attribute. An example of the attributes and associated att ibute values for the feature instance of the bridge is given in table 2 .

Table 2. The encoding of attribute values for a feature instance

Feature: Bridge
Attributes:

Covering:

Name:

Number of decks:

Operational status:

\author{
Attribute values: \\ Not covered \\ Roosevelt Bridge \\ 1 \\ Operaticnal
}

Three special attribute values, "not applicable," "unspecified," and "unknown," are available fo- selected attributes. They are defined as follows:

Not applicable:

Used to describe a feature instance that cannot take on a value for a particular attribute.

\section{An Enhanced Digital Line Graph Design}


Unspecified: Used to value attributes of a feature instance for which the data collector does not provide a measurement.

Unknown: Used to note that an attribute could not be measured for a feature instance. In general, attributes having an attribute value of "unknown" will be resolved prior to the release of the data.

Every attribute in the domain of attributes describing a feature must be assigned at least one attribute value. More than one value may be required for an attribute to describe a feature instance. For example, for an instance of the feature "road," the attribute "route designator" may have multiple values (route numbers).

Attributes may also refine other attribute values. For example, the feature "well" has the attribute "product." An instance of the feature might have the value "water" for this attribute. The attribute value "water" is further modified by the attribute "water characteristics," which could contain a number of values as shown in table 3 .

Table 3. Example of attributes of attribute values

\begin{tabular}{cll}
\hline Feature: & Well & \\
Product: & & \\
& Gas & \\
& Heat & \\
& Oil & \\
& Water $\ldots . . . \rightarrow \quad$ Water characteristics: \\
& & Alkaline \\
& Hot \\
& Mineral \\
& Salt \\
\hline
\end{tabular}

Features are represented as they exist at a given instant of time. Any temporal data are given as attributes of the feature objects. Appendix B contains examples of feature instances fully encoded with attributes and attribute values.

The spatial objects of the data model are defined for two dimensions upon a surface. Thus, the locational attributes for the spatial objects are limited to the definition of the surface upon which the zero-, one-, and twodimensional objects occur. The coordinate data associated with a spatial object reflects that object's position on the surface of the Earth. For example, a section of road may be represented by a chain with $\mathrm{x}, \mathrm{y}, \mathrm{z}$ coordinates as locational attributes. The $\mathrm{z}$ coordinates reflect the surface elevation at the $\mathrm{x}, \mathrm{y}$ location. Such $\mathrm{z}$ coordinates are optional in DLG-E. If a feature is elevated above the surface, that elevation measure is associated with the feature object. Other elevation values, such as the elevation of the surface of a pond, are also considered to be attributes of the feature object.

\section{Relationships}

Relationships define the topological and nontopological links between objects. They are used within the model to describe not only the topological relationships of the elements of the graph but also the relationships between feature objects and spatial objects and between feature objects and other feature objects. Relationships are also used to model various aspects of spatial information that cannot be inferred from the spatial objects alone. The relationships between model components currontly used are listed in table 4. The relationships listed are between members of the object classes and not betwe $n$ the classes themselves.

Table 4. Relationships between the objects of the DLG-E data model

\begin{tabular}{|c|c|c|}
\hline Object class & Relationship & Object class \\
\hline feature & $\begin{array}{l}\text {---composed of--->> } \\
<-- \text { part of----- }\end{array}$ & * \\
\hline feature & $\begin{array}{l}\text {----bounded by--.--> } \\
\text { <--bounds---. }\end{array}$ & feature \\
\hline feature & $\begin{array}{l}\text {----inflow from---> } \\
<-- \text { outflow to---- }\end{array}$ & feature \\
\hline feature & $<--$ connected to---> & feature \\
\hline feature & --vertically related to--> & feature \\
\hline point & $\begin{array}{l}\text {---within-------> } \\
<--- \text { contains------ }\end{array}$ & polygon \\
\hline node & $\begin{array}{l}\text {----bounds--------> } \\
<-- \text { bounded by---. }\end{array}$ & chain \\
\hline chain & ----within-------->> & polygon \\
\hline chain & $\begin{array}{l}\text {---bounds-.......-> } \\
<-- \text { bounded by---- }\end{array}$ & polygon \\
\hline
\end{tabular}

\footnotetext{
*Any of the objects (feature, point, node, chain, or face) can be used in this relationship.

The relationships between feature objects are further described as follows:

"composed of/part of": Describes the formation of feature objects from feature objects and (or) spatial objects. Can be used to aggregate either disjoint or
} 
adjoining spatial objects or feature objects. Example: Lake Michigan is part of the Great Lakes.

\begin{abstract}
"bounded by/bounds": Describes the limits of the contiguous spatial extent that limit all or part of a given areal feature. Consists of a "boundary feature" that is an outer ring of chains containing the feature and inner rings that bound areas ("holes") that are not the feature. Example: Fairfax County, $\mathrm{Va}$., is bounded by a boundary that is composed of a set of chains. One subset of chains defines the outer boundary of the county, and other subsets define holes in the county, such as the set of chains that denotes the limits of the Town of Vienna, a jurisdiction that is spatially within the outer boundary of the county but politically a separate entity.
\end{abstract}

\begin{abstract}
"inflow from/outflow to": Used to model flows through networks in the cases where the network links are represented as areal features. The inflow and outflow relationships represent the source and discharge locations (that will be represented by a feature termed a "junction") for modeling network flows. Example: Where the Potomac and Anacostia Rivers (each represented by areas) meet, a junction is formed and the information that the water from the Anacostia River flows into the Potomac River is recorded using the inflow from and outflow to relationships. Also used with the feature "connector" to model flow through a network in cases where flow is known to exist, but the location of the objects are unknown.
\end{abstract}

"connected to": Similar to the inflow and outflow relationships but used where the flow is bidirectional, alternating, or unknown (as in the case of a road that is wide enough to be represented as an area).

"vertically related to": Used to link an instance of an underpass feature with the features that created the instance. The ordered relationship preserves the information that the first feature is "on top" and the second is "on the bottom."

The relationships between spatial objects consist of the boundary/coboundary topological relationships. These relationships were discussed in "Objects" and are defined in "Data Model Definitions." Note that the topological relationships of the spatial objects do not reflect any feature relationships. For example, the fact that a point (representing an oil tank) is contained in a polygon (representing an airport) does not necessarily define any relationship between the features that those spatial objects represent. A definite relationship between the oil tank and the airport should not be assumed unless a specific relationship gives the information (for example, an indication that the oil tank is owned by the airport).

The most prevalent feature relationship is the "composed of" relationship (road A is composed of chains 1, 2, and 3) used to form the geometric representation of a feature instance from a set of spatial object: (which can also be done indirectly through other feature objects). Other relationships between feature objec $*$ could be defined to describe situations such as stministrative hierarchies (the Town of Vienna, spatially cortained within Fairfax County, is not part of the county's police jurisdiction). For flexibility and expansion, the model is open ended with respect to the addition of new re'ationships.

Note also that relationships can have at ${ }^{-1}$ ibutes. One use of attributes of relations would be to dercribe the set of members included in the relation, particu' ${ }^{1}$ rly if those members were to be considered in an orderef or directed sense. For example a road might be corryosed of an ordered set of chains, or a stream composed of an ordered and directed set of chains. Chains are ordered in a linear sequence, with no branches, when chain $(i+1)$ of the set has a common node with chain (i), and chain (i+2) has a common node with the other node of chain $(i+1)$, and so on for each chain in the set. The elements are directed when a mechanism exists to arrange the chain set so that the end of one chain corresponds to the start of the next chain in the set. There is no requirement for all the coordinates in the chains in a directed set to be similarly sequenced, as long as some mechanism exists to record the "sense" of each chain being referenced ("forward" or "backward").

The representation of flows through a network and overpassing/underpassing features may require. such attribution of relationships. For example, given feature objects composed of chains, the chains are to be corsidered as an ordered set having uniform direction. The dirsction is indicated by an attribute describing the direction for traversing the chain. In addition, a real world (ground) significance to this direction is indicated by attribution of the feature object. For the underpass, the relationship is ordered, with the first feature object overpassing the secont. Under the present design, these are the only cases that utilize attributes of relationships. Any other cares requiring attribution of relationships are proposed to te handled by attributes of feature objects.

In another, hypothetical usage, attributes of relationships might be used to describe the accurac'" of a spatial object, a chain, that represented both a road segment and the edge of a forest. The locational accuracy for the road is different from the locational accuracy of the forest edge (the edge being a gradual transition zon? or "fuzzy" boundary). The respective accuracy figure could be used as an attribute on each instance of the "comfosed of" relationship. 


\section{DLG-E Data Model Summary}

Features are the sum of our interpretations of phenomena on or near the Earth's surface. The components of the data model used to represent these features are objects, attributes, and relationships. Objects are the basic units of representation of the encoded phenomena. Attributes are the locational and nonlocational characteristics of the entities represented by the objects. Relationships are the links between the objects. Taken collectively, these objects, attributes, and relationships constitute the DLG-E data model.

Various logical components of DLG-E are shown diagrammatically in figure 3 . The locational components of a feature instance are described by the spatial objects: points, nodes, chains, and polygons, or combinations of these objects. The spatial objects have a set of locational attributes, typically a set of coordinates that characterize their location in space. These consist of $\mathrm{x}, \mathrm{y}$, and optional $z$ coordinates. A feature object identifies a feature instance and its nonlocational attribute.

A given feature object may consist of other feature objects. A given entity may always be represented as one feature object. However, for the representation to be complete, one or more spatial objects must also be associated with the feature object either directly or through other feature objects. Flow and connectivity information is encoded through the ordering of chains and the relationships of the features. Additional flow characteristics are nonlocational attributes of a feature instance. These constraints bound the data modeling task.

\section{Data Model Definitions}

The following definitions describe the components of the DLG-E data model. In some cases they replicate or further refine the definitions of cartographic objects given in "Spatial Data Transfer Standard."

Entity: A real world phenomenon that is not subdivided into phenomena of the same kind.

Feature: A class of entities with common attributes and relationships. The concept of feature encompasses both entity and object.

Feature instance: An occurrence of a feature defined by a unique set of attribute and relationship values.

Object: A digital representation of all or part of an entity.

Feature object: An element that identifies a feature instance and its nonlocational attributes and relationships. A feature object may consist of other feature objects. The locational aspects of the feature instance are represented by spatial objects, either directly or through other feature objects.
Spatial object: An element used to represent locational attributes and topological relationships of a feature instance. Spatial objects are defined for zero, one, and two dimensions. Data for the third dimension are limited spatially to the definition of a surface upon which the zero-, one-, and two-dimensional objects occur.

Attribute: Characteristic of a feature or of an attribute value.

Attribute value: Measurement assigned to ar attribute for a given feature instance or for (another) attribute value.

Locational attribute: An attribute that describer the geographic position of a feature instance; locational attributes are assigned to a spatial object.

Nonlocational attribute: Characteristic of a feature instance or attribute value other than location.

Relationships: Linkages between objects.

Topological relationship: Boundary/cobound ry relationship between spatial objects.

Nontopological relationship: Relationships between feature objects and (or) feature objects and spati 9 objects.

Graph: A set of topologically interrelated zero-dimensional (node), one-dimensional (chain), and sometime twodimensional (polygon) objects, conforming to a set of defined constraint rules: each chain is bounded by an ordered pair of nodes, not necessarily dist 'zct; a node may bound one or more chains; and when realized in vector space, not more than one node may ex'st at any given point, and chains may not intersect (ercept at nodes). (SDTS definition)

Node: A zero-dimensional object that is the junction of two or more chains or is an end point of a chain. A node is a component of one and only one graph; as such, it may be located at one and only one point, and if so located it must be the only node of its graph located at that point. (SDTS definition)

Chain: A directed sequence of nonintersectirg line segments with nodes, not necessarily distinct, at ea-h end. A chain is a directed link (a one-dimensional object that is a connection between two nodes) with geometric location specified by a sequence of one or more line segments. A chain is a component of one and only on : graph; as such, a chain may not intersect itself or any other chains within its own graph. (SDTS definition)

A chain may be contained within one polygon of a graph. The topological relationships of such a chain are still defined by the dual two-element ordered sets of nodes and polygons; however, the start and end nodes must be different, and the right and left polygons must be the same.

Polygon: A two-dimensional object of one ard only one twodimensional cell complex (a graph and it: complement set 


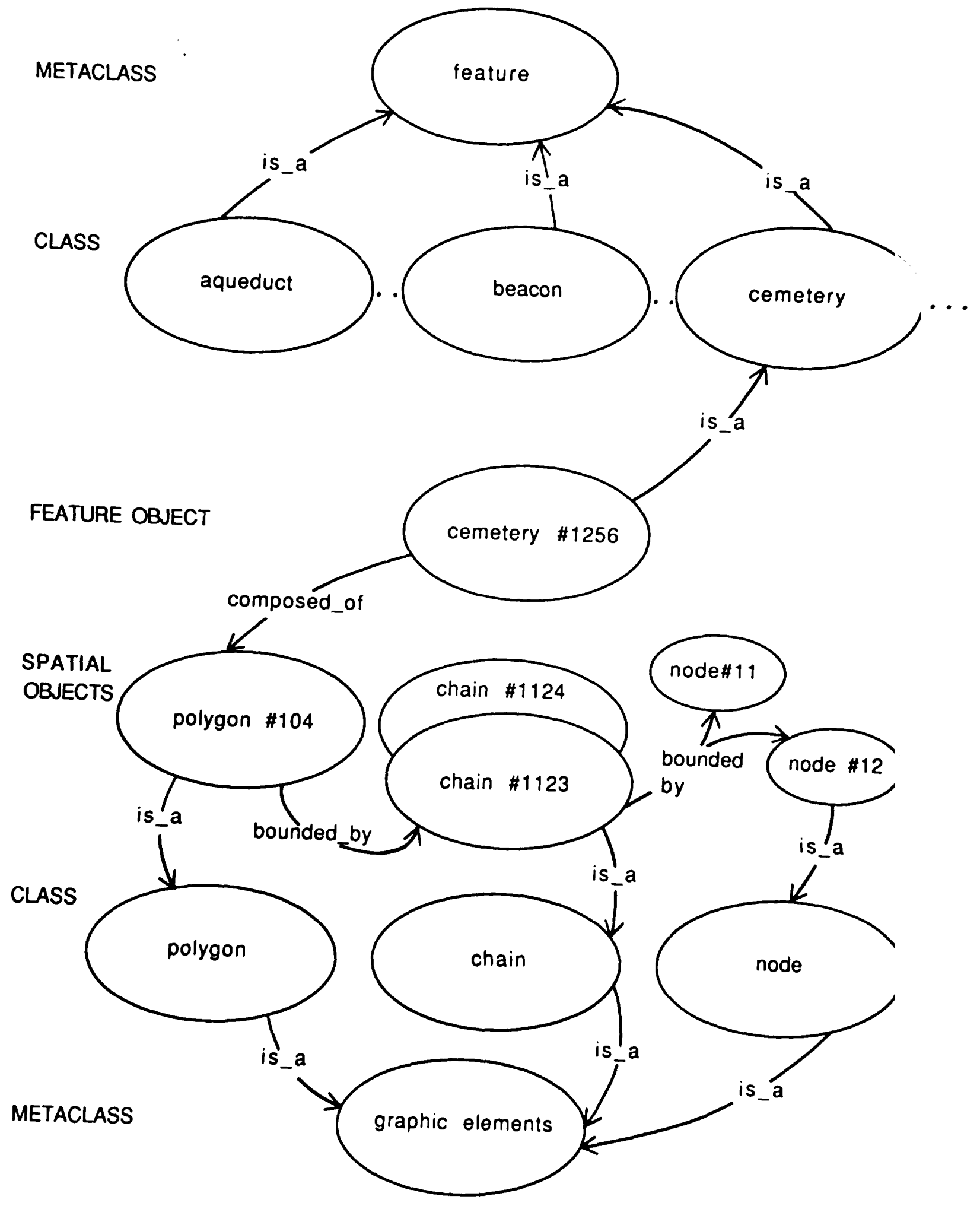

Figure 3. Logical components of the DLG-E data model. 
of polygons). The polygon is bounded by one or more chains of the complex. (SDTS Definition)

Point: A zero-dimensional object that specifies geometric location. One coordinate pair or triplet (or equivalent locational attribute value) specifies the location. (SDTS Definition)

\section{DEFINITION OF DLG-E FEATURES}

\section{Background}

The DLG-E data model has a variety of components for representing a feature. However, before describing how those components are used to represent any given feature, the domain of features (that is, the data reality) to be described by the model should be discussed. The report "Proposed Definition of Cartographic Features for Digital Line Graph - Enhanced (DLG-E)" (April 1988), by the Committee Investigating Cartographic Entities, Definitions, and Standards, defined an initial domain of features. A synopsis of that work is incorporated in this report. In preparing the set of DLG-E features, the committee reviewed related efforts including those of the Digital Cartographic Data Standards Task Force (1988), the Defense Mapping Agency (1987), the Canadian Council of Surveying and Mapping (1982), the Bureau of Land Management (1978), and the South African Natural Research Institute for Mathematical Sciences (1987). The current list of DLG-E features is given in appendix A.

\section{Methodology for Identifying Features}

Persons reading a map perceive features according to their needs and experiences. For example, one may be interested in the extent of a given named feature, such as the Potomac River or the Blue Ridge Mountains. Others may have a different interest and employ a different set of criteria. They may be interested in bicycling from Mount Vernon, Va., to Leesburg, Va., and would be concerned with a connected network of roads and trails between the two locations. In a digital environment, one attempts to explicitly encode information that best satisfies most users. The designers are faced with the problem of specifying a set of information in a form that can be perceived unambiguously by the majority of users. This specification process can be viewed as a process of classification. An expandable method of classification is necessary when defining features.

Classification involves the selection and grouping of phenomena into classes on the basis of common properties or relationships. The selection of a classification system has implications beyond the definition of common names for things. It is the classification scheme that defines the nature of the generalizations that are made about the phenomenon under study (Abler and others 1971). Note the linkage between the classification of min features and the concept of the map as a model. As stated by Board (1967), "it is important to realize that they [maps] are also conceptual models containing the essence of some generalization about reality." In the map model, the characteristics of the classification scheme and the remilting features specify this essence of the generalization of reality.

In the DLG-E feature classification process, an approach was taken that initially subdivider the world of geographic phenomena into five classes, terned views, that correspond to the major facets of a model of geographic reality as described by Geological Survey rexuirements and specifications. A view is defined as a systematic classification of a set of entities in which all members of the set possess a common defining characteristic. $T^{T}$ is characteristic is specified explicitly in the definitior of the view. Views are similar to the geographical concepts of region and spatial system (James and Jones, 1954; James, 1972) and "geographic matrix" (Berry and Marble 1968). Common cartographic terms such as category and overlay are related to views in derivation but lack th? rigor of the defining characteristic.

While views provide a methodology for classifying features, it is the classification scheme trat defines the nature of the generalizations about the phermmenon under study. These generalizations are reflected in feature definitions. For example, a road is an entity that covers a part of the Earth's surface. In the DLG-E methodology, it is classified in a view called "cover," a view with the defining characteristic of material at a location on or near the surface of the Earth. Other feature in the view "cover" include "building," "bridge," "railway," and "grassland." A "county" is not a feature in the view "cover" because it is not covering material on the Jarth's surface. A county is in the view "division" because it is a political entity independent of the actual material on or near the Earth's surface. Other examples of featur's in the view "division" include "state," "city," "reser'ation," and "census block."

New views are introduced in the met hodology when an entity cannot be appropriately classified in existing views. For example, a contour line is an entity that does not fit the views "cover" or "division." A contour line reflects measurement data about the Earth's surface. The feature "contour" requires a view in which measurement data are the focus. That same view is neerded to classify features such as "control station" and "spot elevation." Thus, a new view called "geoposition" that reflects entities of measurement was created.

In an approach similar to creatin : views, finer divisions of a view, called subviews, may be created to further refine the concepts included in the view. The view and subview approach allows a user to fit unclassified 
entities into the appropriate part of the schema. It also provides a framework for comparison to other sets of features as defined by other organizations.

While the approach uses the concept of multiple views of the world and a hierarchy of subviews within each view, neither the views nor the hierarchy need be stored with feature data. Nor is it necessary to group the features into categories. The views and subviews are used only to define the domain of features. Alternative views will yield different features, and features within a single view can be modified or expanded. Users can apply other views or hierarchies to add new features to the list. Use of features in the domain and use of the data require limited information concerning the approach methodology. The views and subviews are illustrated in figure 4.

This approach allows for expansion by creating a completely different view, adding new subviews, or augmenting the features within the existing five views. To classify a new entity, one would first determine whether an existing view, subview, feature, attribute, or attribute value is appropriate by comparing the characteristics of the new entity to existing definitions in the domain. After making this comparison, the new entity would be placed in the correct level of the hierarchy either by creating new views or subviews, or by expanding the list of features, attributes, or attribute values. Some examples are given below.

Large-scale mapping of base category information considers entities not currently listed in the domain as features. A specific instance is a "curb." Examining the views, a curb would be classified as cover. Within the view "cover," the curb is considered to be in the subview "built-up land" and a "structure." In the subview "structure," entities are differentiated into features based on form. Examining the list of features under "structure," a curb does not fit any of the existing feature definitions, and, thus, a new feature must be created.

A second example from a large-scale product is a single housetrailer with a permanent foundation. A housetrailer is a type of cover, built-up land, and a structure. The feature "building" encompasses housetrailers, and the attribute "text" with a value of "housetrailer" is appropriate. An alternative would be to institute a new attribute such as "building construction type" with one possible value being "housetrailer."

Expanding the number of views can be used to encompass features such as those that occur on geologic or other thematic maps. A geologic or other thematic view would require complete generation of the hierarchy within the view and the development of a list of features and attributes for that view. The resulting set of features then becomes a part of the total list of features independent of the approach methodology and completely usable with the other features in the total set.

\section{Flve Views}

The current DLG-E model classifies selected entities into five views on the basis of common defining characteristics. The five views are cover, division, ecosystem, geoposition, and morphology. The views are exclusive; each view reflects a self-contained analytical approach to world features. Because each view is independent, a single point on the surface of the Earth can be represented under multiple views, and features within any one view may coexist with features in the same or any other view. For example, examine the entity "boundary point." If a monument exists at the location of the bountary point, then two features will be recorded in the data. The feature "boundary point," referring to the monumented location on a boundary, is in the view "division" while the second feature, "point monument," denoting the stru?ture on a boundary line, is in the view "cover." Brief definitions of the five views follow:

Cover: Reflects physical or material features at a location on or near the surface of the Earth. While this view is based on form, at the lowest level features it may be differentiated by function.

Division: Reflects cultural demarcations of the Earth's surface for a particular purpose or for separations resulting from human activity.

Ecosystem: Based on climate, vegetatior. soils, and other controlling environmental factors th at result in unique ecological units.

Geoposition: Reflects measurement data about the Earth's surface and contains points or lines on the Earth or its representation for which th $:$ location, relative to a particular datum, is well krown.

Morphology: Based on the form of the land. While a strict geomorphological interpretation of landforms based on process is inherent in the conto in information on Geological Survey maps, the act tal features must be interpreted. However, some of the features carry names and those features must be coded in the digital data. Thus, morphological features are those landform features that are named, labeled, or symbolized as distinct entities on current map products.

\section{Discussion of Views}

The following section offers a more detciled discussion of each view and includes definitions of subviews. 


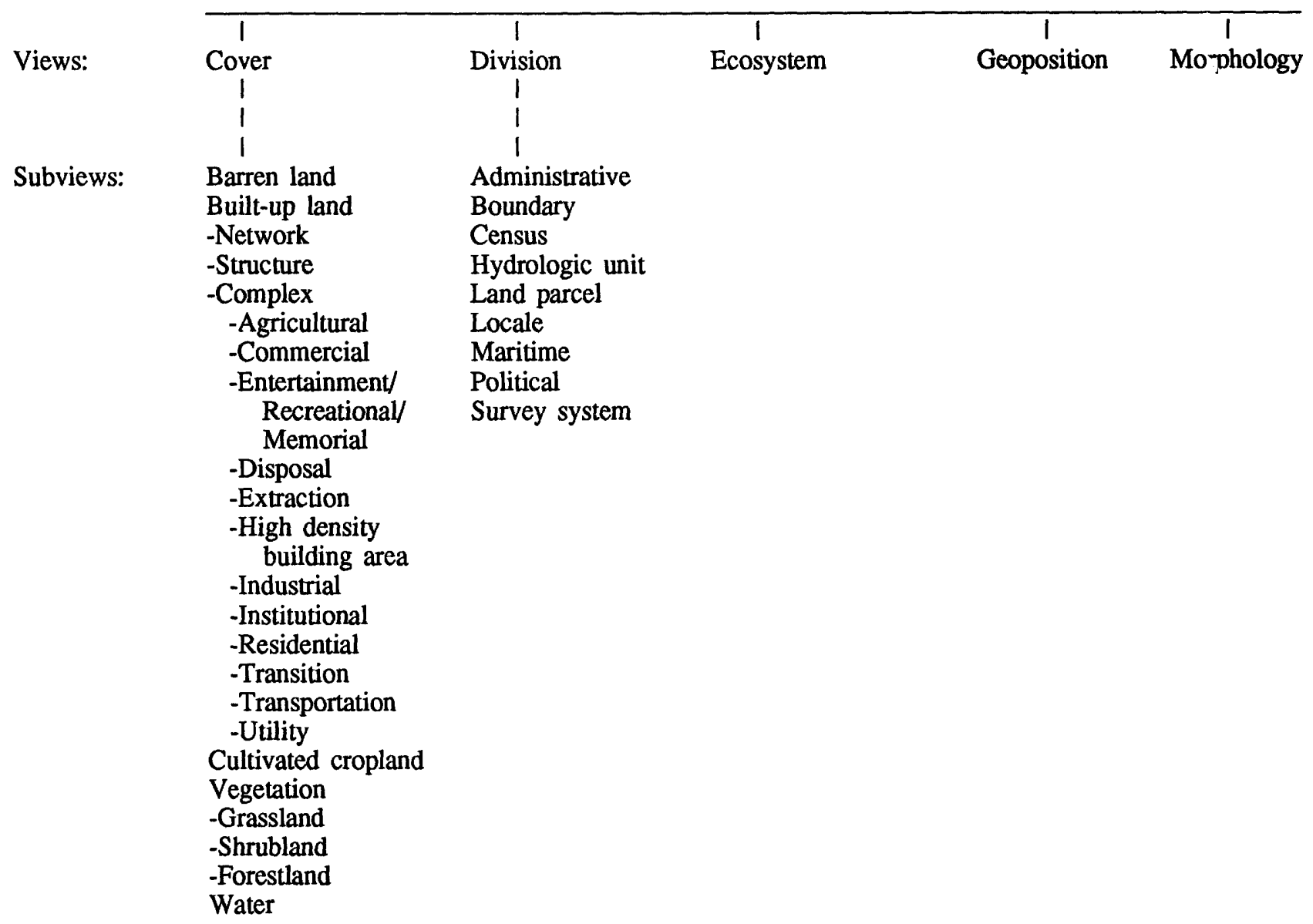

Figure 4. The five views and associated subviews.

Cover

The view of cover reflects physical or material features at a location on or near the surface of the Earth. This view contains a mixture of land use and land cover information. Multiple features derived from this view may occupy the same location.

Because of the diversity in the features defined by this view, additional subviews were added to clarify the distinctions between features. There are five subviews, based on the land use and land cover terms and definitions recommended by the Department of the Interior Land Use and Land Cover Common Terminology Work Group (Department of the Interior, 1985).
Barren land: A surface composed of expc ${ }^{\circ}$ d bare rock, other earthen material, or ice witr little or no vegetation.

Built-up land: Structures and areas associa $\bullet d$ with intensive land use. This subview is furthar divided into network, structure, and complex.

Network-- An interconnected set of constructions used for transportation or communication.

Structure--A construction having a uniq'e form. 
Complex--Cover of intensive use with much of the land covered by constructions.

Agricultural. A group of associated structures functioning as a unit used predominantly for the production of food and fiber, such as livestock holding areas, fish hatcheries, and other developed land.

Commercial. A group of associated structures functioning as a unit used predominantly for wholesale and (or) retail sale of goods and services.

Entertainment/Recreational/Memorial. An area or group of associated structures functioning as a unit used predominantly (1) for leisure activities, (2) for athletic or artistic events, (3) as archaeological or historic sites, or (4) for burial of the dead.

Disposal. A designated area where refuse is dumped or exists.

Extraction. An excavation or a group of excavations or drillings in the Earth for the purpose of removing earth materials.

High density building area. A congested, built-up area where all buildings cannot be represented on the map because of map scale.

Industrial. A group of associated structures functioning as a unit used predominantly for manufacturing, testing, processing, or storage.

Institutional. A group of associated structures functioning as a unit used predominantly for educational, correctional, governmental, medical, or religious purposes.

Residential. A collection of structures used for human habitation.

Transition. Area in change from one land use activity to another and characterized by a lack of information to predict future use or discern past use.

Transportation. An area or group of structures that function as a unit associated with travel or conveyance of people and (or) goods, together with the necessary adjacent facilities.

Utility. An area or group of structures that function as a unit to provide a public service and are used for the generation and (or) transportation of communications, water, gas, oil, or electricity.
Cultivated cropland: Areas characterized by f nction that are tilled and dominated by vegetation growth for the production of food and (or) fiber. Cultivated cropland includes fallow land, land in ary stage of annual crop production, and land being regularly cultivated for production of crops from perennial plants.

Vegetation: An area that is extensively covered with plant life.

Grassland--An extensive noncultivated area where vegetation is dominated by grasses o- grass-like plants.

Shrubland--Areas covered with low-growing or stunted perennial vegetation, such as cactus, mesquite, or sagebrush, common to arid regions and usually not mixed with trees.

Forestland--Areas on which vegetation is dominated by woody perennial plants having a sin re, usually elongated main stem and generally few or no branches on its lower part.

Water: Cover composed of flowing or standing water, impounded or naturally occurring, with channels or basins that are largely naturally occurrir.

\section{Division}

This view includes the cultural demarcations of the Earth's water and land surfaces. Two types of features exist in this view: areal divisions and boundaries. Boundaries may either delimit the areal divisions or, for historical reasons, occur as independent features. The subviews of the division view are defined as follows:

Administrative: A division under the jurisdiction of a common group for purposes such as preservation or exploitation of cultural or natural resources.

Boundary: Part or all of a bounding or separsting line on the Earth's surface having current or past significance.

Census: Divisions of the Earth's surface established by the Bureau of the Census for enumrating and reporting the population of the United r'ates.

Hydrologic unit: Divisions of the Earth's sc face established by the U.S. Geological Survey based on properties, distribution, and circulation of water.

Land parcel: Divisions of the Earth's surface based upon land ownership. 
Locale: A named place not otherwise categorized.

Maritime: Divisions of the Earth's water surface identified for the purpose of navigation or control of ship traffic.

Political: Divisions of the Earth's surface based upon governmental jurisdiction and activities such as voting and taxation.

Survey system: Divisions of the Earth's surface to determine and delineate the form, extent, and position of land tracts by taking linear and angular measurements.

\section{Ecosystem}

Ecosystem is a view based on climate, vegetation, soils, and other controlling environmental factors that result in unique entities. These entities are often of large extent and mapped as land use/land cover classes or as named places. Tundra, desert, and wetland are included in this view.

\section{Geoposition}

Geoposition contains features associated with the measurement of the size and shape of the Earth. The view reflects points or lines on the Earth or its representation for which the location, relative to a particular datum, is well known.

\section{Morphology}

Morphology is a view based on the form of the land surface. A domain of features has been developed that reflects morphology as presented on Survey map products. Although morphologic features appear on map graphics through hypsography, within the scale limitations of the products, only those features that are named, labeled, or otherwise symbolized as unique entities appear in the feature list. While these features may require interpretation of boundary limits, the text and symbol information distinguish them.

Attempts were made to organize morphologic features according to classical geomorphological treatments including processes such as erosion and deposition and generating agents such as glaciers, streams, wind, or volcanoes. While these approaches yield consistent features and correlate directly with geomorphological theory and practice, the information required to make these types of feature distinctions is not available on map source materials without significant effort in the interpretation of hypsography. The level of knowledge necessary to perform this interpretation requires a skilled geomorphologist. Therefore an alternate approach was taken whereby the morphology of the land surface was organized directly into a domain of features that can be readily obtained from map graphics. The feature list reflects the named and symbolized entities organized and grouped to account for aliases such as cliff and bluff, or valley and hollow.

\section{Examples of Feature Objects}

This section provides examples of feature objects used to represent entities. The feature object represents the nonlocational aspect of the entity. To complete the representation of the entity, the feature ob: 9 ct would be related to the spatial objects that represent the position and extent of the entity.

\section{Building}

Feature: Building

Angle of orientation: 45

Text: Not applicable

Name: Not applicable

Operational status: Operational

Feature: Building

Angle of orientation: Not applicable

Text: Church

Name: Not applicable

Operational status: Operational

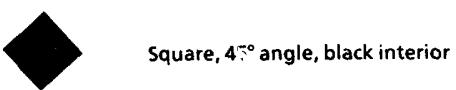

Feature: Building

Angle of orientation: Not applicable

Text: Not applicable

Name: The White House

Operational status: Operational

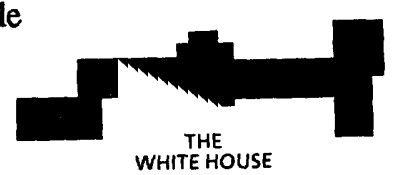

Each of the feature objects would be related to the spatial objects (points, nodes, chains, or polygons as appropriate) to complete the description of the feature.

\section{Complex}

Feature: Institutional site Institutional function: Education

Name: Smithsonian Institution

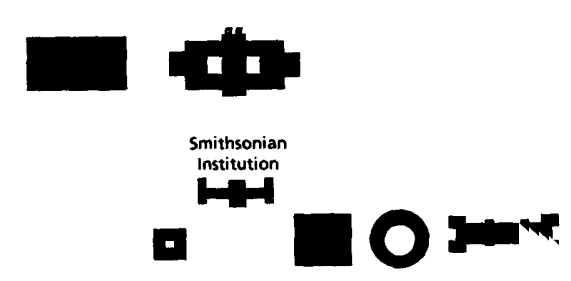


In addition to this feature object, the individual buildings would be encoded as building feature objects ("Building"). The feature object representing the Smithsonian Institution would be related to spatial objects (representing the grounds of the feature) and (or) other component features (representing the buildings or other component structures) to complete the description of the feature.

\section{Road}

Feature: Road

Access restrictions: None

Flow direction: Bidirectional

Median category: Without median

Name: Pletcher Road

Number of lanes or tracks: Unspecified

Operational status: Operational

Road class: 2nd

Road type: General case

Route designator: Not applicable

Width: Unspecified

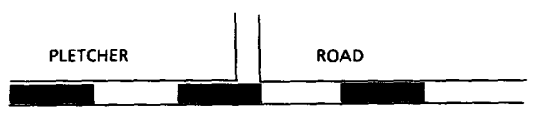

The individual instances of the road feature are shown in the illustration. One feature object (feature, attribute, and attribute value set) is required for each feature instance.

\section{REPRESENTATION OF FEATURES}

By using the components of the DLG-E data model, it is possible to create a number of different configurations of objects, attributes, and relationships to describe the members of the domain of defined features. Therefore, rules must be established for the representation of feature instances. Representation rules for feature instances may be based on spatial (that is, locational attributes and topological relationships) and (or) nonspatial aspects of the data. There are two types of feature instances: a basic feature instance and a compound feature instance. The basic feature instance consists of a feature object that is "composed of" a set of spatial objects (nodes, points, chains, or polygons). A compound feature instance consists of a feature object that is "composed of" basic feature instances and (or) other compound feature instances. For example, a named road such as "Lee Highway" is a compound feature consisting of a set of basic features corresponding to the segments of the road.
In many cases, the feature instances are easily defined. For example, the feature instance of the feature "well" is a feature object "composed of" a single point representing the "well" location. Areal entities that are well-defined homogeneous regions, such as a pond without islands, are also easily represented with a single area corresponding to each instance. However, entities such as linear network systems present more difficulties in defining feature instances.

A drainage network, for example, as shown on a map may consist of single- and double-line streams with islands and may be crossed by road, railroad, and other features. Determination of feature instances for this case must account for the intersection of single- and doubleline streams, direction of flow of the water, and intersections with the other features. Changes in nonlocational attributes, such as a name, also influence th ? extent of these instances.

For the purpose of creating the National Digital Cartographic Data Base from existing maps, a set of rules for the representation of feature instances should allow the basic features to be constructed directly frcm the map graphics. Aggregation of the basic feature instances to compound feature instances requires a combination of spatial and nonspatial rules. The delineatior and representation rules should provide basic feature irstances that are useful for aggregating into compound feat ure objects.

The preparation of a set of representation rules for feature instances is critical to the use of the domain of features. Although a domain of features has been developed, a variety of representations is possitle for each instance of that feature. The work to arrive at a single consistent set of feature instance representat on rules to complete the design of DLG-E is continuing.

\section{Feature Dellneation Strategies}

A set of feature instance representation rules could be developed using a variety of criteria. A number of alternatives are discussed in this section. The specific set of rules chosen for the implementation of the DLG-E data model is described in "Rules for Feature Instances."

Representation rules describe what objects are used to represent a feature instance. Delimiting rules define where any given feature instance starts and $s^{+}$ops. These rules can be developed on the basis of spatial characteristics (locational attributes and topological relationships), nonlocational attributes, nontopological relaticnships, or a combination of these.

One method is for feature instances to correspond to topological elements within the line graph repr sentation of the features. This rule works well for entities represented as point and line objects. Areal features such as double-line streams present problems because of 
intersecting single-line streams. Treating the entire area, that is, the topological elemental area, as a feature instance fails to retain critical information about direction of flow of water from the single-line streams into the double-line representation. Also, in a composite data base, this rule results in features in one category; for example, roads, delineated by intersection of features from the same or any other category. Thus, a road feature instance may be delineated by the intersection of a stream with the road on one end and the intersection of a contour line with the road on the opposite end. If the composite data base is structured as a single graph, all topological element intersections become delimiters of feature instances.

To avoid these problems, the rule can be changed so that feature instances are bounded by only "like" features; for example, a stream feature instance begins at the intersection with another stream and continues until a second intersection with a third stream occurs. Termination of the coordinate representation of an entity is also a bounding criteria. Essentially, road feature instances would only be bounded by road intersections, not by road/contour intersections and so forth. A problem with this rule is that changes in nonspatial attributes do not yield separate feature instances. For example, a two-lane road changing to a four-lane would all be part of the same feature instance and the two- and four-lane attributes must be attached to a single feature instance. Under this rule, are single- and double-line streams like features? One could impose a subrule that states that like features must be of the same dimensionality. The term "like" must be rigorously defined for this rule to be effective.

An alternate strategy is to delineate feature instances based solely on their nonspatial attributes. A new feature instance would occur only with a change in nonspatial attribution. For example, a road changing from four lanes to six lanes would dictate a new feature instance, but a road intersecting another road would not. A problem with this rule is that all roads with the same value for the attribute "road class," regardless of location, are a part of the same feature instance. A requirement of continuity partly solves this; however, roads that intersect and retain the same nonspatial attributes would still form the same feature instance.

The most useful representation of feature instances requires both spatial and nonspatial rules to be used together. The optimum combination of these rules will vary with the entity under consideration, but one or more rules must be used to specify unique feature instances for the Geological Survey.

\section{Rules for Feature Instances}

DLG-E uses a combination of spatial and nonspatial rules to represent feature instances. The sections below list a general set of rules that have been developed for determining feature instances in the DLG--E data model. These general rules are augmented by featur? specific rules, examples of which are given in appendix $?$.

\section{Basic Features}

All objects that are part of a basic feature instance must be contiguous, uniform in dimensionality, and homogeneous in attribution. The feature. instances are bounded by the intersection with a like feature.

Ground features having linear extent are represented by basic feature instances composed of a set of chains that are homogeneous in orientation and contigusus (that is, the chain sets are both ordered and directed). A linear basic feature instance has one starting point and one ending point and shall not contain any network type branches.

All features having areal extents ar: composed of the spatial object "polygon." Objects in the "composed of" relation will be unordered.

A defined subset of features having areal extent will, in addition to the "composed of" relation, carry a "bounded by" relation. The "bounded by" relation holds an ordered set of chains that define the boundary of th $\mathrm{a}$ areal feature. The following features carry the "bounded by" relation:

All features in the Divisions/Administrative subview

All features in the Divisions/Politica! subview

All areal features in the Divisions/Survey Systems subview

Selected features in the Cover/Water subview

Features having areal extent but indeterminate boundaries will be spatially represented by an unordered set of topological polygons using the "comnosed of" relation. Nonfeature chains will be used where necessary to arbitrarily close off the extent of the areal feature. Ties to structures inside a complex (buildings in a university, for example) will not be directly represented.

\section{Named Features}

Features having a proper name may be represented by either the basic or compound type of feature. If the feature can be represented as a single bisic feature instance, the name is stored as an attribute $c n$ that instance. If, however, the feature must be represented as a compound feature, the name is stored as an attribute on the higher level compound feature. Since a single name may apply to a number of different features at the basic level, the entity label of the higher level named feature need not match the constituent basic feature instances. Most often, the feature "Named Feature" will be used. Currently, the only attribute that may cause basic features to be linked to a higher level feature due to equivalence of the value assigned to that attribute is the "name" att ibute. 


\section{Modeling Constructs}

Most aspects of geographic reality are readily described using the feature objects derived from the five views, spatial objects, topological relationships, and the "composed of" and "bounded by" relationships. However, to model certain conditions some additional features, attributes, and relationships are required. [Note: The additional features referred to in this section are not listed in appendix A.] The use of these in modeling certain phenomena is discussed in the following sections.

\section{Modeling of Network Flows}

Flow and connectivity of linear features are encoded through the direction of the chains and by relationships between chains and nodes. Flow is represented as a nonspatial attribute on the feature instance as shown below.

Attribute: Directional status

Alternating
Bidirectional
Not applicable
One way
Unknown
Unspecified

This attribute indicates if the flow moves in both directions along the instance ("bidirectional"), alternates in direction along the flow ("alternating"), or moves one way along the instance.

Connectivity between linear and areal features is encoded using the nodes common to the chains that are part of the linear feature and the edge of the areal feature. Flow between areal features is encoded using the feature "junction" (the occurrence of an intersection of two areal features having flow) and the relationships "connected to" or "inflow from/outflow to." These relationships are attached to the areal features and link the features to the junctions where they meet other features. Sometimes in the map of hydrographic features, gaps will occur in the flow network (such as between the shoreline of a reservoir behind an earthen dam and the stream flowing from the reservoir). To model this situation the feature "connector" is used with the relationships "inflow from/outflow to." If the location of the "connector" is unknown, the connector feature object will not be composed of any spatial objects.

\section{Vertical Feature Relationships}

$$
\text { Use of attributes }
$$

The attribute "relationship to surface" is used with various feature instances to indicate the vertical location of a feature relative to the surface of the domair in potentially ambiguous situations. The attribute has the following attribute values:

$\begin{array}{ll}\text { Attribute: } & \text { Relationship to surface } \\ & \text { Awash at water surface } \\ & \text { Elevated or suspended above } \\ \text { surface } \\ \text { Exposed at surface } \\ \text { Submerged below water surface } \\ \text { Under land surface }\end{array}$

In general, the features of the cover and ecosystem view are considered to be on the surface in land areas and to be exposed at the water surface in water areas. Exceptions include features normally considered elevated or suspended above surface, such as:

\section{Bridge \\ Cableway \\ Conveyor \\ Transmission line}

and features normally considered under the land surface, such as:

\section{Pipeline \\ Tunnel}

Selected features in the cover view (aqueduct, canal/ditch, railway, pipeline, road, road interchange, stream/river, and trail features) that coincide with a bridge or tunnel feature are considered to be on/in th? bridge or tunnel. These coincident features are artomatically considered to be "elevated or suspended above surface" or "under land surface" where they coincide with the bridge or tunnel. The "relationship to surface" attri "nte is not applied in these cases. Features that have instances where the relationship to the surface is other than the conditions described will carry the "relationship to surface" attribute.

The features in the morphology view c'escribe the form of the surface. They are exposed at the lind surface. In cases where they are coincident with wat $\rightarrow r$ features, they are considered to be submerged below the water surface. In one ambiguous case, a rock (repre?ented by a point) may be exposed, awash, or submerged. The rock feature carries the "relationship to surface" attribute.

Similar to morphology, features in the geoposition view are measurements of the surface, and oncur at the surface. Because spot elevations and control stations are 
occasionally located on elevated or suspended structures, this feature carries the "relationship to surface" attribute.

\section{Use of "underpass"}

Where it is necessary to preserve a vertical relationship between two feature instances, the feature "underpass" shall be utilized. This feature is employed where the relative vertical information between the features cannot be determined by other information. It is normally used where features carrying traffic or having flow (such as aqueduct, canal, railway, road, and stream) pass under other features.

It is not used where the relative vertical relationship between features can be determined from other information, such as knowledge of one feature being underground or elevated while the second feature is on the surface. For example, it would not be used where a road coincident with a bridge passes over another (not coincident) road, or where a road coincident with a tunnel passes under a railroad.

The dimensionality of an instance of an underpass shall depend on the dimensionality of the overpassing/ underpassing features, according to the following table.

Table 5. Dimensionality of "underpass" instance from intersection of features

\begin{tabular}{cccc}
\hline & \multicolumn{3}{c}{ Dimension of feature 2 } \\
\cline { 2 - 3 } Dimension of feature 1 & $\underline{1}$ & 0 & $\underline{2}$ \\
& $\underline{2}$ & 1 & 2 \\
\hline
\end{tabular}

Only two features may be vertically related with the "underpass" feature. In the case of three or more features overpassing each other at the same spatial location, only vertically adjacent features shall be referenced in the underpass feature. Thus, a triple overpass shall generate two underpass instances: one for the top and middle features and one for the middle and bottom features.

\section{Spatial Extent}

The feature "domain" is used to define the spatial extent of the data set. It includes the area of the Earth covered by the data set being transferred. It excludes the area outside the domain and any void or holiday areas occurring within the area. Features represented by points and (or) chains (or portions thereof) that coincide with the edge of domain appear in both data sets that adjoin that edge. Features represented by areas, of which only the boundary is coincident with the edge of domain, appear only in the data set that contains the areal extent.

\section{Using the Model to Represent Cartographic Features}

Rules for bounding feature instances composition rules for representing feature instances, rules for aggregating feature instances, and rules for morleling various situations have been discussed in this section. Different sets of rules for representing a feature may be useful in different applications of that feature. By varying these rules for creating instances of the features a variety of implementations are possible using the elements and structure provided by the model.

However, for any given implementation, specific rules must be created and observed to define the representation of feature instances. A prototype set of rules for use with the set of features contained in the example data set is given in appendix $B$.

\section{DATA MODEL IMPLEMENTATION}

Previous sections have defined the DLG-E data reality, that is, the scope of the data that is of interest in this application, and the DLG-E data modsl, the sets of components and relationships that are used to describe the elements of the data reality. However, to ercode, transfer, or use the data, the logical organization of the components and the component relationships of the DLG-E data model must be explicitly defined. This definitic $n$ is done by creating a specific data structure. A data stucture can, in turn, be translated into a specific file structure by a set of rules that specify the logical implementation of the data structure within a given computing system environment. Many different data structures and file strintures can be generated from one data model.

Two implementations of the DLG-E data model are considered. The first implementation of the model uses the existing DLG-O file structure (USGS, 1987a) and adds modules to hold the DLG-E elements. This new file structure is called DLG-O+. The "DLG-O" part holds the spatial objects, locational attributes, ant topological relationships. The " + " part adds a series of files to hold the DLG-E features, nonlocational attributes, and nontopological relationships. Details on this implementation are given in appendix B. The example data set described in appendix $\mathrm{B}$ is implemented in the DLG-O+ data structure.

The second implementation uses the framework of the Spatial Data Transfer Specification (SLTS) described in "The Proposed Standard for Digital Cartiographic Data" (Digital Cartographic Data Standards Task Force, 1988). This framework has a strictly defined and o-ganized set of modules, fields, and subfields that are used to hold the 
various components of the DLG-E data model. The details on implementing the DLG-E model in SDTS are given in appendix $\mathrm{C}$.

\section{SUMMARY AND FUTURE RESEARCH}

\section{Summary}

In the DLG-E model, the phenomena of geographic and cartographic data are considered, in totality, as entities. Entities are individual phenomena in the real world. A feature is an abstraction of a set of entities, defined by a selected set of common attributes and relationships that are properties of the corresponding entities. Features represent the sum of our interpretations of phenomena on or near the Earth's surface. Buildings, bridges, roads, streams, grassland, and counties are examples of features. The components of the digital representation of a feature instance are termed objects. Cartographic data may be considered to be composed of objects, attributes, and relationships.

Objects are the basic units of representation of the encoded phenomenon. Attributes are the locational and nonlocational properties of the entities represented by the objects. Relationships are the topological and nontopological links between the objects. The objects in the DLG-E model are of two types, feature objects and spatial objects. Nonlocational attributes and nontopological relationships are associated with feature objects. Locational attributes and topological relationships are associated with spatial objects. Four spatial objects are defined: points, nodes, chains, and polygons. A given feature object has relationships with other feature objects and (or) spatial objects. Taken collectively, these objects, attributes, and relationships constitute the DLG-E data model. These concepts are developed in "Concepts of the DLG-E Design."

To establish the domain of features for DLG-E, an approach using a set of classes, or views, of geographic entities was adopted. The views are exclusive; each view is a self-contained analytical approach to the entire range of world features. Because each view is independent of the others, a single point on the surface of the Earth can be represented under multiple views. The five views that were developed are cover, division, ecosystem, geoposition, and morphology. "Definition of DLG-E Features" describes the methodology used in creating the DLG-E features, and the domain of DLG-E features is enumerated in appendix $\mathrm{A}$.

By using the DLG-E data model, a wide variety of representations of features could be formulated from the domain of defined features. Therefore, rules must be established for the representation of occurrences of the features or "feature instances." Representation rules for feature instances may be based on spatial and (or) nonspatial attributes of the data. A prototype set of rules for the representation of feature instances wa" created. Combining selected basic feature instances into compound feature instances uses a combination of spatia' and nonspatial rules. Representation rules are discussed in "Representation of Features." An example DLG-E data set and the set of rules used to create it are provided in appendix $\mathrm{B}$.

A specific data structure explicitly defines the logical organization of the components and the component relationships of the DLG-E data model. A data structure can, in turn, be translated into a file structure by a set of rules that specify the logical implementation of the da+a structure within a given computing system environment. Many different data structures and file structures can be generated from one data model. Two implementations of the DLG-E data model are discussed in "Data Model Implementation," and appendixes $B$ and $C$ provide the respective guidelines for implementing the DLG-E data model in the DLG-O+ data structure and in SDTS.

\section{Future Research}

The preparation of a set of representaticn rules for all feature instances is critical to the use of the domain of features. Although a domain of features has been developed, a variety of representations are possible for each instance of that feature. The work to arrive at a single, consistent set of feature instance representation rules to complete the design of DLG-E is continuing.

Further work on the implementation of the DLG-E data model in a variety of computer environments needs to be performed. One implementation of the motel will be within the context of relational and (or) object-oriented data base systems. Research on this topic will be pursued.

Finally, a series of system developmert. activities required to implement prototype DLG-E prodiction must be undertaken. These activities include further refinement of feature, attribute, and attribute value definitions; creation of extraction and product rule sets; establ'shment of procedures and software for data collection and conversion of existing data sets; and further testing of implementations of the DLG-O+ and SDTS data stru?tures with more extensive data sets.

Of course, these activities may point out areas not adequately addressed by the model. Therefore, modifications and improvements to the model may occur.

\section{SELECTED REFERENCES}

Abler, R., Adams, J., and Gould, P., 1971, Spatial organizationThe geographer's view of the world: Englewood Cliffs, N.J., Prentice-Hall Inc., p. 149-158. 
Anderson, J.R., Hardy, E.E., Roach, J.T., and Witmer, R.E., 1976, A land use and land cover classification system for use with remote sensor data: U.S. Geological Survey Professional Paper 964, 28 p.

Barwinski, Klaus, and Brüggemann, Heinz, 1986, Development of digital cadastral and topographic maps--Requirements, goals, and basic concept: Auto Carto London, Imperial College, South Kensington, London, Proceedings, v. 2, p. 76-85.

Bemard, Antoine, and Piquet-Pellorce, Daniel, 1986, A workstation for handling located data: PISTIL: Auto Carto London, Imperial College, South Kensington, London, Proceedings, v. 1, p. 166-174.

Berry, B.J.L., and Marble, D., 1968, Spatial analysis: A reader in statistical geography: Englewood Cliffs, N.J., Prentice-Hall, p. 24-34.

Board, C., 1967, Maps as models, in Chorley, R.J., and Hagget, P., eds., Models in geography: London, Methuen, p. 672.

Bondy, J.A., and Murty, U.S.R., 1976, Graph theory with applications: New York, North Holland, 264 p.

Borgida, Alexander, 1986, Conceptual modeling of information systems, in Brodie, Michael J., and Mylopoulos, John, eds., On knowledge base management systems: New York, Springer-Verlag, p. 461-469.

Borgida, Alexander, Mitchell, Tom, and Williamson, Keith, 1986, Learning improved integrity constraints and schemas from exceptions in databases and knowledge bases, in Brodie, Michael J., and Mylopoulos, John, eds., On knowledge base management systems: New York, Springer-Verlag, p. 259286.

Brodie, Michael J., and Mylopoulos, John, eds., 1986, On knowledge base management systems: New York, SpringerVerlag, $660 \mathrm{p}$.

Bureau of Land Management, 1978, Glossary of Bureau of Land Management (BLM) survey and mapping terms: Bureau of Land Management Cadastral Survey Training Staff, Service Center, Denver, Colo., 21 p.

Canadian Council of Surveying and Mapping, 1982, National standards for the exchange of digital topographic data, in Standards for the classification of topographic features: $202 \mathrm{p}$.

Corbett, J.P., 1979, Topological principles in cartography: U.S, Department of Commerce Technical Paper 48.

Defense Mapping Agency, 1987, Feature attribute coding standard (FACS): $1351 \mathrm{p}$.

1988, Digitizing the future: DMA Stock No. DDIPDIGITALPAC, $104 \mathrm{p}$.

Department of the Interior, 1985, Recommended land use and land cover terms and definitions: Department of the Interior Land Use and Land Cover Common Terminology Work Group, January 1985, 45 p.

Digital Cartographic Data Standards Task Force, 1988, The proposed standard for digital cartographic data, The American Cartographer, v. 15, no. 1,142 p.

Giblin, P.J., 1977, Graphs, surfaces, and homology, New York: Halsted Press, 329 p.

Goodchild, M.F., 1987, Towards an enumeration and classification of GIS functions: International GIS Symposium, Arlington, Va., November 1987, Proceedings, v. 2, p. 6777.

Guptill, S.C., 1986, A new design for the U.S. Geological Survey's National Digital Cartographic Data Base: Auto
Carto London, Imperial College, South Kensington, London, Proceedings, v. 2, p. 10-18.

Guptill, S.C., Fegeas, R.G., and Domaratz, M.A., 15 २६, Designing an Enhanced Digital Line Graph: American Congress on Surveying and Mapping, 1988 ACSM-ASPRS Annual Convention, Technical Papers, v. 2, p. 252-261.

Guptill, S.C., and Starr, L.E., 1984, The future of cartography in the information age, in Computer-assisted cartog aphy research and development report: International Cartographic Association Commission C Report, July 1984, p. 1-15.

Harary, Frank, 1969, Graph theory: Reading, Mass., AddisonWesley, 274 p.

Haywood, Peter, 1988, From digital maps to structured data and database management at Ordnance Survey: Eurocarto Seven Proceedings, Enschede, The Netherlands, p. 115-125.

James, P.E., 1972, All possible worlds: A history of geographical ideas: Indianapolis, The Bobbs-Merrill Ciompany, Inc., p. 622 .

James, P.E., and Jones, C.F., 1954, Americen geography, inventory and prospect: Syracuse, N.Y., Syrac'se University Press, $590 \mathrm{p}$.

Kinnear, C., 1987, The TIGER structure: Eightl Intemational Symposium on Computer Assisted Cartography (Auto Carto 8), Baltimore, Md., Proceedings, p. 249-257.

Lefschetz, Solomon, 1975, Applications of algeb-aic topology: New York, Springer-Verlag, 189 p.

Loelkes, G.L., Jr., Howard, G.E., Jr., Schwertz, E.L., Jr., Lampert, P.D., and Miller, S.W., 1983, Land use/land cover and environmental photointerpretation keys: U.S. Geological Survey Bulletin 1600, $142 \mathrm{p}$.

Marx, R.W., 1986, The TIGER system: Automating the geographic structure of the United States census: Government Publications Review, v. 13, p. 181-201.

Morrison, J.L., Callahan, G.M., and Olsen, R.W., 1987, Digital systems development at the U.S. Geolorical Survey: International Cartographic Association Conference, Morelia, Michoacan, Mexico, October 12-21, Proceedings, p. 201-214.

Peuquet, D.J., 1984, A conceptual framework and comparison of spatial data models: Cartographica, v. 21, no. 4, p. 66-113.

Salgé, Francois, and Piquet-Pellorce, Daniel, 1986, The I.G.N. small scale geographical data base $(1: 100,000$ to $1: 500,000)$ : Auto Carto London, Imperial College, Sout ${ }^{\text {h }}$ Kensington, London, Proceedings, v. 1, p. 433-446.

South African National Research Institute for Mathematical Sciences, 1987, A proposed national standard for the exchange of digital geo-referenced information: Pretoria South Africa, $151 \mathrm{p}$.

Spatial Data Transfer Standard Technical Review Board, 1990, Spatial Data Transfer Standard, 181 p. (Available from U.S. Geological Survey, National Mapping Division, 510 National Center, Reston, VA, 22092).

U.S. Geological Survey, 1954, Glossary of names for topographic forms: U.S. Geological Survey National Mapping Division Topographic Instructions, ch. 7E1, $21 \mathrm{p}$.

1980, Cultural features (4A2), 46 p.; Borndaries (4A3), 17 p.; Public land subdivisions (4A4), 14 p.; Hydrographic features (4A5) 53 p.; Relief features (4AG) 27 p.; and Woodland (4A7), 4 p.: U.S. Geological Survey National Mapping Division Topographic Instructions, cl . 4A2-7.

1980, Features shown on topographic maps: U.S. Geological Survey National Mapping Division Topographic Instructions, ch. 1B1, 41 p. 
1985, Attribute coding, pt. 3 of Standards for Digital Line Graphs: U.S. Geological Survey National Mapping Program Technical Instructions, 239 p.

1987a, Digital Line Graphs from 1:24,000-scale maps:

U.S. Geological Survey Data Users Guide 1, 109 p.

1987b, Geographic Names Information System: U.S.

Geological Survey Data Users Guide 6, 30 p. 1987c, Publication symbols, pt. 5, and, 1984 , Supplement, pt. 6, of Standards for 1:24,000- and 1:25,000scale quadrangle maps: U.S. Geological Sur'ey National Mapping Program Technical Instructions, 99 p. (pt. 5), 26 p. (pt. 6).

Winston, Patrick Henry, 1984, Artificial intelligence, Second Edition: Reading, Mass., Addison-Wesley, p. 251-289. 
APPENDIXES 



\section{APPENDIX A \\ DLG-E FEATURES}

\section{Section}

1. An introduction to the DLG-E domain A-1

2. Summary of DLG-E domain and feature count A-4

3. Features of the DLG-E domain listed by view A-5

4. Alphabetic list of features A-10

5. DLG-E feature domain A-12

6. Alphabetic list of DLG-E attributes and associated attribute values A-51

7. Alphabetic list of DLG-E attributes of attribute values A-64 



\section{APPENDIX A}

\section{DLG-E FEATURES}

\section{AN INTRODUCTION TO THE DLG-E DOMAIN}

This appendix details the contents of the DLG-E domain. The content of this domain is not all-inclusive and does not attempt to define all the entities in the real world. This domain was established to define a set of features that are found on U.S. Geological Survey National Mapping Division (NMD) source materials and reflect the requirements of the NMD. The DLG-E domain is organized as follows:

View: $\quad$ Subview 1: $\quad$ Subview 2: $\quad$ Subview 3:

Feature: $\quad$ Feature Definition

Attribute

Attribute Values----.-->Attribute of Attribute Value

Attribute Values

A description of each of these concepts follows.

VIEW

The DLG-E domain was developed by using an approach that incorporates a concept of world views of spatial entities. The concept of multiple views of the world and a hierarchy of subviews within each world view was used to define a domain of features found on NMD products. The views should not be confused with data collection categories. Neither the views nor the subview hierarchy will be stored with the feature data. Categories may be chosen, if so desired, to group features during data collection.

A world view is defined as a systematic classification of a set of real world phenomena in which all members of the set possess a common defining characteristic. The defining characteristic is specified explicitly in the definition of each view. Five world views were developed and documented to reflect the source material and requirements of the NMD. The views along with their definitions and a brief explanation are as follows:

Cover: This world view reflects physical or material features at a location on or near the surface of the Eartl While this view is strictly based on form, at the lowest level features may be differentiated by function.

Most of the features in the domain are contained in this view (122 out of 202). Due to the diversity in the features defined by this view, additional subviews were added. These subviews clarify the distinctions between features in the view.

Division: $\quad$ This world view reflects cultural demarcations of the Earth's surface for a particular purpose or separations resulting from human activity.

This view includes the cultural demarcations of the Earth's water and land surfaces. Two types of features exist in this view: areal divisions and boundaries. Boundaries may either delimit the areal divisions or occur as independent features.

Ecosystem: This world view is based on the climate, vegetation, soils, and other controlling environmental factors that result in unique ecological units.

The entities in this view are often of large extent and are mapped as land use/land cover classes or is named places. Tundra, desert, and wetland are the features included in this view.

Geoposition: This world view reflects measurement data about the Earth's surface and contains points or lines on the Earth or its representation for which location, relative to a particular datum, is well known.

Several of the features in this view, such as contours and spot elevations, exist only on maps even though they represent real world phenomena.

Morphology: This world view is based on the form of the land. While a strict geomorphological interpretation of landforms based on process is inherent in the contour information on USGS maps, the actual features 
must be interpreted. However, some of these features carry names and those features must be coded in the digital data. Thus, morphological features are those landform features that are named, labeled, or symbolized as distinct entities on current NMD products.

Attempts were made to organize morphologic features according to classical geomorphological treatments, including processes such as erosion and deposition and generating agents such as glaciers, stream, wind, or volcanoes. While these approaches yield consistent features and correlate directly with geomorphological theory and practice, the information required to make these types of feature distinctions is not available on NMD source materials without significant interpretation of hypsography. The level of knowledge necessary to perform this interpretation requires a skilled geomor hologist. Thus, the morphology of the land surface was organized directly into a domain of features that can be readily obtained from NMD graphics. The feature list reflects the named and symbolized entities organized and grouped to account for aliases such as cliff and bluff, valley and hollow, etc.

This world view approach for specifying features was designed to be flexible and expandable by providing the capability to appropriately fit unclassified entities into the schema. It also provides a framework for comparison to other sets of features as defined by other organizations. Other organizations may have requirements for different views, subviews, or augmenting the features within the existing five views.

\title{
FEATURE
}

The DLG-E model defines the concept of feature as a class of phenomena with common attributes and relationships encompassing both real world entities along with their digital (object) representation.

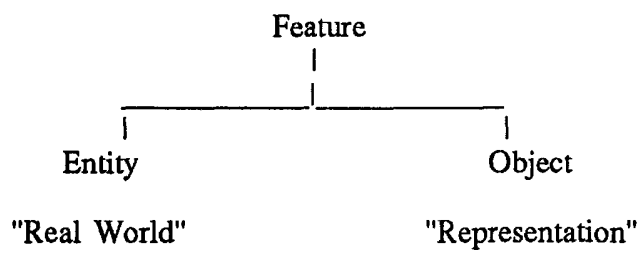

Only features found on NMD source material and reflecting NMD requirements are included in the domain. Features along with their definitions are listed alphabetically under each view or subview 1,2 , or 3 headings. Several indexes are provided in this appendix to help locate any feature.

\section{ATTRIBUTE}

Attributes are the locational or nonlocational characteristics of a feature or of an attribute value. Locational characteristics of a feature describe the geographic location or geometric dimension, while nonlocational characteristics include such concepts as operational status, name, and product. All attributes that are listed in the DLG-E domain for a feature must be populated with at least one attribute value. A list of all attributes with their associated attribute values existing in the DLG-E domain can be found in section 6 of this appendix. No definitions are included for the attributes and attribute values in this domain; an effort to complete this work is ongoing.

In the domain, all attributes along with their associated attribute values are listed for each feature. For example, the feature "Pipeline" has the following attributes:

\author{
Name \\ Operational status \\ Product \\ Relationship to surface
}

Other attributes such as "length" or "width" may be associated with the feature "pipeline"; however, they ar: not included in the DLG-E domain because they are not requirements of the Geological Survey.

\section{ATTRIBUTE VALUE}

Attribute values are measurements assigned to an attribute for a given feature occurrence or for another attribute value. At least one attribute value must be assigned to every attribute listed for a feature. Several of the attribute values that are frequently used in the DLG-E domain are described below. 


\section{Not Applicable, Unspecified, Unknown}

These special attribute values are available for selected attributes and should be used as follows:

Not applicable: Used when there is no relevant value for a particular attribute.

Unspecified: Used when there is a possible value for an attribute but no value is provided.

Unknown: Used when a value should be provided but for some reason the information is not availabls. In general, values of unknown will be resolved prior to the release of the data.

\section{General Case}

The attribute value "general case" is used when the common usage of an attribute is required. For example, "railway category" is an attribute of the feature "railway," with values of "general case," "inclined railway," "logging," "rapid transit," and "unknown." The options "inclined railway," "logging," and "rapid transit" are special cases of railways that occur infrequently. Since the DLG-E model specifies that at least one attribute value must be chosen for each attribut:, a general purpose railway would be coded as "general case."

\section{ATTRIBUTE OF ATTRIBUTE VALUE}

An attribute of an attribute value is a valid construct in the DLG-E model. The feature "well" will be used to illustrate this concept. A portion of the entry for "well" from the DLG-E domain is reproduced below.

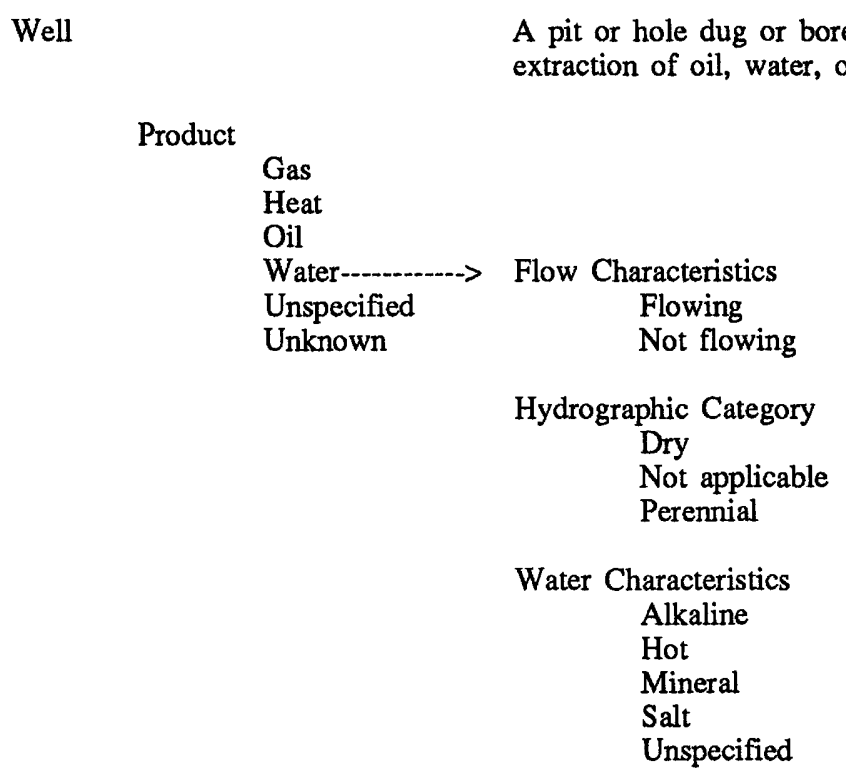

The attributes "flow characteristics," "hydrographic category," and "water characteristics" are attributes of the attribute value "water" under the attribute "product." This is modeled in this way because these three attributes are pertinent only when the value "water" is chosen from the attribute "product." These three attributes are not relevant for oil wells or natural gas wells but apply to water wells only, and therefore are associated as attributes of the attribute value "water" under the "product" attribute.

"Text" is a common attribute of an attribute value. The attribute "text" is used when a description for an attribute va'ue is needed. For example, "text" is an attribute of the attribute value "sports site type" for the feature "sports site." If a municipal golf course must be collected, "golf course" is chosen as a value, and the "text" attribute would be used to hold the text "municipal." Any type of descriptive text may be included in the "text" field. This field is not to be ured to record proper names. 


\section{SUMMARY OF DLG-E DOMAIN AND FEATURE COUNT}

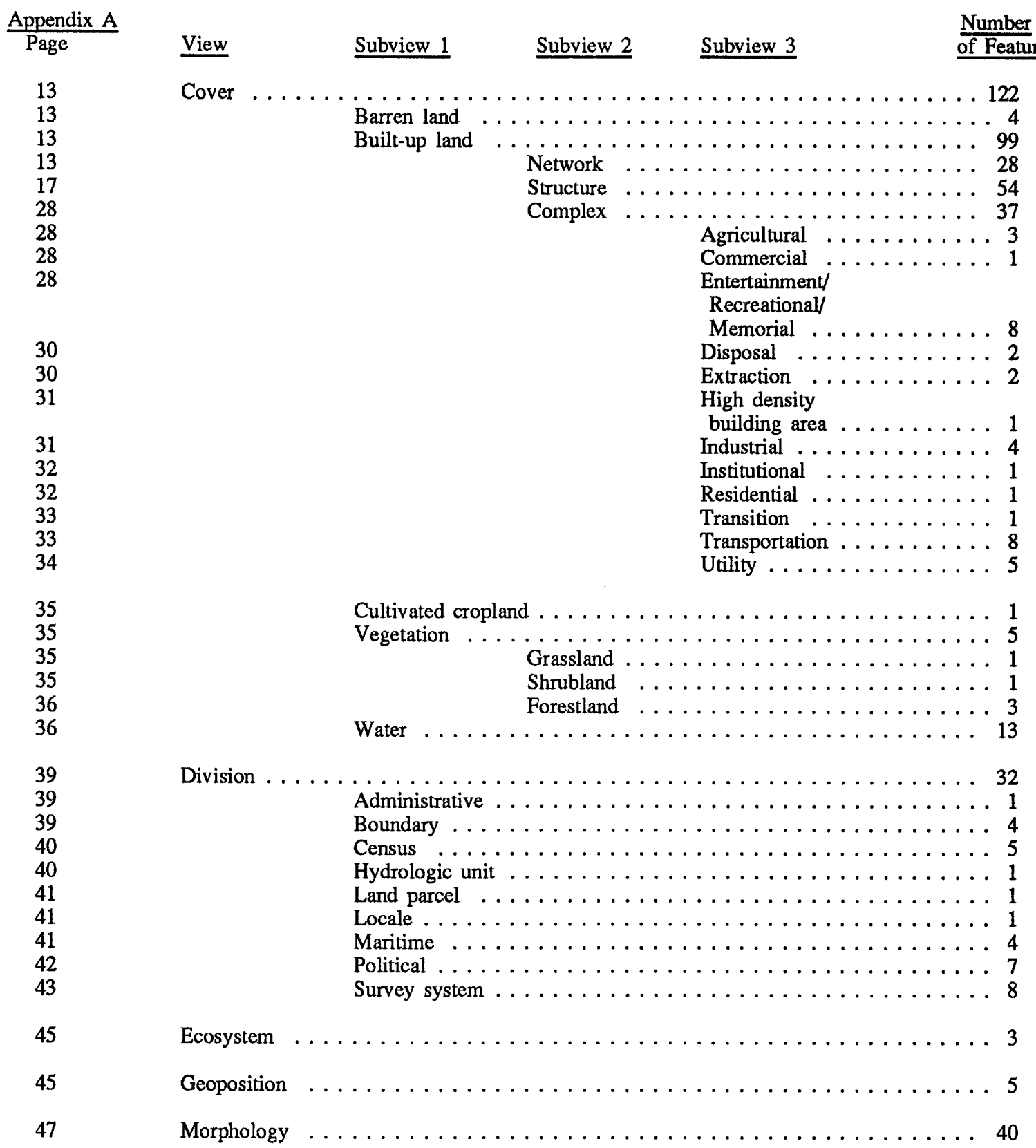

Total . . . . . . . . . . . . . . . . . . . . . . 202 


\section{FEATURES OF THE DLG-E DOMAIN LISTED BY VIEW}

View

$\underline{\text { Subview } 1}$

Subview 2

$\underline{\text { Subview } 3}$

Cover

Barren land

Barren land

Firebreak

Ice mass

Mud pot

Built-up land

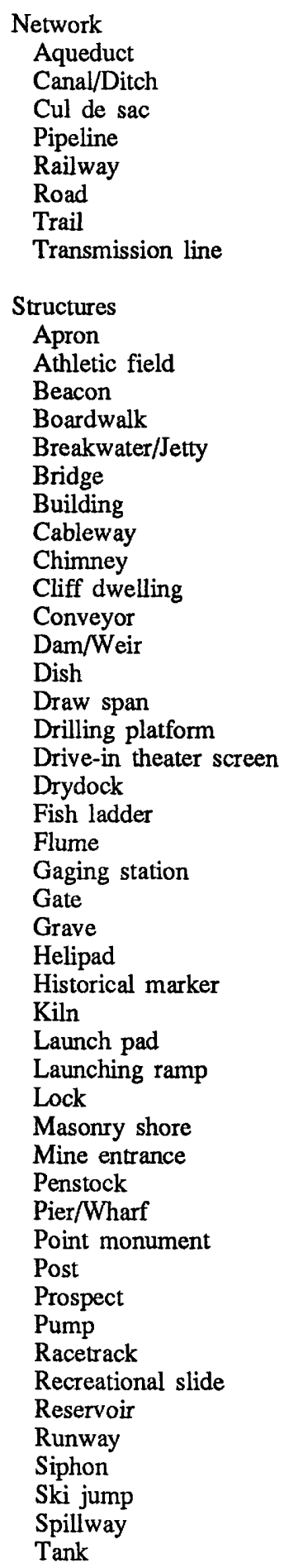


Structures (continued)

Taxiway

Tower

Tunnel

Tunnel entrance

Tumtable

Wall

Water intake/outflow

Well

Windmill

Wreck

Complex

Agri?ultural

Fish hatchery

Holding pen

Marine activity site

Commercial

Shopping center

Entertainment/

Rerreational/

Menorial

Archeological site/Ruins

Campground

Cemetery

Erhibition

ground

Marina

Outdoor theater

Park

SForts site

Disposal area

Disposal site

Wrecking yard

Extraction area

Mne

Well field

High density

building area

High density

building area

Indestrial

In Justrial site

Mineral pile

Proving ground

Tank farm

Inst: tutional

Institutional site

Residential

Trailer park

Transition area

Transition area

Transportation

Aircraft facility

Ir terchange

Launch facility

Parking site

Railway yard

Rest site

Toll plaza

Traffic

inspection

facility 
Utility Cable/Pipelire site

Dam site

Pipeline regulation station

Power site

Substation

Cultivated cropland

Cultivated cropland

Vegetation

Water

Grassland

Grassland

Shrubland

Shrubland

Forestland

Tree

Trees

Snag/Stump

Area to be submerged

Bay/Estuary/Inlet

Ford

Gut

Inundation area

Lake/Pond

Rapids

Sea/Ocean

Shoreline

Spring

Stream/River

Submerged stream

Waterfall

Division

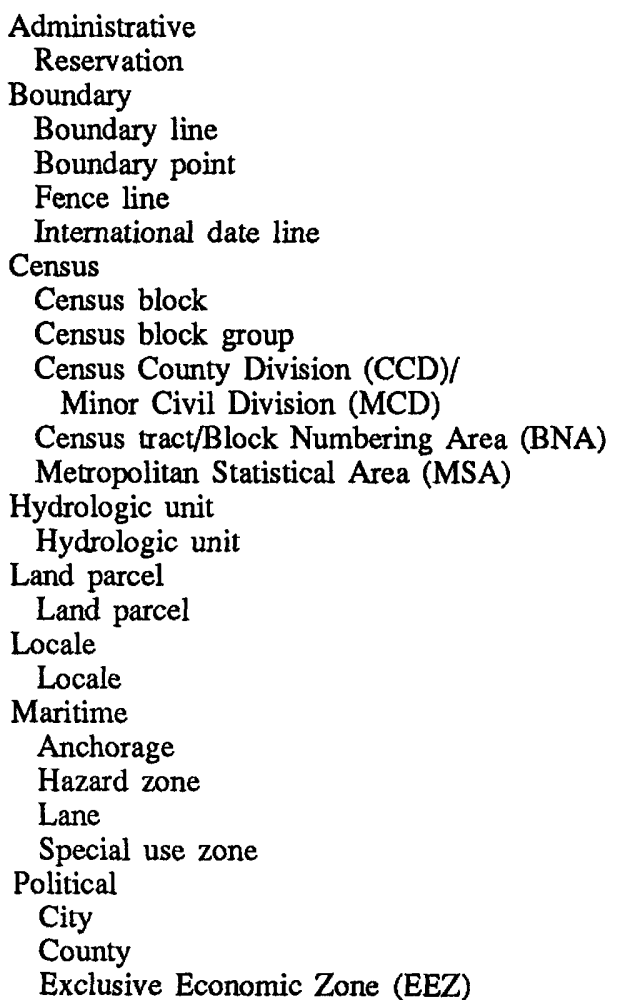


Division

Political (continued)

Minor civil unit

Minor civil subunit

Nation

State/Territory

Survey system

Baseline

Georgia Survey District

Homestead entry

Land grant

Principal meridian

Public survey area

Survey corner

Survey point

Ecosystem
Desert
Tundra
Wetland
Geoposition
Contour (bathymetric)
Contour (land)
Control station
Mile marker
Spot elevation
Morphology
Arch
Bar
Basin
Beach
Bend
Cape
Cave
Cave entrance
Cliff
Crevasse
Disturbed surface
Dunes
Embankment
Fault
Flat
Foreshore
Fumarole
Gap
Geyser
Iceberg
Iceberg tongue
Incline/Flow
Island
Isthmus
Moraine
Mount
Pinnacle
Plain
Range
Reef
Ridge
Ridge line
Rock
Sastrugi
Sink
Summit
Terrace


Morphology (continued)

Trench

Valley

Wash 


\section{ALPHABETIC LIST OF FEATURES}

Page

Aircraft facility ........... 33

Anchorage $\ldots \ldots \ldots \ldots \ldots \ldots . \ldots 41$

Apron .................. 17

Aqueduct $\ldots \ldots \ldots \ldots \ldots \ldots \ldots$

Arch . . . . . . . . . . . . 47

Archeological site/Ruins . . . . . . . . 28

Area to be submerged . . . . . . . 36

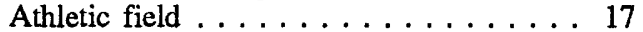

Bar ................. 47

Barren land ............. 13

Baseline .............. 43

Basin . . . . . . . . . . . 47

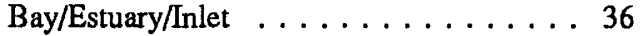

Beach ............... 47

Beacon $\ldots \ldots \ldots \ldots \ldots \ldots \ldots 17$

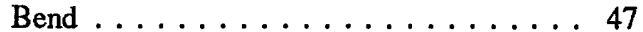

Boardwalk ............ 18

Boundary line . . . . . . . . 39

Boundary point $\ldots \ldots \ldots \ldots \ldots 40$

Breakwater/Jetty . . . . . . . . . 18

Bridge . . . . . . . . . . 18

Building . . . . . . . . . . . 19

Cable/Pipeline site .......... 34

Cableway ................ 19

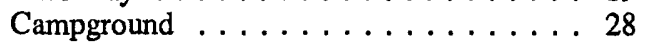

Canal/Ditch . . . . . . . . . 13

Cape ................ 47

Cave ............... 47

Cave entrance ........... 48

Cemetery . . . . . . . . . . . 29

Census block . . . . . . . . . . 40

Census block group . . . . . . . 40

Census County Division/Minor

Civil Division . . . . . . . . . . 40

Census tract/Block Numbering Area ... 40

Chimney .............. 19

City $\ldots \ldots \ldots \ldots \ldots \ldots \ldots \ldots \ldots \ldots \ldots \ldots$

Cliff $\ldots \ldots \ldots \ldots \ldots \ldots \ldots \ldots . \ldots 48$

Cliff dwelling ........... 19

Contour (bathymetric) ........ 45

Contour (land) . . . . . . . . 46

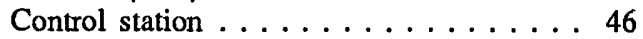

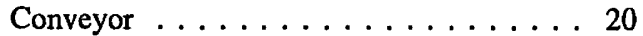

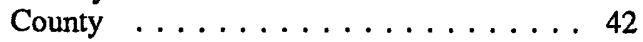

Crevasse $\ldots \ldots \ldots \ldots \ldots \ldots \ldots 48$

Cul de sac ............. 14

Cultivated cropland . . . . . . . 35

Dam site ............... 34

Dam/Weir . . . . . . . . . . 20

Desert ............... 45

Dish ................ 20

Disposal site . . . . . . . . . . 30

Disturbed surface . . . . . . . . 48

Draw span ............ 20

Drilling platform $\ldots \ldots \ldots \ldots \ldots 20$

Drive-in theater screen . . . . . . . 20

Drydock . . . . . . . . . . . 20

Dunes $\ldots \ldots \ldots \ldots \ldots \ldots \ldots 48$

Embankment . . . . . . . . . 48

Exclusive Economic Zone . . . . . . 42

Exhibition ground . . . . . . . . 29

Fault ................ 48

Fence line $\ldots \ldots \ldots \ldots \ldots \ldots 40$

Firebreak ............. 13

Fish hatchery $\ldots \ldots \ldots \ldots \ldots \ldots 28$

Fish ladder $\ldots \ldots \ldots \ldots \ldots \ldots 21$

Flat $\ldots \ldots \ldots \ldots \ldots \ldots \ldots \ldots$

Flume $\ldots \ldots \ldots \ldots \ldots \ldots \ldots 21$

Ford $\ldots \ldots \ldots \ldots \ldots \ldots \ldots$

Foreshore $\ldots \ldots \ldots \ldots \ldots \ldots \ldots 48$

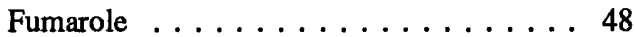

Gaging station $\ldots \ldots \ldots \ldots \ldots \ldots 21$

Gap $\ldots \ldots \ldots \ldots \ldots \ldots \ldots 48$

Gate ............... 21

Georgia Survey District . . . . . . . 43

Geyser . . . . . . . . . . . . . 49

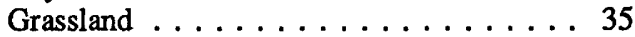

Grave .............. 21

Gut ................ 36

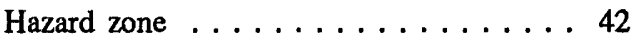

Helipad .............. 21

High density building area $\ldots \ldots \ldots . .31$

Historical marker ............ 22

Holding pen $\ldots \ldots \ldots \ldots \ldots \ldots 28$

Homestead entry $\ldots \ldots \ldots \ldots \ldots 43$

Hydrologic unit . . . . . . . . . 40

Iceberg $\ldots \ldots \ldots \ldots \ldots \ldots \ldots 49$

Iceberg tongue $\ldots \ldots \ldots \ldots \ldots \ldots 49$

Ice mass $\ldots \ldots \ldots \ldots \ldots \ldots 13$

Incline/Flow . . . . . . . . . 49

Industrial site $\ldots \ldots \ldots \ldots \ldots \ldots 31$

Inundation area $\ldots \ldots \ldots \ldots \ldots \ldots 37$

Institutional site $\ldots \ldots \ldots \ldots \ldots \ldots 32$

Interchange $\ldots \ldots \ldots \ldots \ldots \ldots \ldots$

International Date Line . . . . . . . . 40

Island $\ldots \ldots \ldots \ldots \ldots \ldots \ldots 49$

Isthmus $\ldots \ldots \ldots \ldots \ldots \ldots \ldots 49$

Kiln ................. 22

Lake/Pond . . . . . . . . . 37

Land grant ............ 44

Land parcel $\ldots \ldots \ldots \ldots \ldots \ldots 41$

Lane .............. 42

Launch pad ............. 22

Launch facility ........... 33

Launching ramp $\ldots \ldots \ldots \ldots \ldots 22$

Locale . . . . . . . . . . . . 41

Lock . . . . . . . . . . . . 22

Marina . . . . . . . . . . . . 29

Marine activity site ......... 28

Masonry shore . . . . . . . . 22

Metropolitan Statistical Area (MSA) . . . 40

Mile marker ............. 46

Mine $\ldots \ldots \ldots \ldots \ldots \ldots \ldots . \ldots 30$

Mine entrance $\ldots \ldots \ldots \ldots \ldots \ldots 22$

Mineral pile . . . . . . . . . 32

Minor civil unit $\ldots \ldots \ldots \ldots \ldots \ldots 43$

Minor civil subunit . . . . . . . 43

Moraine . . . . . . . . . 49

Mount . . . . . . . . . . . 49

Mud pot $\ldots \ldots \ldots \ldots \ldots \ldots 13$

Nation . . . . . . . . . . . 43

Outdoor theater $\ldots \ldots \ldots \ldots \ldots \ldots 29$

Park ............... 29

Parking site $\ldots \ldots \ldots \ldots \ldots \ldots 33$

Penstock $\ldots \ldots \ldots \ldots \ldots \ldots \ldots 22$

Pier/Wharf $\ldots \ldots \ldots \ldots \ldots \ldots 23$ 
Pinnacle . . . . . . . . . . . . . . . . 49

Pipeline . . . . . . . . . . . . . . 14

Pipeline regulation station . . . . . . . . 34

Plain . . . . . . . . . . . . . 49

Point monument . . . . . . . . . . 23

Post ................. 23

Power site ... . . . . . . . . . 34

Principal meridian $\ldots \ldots \ldots \ldots \ldots 44$

Prospect ................ 23

Proving ground $\ldots \ldots \ldots \ldots \ldots \ldots \ldots$

Public survey area ... . . . . . . 44

Pump .................. 23

Racetrack . . . . . . . . . . . 23

Railway . . . . . . . . . . . . . . 14

Railway yard .............. 33

Range .................. . . 49

Rapids ... . . . . . . . . . . . 37

Recreational slide . . . . . . . . . . 23

Reef ................ 55

Reservation .............. 39

Reservoir ................ . 24

Rest site .............. 34

Ridge ............... . 50

Ridge line ............. . 50

Road ................... 15

Rock . . . . . . . . . . . . . . 50

Runway ................. . . 24

Sastrugi ............... . 50

Sea/Ocean ............. 37

Shopping center . . . . . . . . . 28

Shoreline . . . . . . . . . . . . . . 38

Shrubland ............... 35

Sink ................ 50

Siphon ................ . 25

Ski jump ............... 25

Snag/Stump . . . . . . . . . . . . . 36

Special use zone ........... . 42

Spillway . . . . . . . . . . . 25

Sports site .............. . . 29
Spot elevation ............. 47

Spring . . . . . . . . . . . . 38

State/Territory ............. . 43

Stream/River . . . . . . . . . . . . . . 38

Submerged stream $\ldots \ldots \ldots \ldots \ldots$

Substation . . . . . . . . . . 35

Summit $\ldots \ldots \ldots \ldots \ldots \ldots$

Survey corner . . . . . . . . . . . 44

Survey point .............. 44

Tank ................ . 25

Tank farm ............ 32

Taxiway ................ 25

Terrace .............. 50

Toll plaza . . . . . . . . . . . . 34

Tower . . . . . . . . . . . . . 25

Traffic inspection facility ........ 34

Trail ................. 16

Trailer park ............. 32

Transition area ............ 33

Transmission line . . . . . . . . . 17

Tree ................ 36

Trees ................ . 36

Trench .............. 50

Tundra ................ . 45

Tunnel . . . . . . . . . . . . . 26

Tunnel entrance ........... 26

Tumtable .............. 26

Valley ................ 50

Wall ................. 27

Wash ............... 50

Water intake/outflow ... . . . . . . 27

Waterfall ................ 39

Well ................. 27

Well field . . . . . . . . . . . 31

Wetland ............... 45

Windmill .............. 27

Wreck . . . . . . . . . . . . 27

Wrecking yard ............ 30 


\section{DLG-E FEATURE DOMAIN}

In this section, features are listed alphabetically under each view and subview 1,2 , and 3 headings.

A definition is listed for each feature. Definitions for view and subview headings may be found on pages 10-13 of the main text of this circular.

For each feature, all attributes with their associated attribute values are listed. For example: Barren land

Attributes: Earth composition

$\begin{array}{ll}\text { Values: } & \text { Gravel } \\ & \text { Rock } \\ & \text { Salt } \\ & \text { Sand } \\ & \text { Shell } \\ & \text { Silt } \\ & \text { Unspecified }\end{array}$

Attributes of attribute values are also possible. Using "barren land" as an example, "rock type" is an attribute of the attribute value "rock" under the attribute "earth composition." This means that the attribute "rock type" applies only to the value "rock" under the attribute "earth composition."

Attribute: Earth composition

$\begin{array}{lll}\text { Value: } & \text { Gravel } & \\ \text { Rock------->Attribute: } & \text { Rock type } \\ \text { Salt } & \text { Values: } & \text { Coral } \\ \text { Sand } & & \text { Lava } \\ \text { Shell } & \text { Unspecified } \\ \text { Silt } & \text { Unknown } \\ \text { Unspecified } & \end{array}$


View: Cover Subview 1: Barren land

Barren land

Places composed of bare rock, sand, silt, gravel, or other earthen material with little or no vegetation and having limited ability to support life.

Earth composition

$\begin{array}{ll}\text { Gravel } & \\ \text { Rock------------>Rock } & \text { type } \\ \text { Salt } & \text { Coral } \\ \text { Sand } & \text { Lava } \\ \text { Shell } & \text { Unspecified } \\ \text { Silt } & \text { Unknown } \\ \text { Unspecified } & \end{array}$

Firebreak An area cleared of vegetation for the purpose of impeding the progress of a grass or forest fire.

Ice mass

A field of ice, formed in regions of perennial frost.

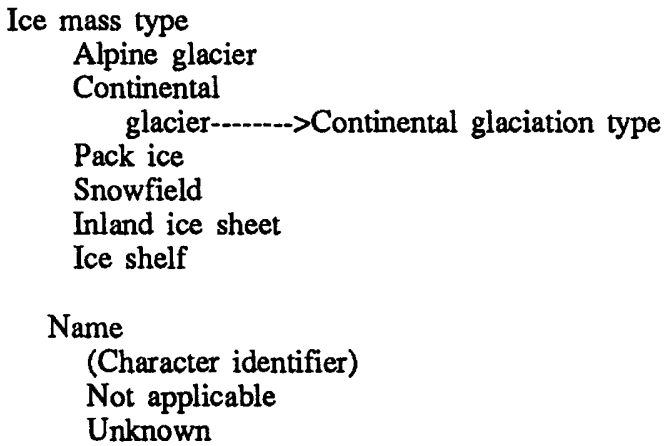

Mud pot

A pool of mud from which gas or vapors issue.

View: Cover Subview 1: Built-up land Subview 2: Network

Aqueduct

A structure designed to transport water from a remote source, usually by' gravity.

Directional status

One way

Unknown

Unspecified

Name

(Character identifier)

Not applicable

Unknown

Operational status

Abandoned

Operational

Under construction

Unknown

Canal/Ditch

An artificial waterway with no flow or a controlled flow used for navigation (canal), or for draining or irrigating land (ditch).

Canal/Ditch category

Canal

Ditch

Unspecified 
Canal/Ditch (continued)

Directional status

One way

Unknown

Unspecified

Hydrographic category

Intermittent

Perennial

Unknown

Name

(Character identifier)

Not applicable

Unknown

Operational status

Abandoned

Operational

Proposed

Under construction

Unknown

Cul de sac

The round or circular section of the end of a dead-end street.

Name

(Character identifier)

Not applicable

Unknown

Pipeline

A tubular conduit of substantial length, with pumps, valves, and control devices, for conveying fluids, gases, or finely divided solids.

Name

(Character identifier)

Not applicable

Unknown

Operational status

Abandoned

Operational

Proposed

Under construction

Unknown

Product

Coal

Sewage

Water

Unspecified

Unknown

Relationship to surface

Elevated above surface

Submerged below water surface

Under ground surface

Railway

A rail or set of parallel rails on which a train or trolley runs.

Number of lanes or tracks

(Integer value)

Unspecified

Unknown 
Railway (continued)

Operational status

Abandoned

Dismantled (Old railroad grade)

Operational

Under construction

Unknown

Railway category

General case

Inclined railway--->Inclined railway type

Cable

Cog

Logging

Unspecified

Rapid transit (includes carline)

Unknown

Railway gauge

Narrow

Standard

Monorail

Unknown

Railway type

Mainline

Siding

Road

An open way for passage of vehicles.

Access restrictions

None

Private

Restricted

Toll

Unknown

Directional status

Alternating

Bidirectional

One way

Unspecified

Unknown

Median category

With median

Without median

Name

(Character identifier)

Not applicable

Unknown

Number of lanes or tracks

(Integer value)

Unspecified

Unknown

Operational status

Abandoned

Operational

Proposed

Under construction

Unknown 
Road (continued)

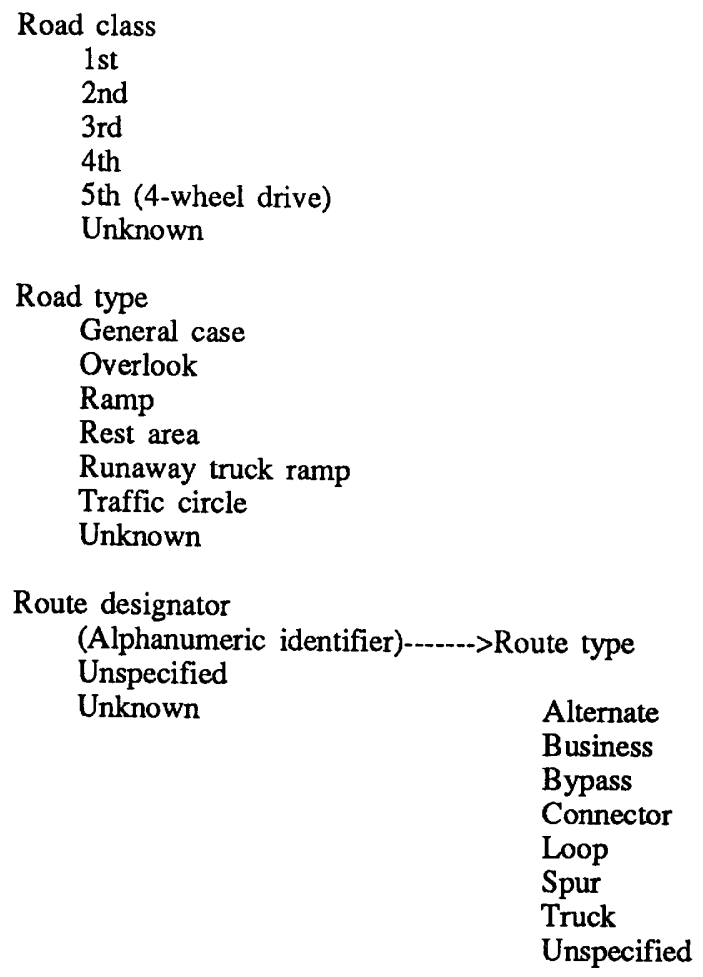

Width (meters)

(Integer value)

Unspecified

Trail

A cleared path, beaten track, or improved surface, as through woods or wilderness, not usually trafficked by vehicles because of width, seasonal conditions, or access restrictions.

Access restrictions

None

Private

Restricted

Unknown

Directional status

Alternating

Bidirectional

One way

Unspecified

Unknown

Historical significance

Not significant

Significant

Unknown

Name

(Character identifier)

Not applicable

Unknown 
Trail (continued)

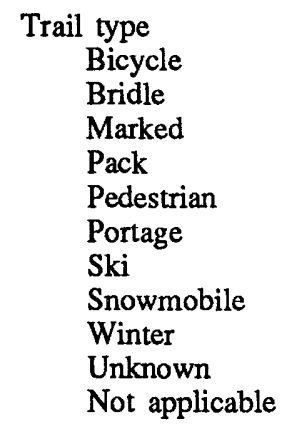

Transmission line

A system of wires that transmit electrical signals or electricity over distance.

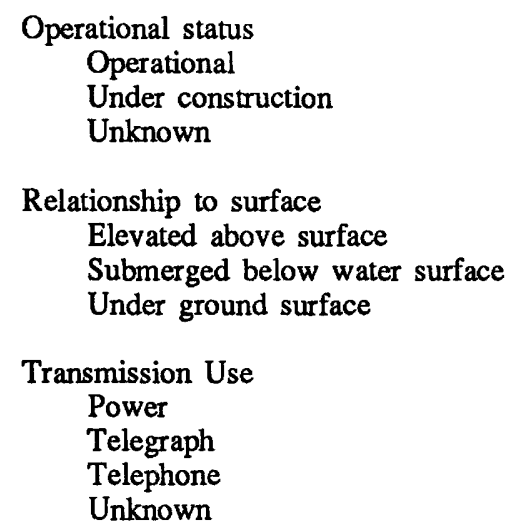

View: Cover Subview 1: Built-up land Subview 2: Structure

Apron

Athletic field
Athletic field type
Archery range
Ball
Equestrian
Pistol range
Polo
Rifle range
Unspecified
Name
(Character identifier)
Not applicable
Unknown

Beacon
A defined paved area at an aircraft facility intended for aircraft parking.

A defined but often urbounded open area constructed and maintained for the purpose of holding sporting events and activities.

A visual, audible, or electronic signal for the guidance of marine or air navigation.

Name

(Character identifier)

Not applicable

Unknown 
Beacon (continued)

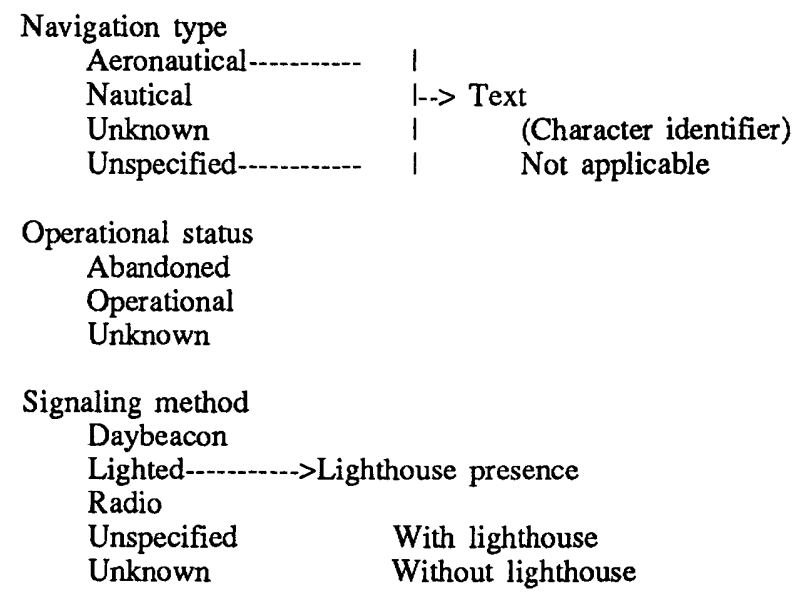

Boardwalk

A promenade, especially of planks, along a beach or waterfront.

Name

(Character identifier)

Not applicable

Unknown

Breakwater/Jetty

Structure built to break the force of waves or to restrain or di*act current so as to protect a beach, harbor, or other waterfront facility.

Name

(Character identifier)

Not applicable

Unknown

Operational status

Operational

Ruined

Unknown

Relationship to surface

Exposed at surface

Submerged below water surface

Bridge

A structure erected over a depression or obstacle to carry traffic.

Covering

Covered

Not covered

Name

(Character identifier)

Not applicable

Unknown

Number of decks

(Integer value)

Not applicable

Unspecified

Unknown 
Bridge (continued)

Operational status

Abandoned

Dismantled

Operational

Proposed

Under construction

Unknown

Building

A permanent construction that is roofed and usually walled.

Angle of orientation

$0 . . .89$ degrees

Not applicable

Building class

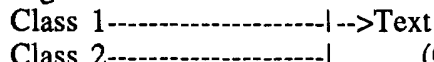

Class 2

(Character identifier)

Not applicable

Name

(Character identifier)

Not applicable

Unknown

Operational status

Abandoned

Operational

Ruined

Unknown

Cableway

Cableway type

Logging

Ski lift

Ski tow

Tramway

Unknown

Name

(Character identifier)

Not applicable

Unknown

Operational status

Abandoned

Dismantled

Operational

Unknown

Chimney

A structure containing a passage or flue for discharging smoke or gases, or for burning waste gases.

Chimney type

Flare pipe

Stack

Unknown

Cliff dwelling

A conveyor system in which carrier units run on wire cables strung between supports.

A habitat built in the recesses of high vertical or overhanging faces of rack. (Geological Survey shows only those sites protected by Federal or State authorizations.)

Angle of orientation

$0 . . .359$ degrees 
Cliff Dwelling (continued)

Name

(Character identifier)

Not applicable

Unknown

Conveyor

Dam/Weir

Material composition

Earthen

Masonry

Unspecified

Name

(Character identifier)

- Not applicable

Unknown

Operational status

Operational

Proposed

Under construction

Unknown

Spillway elevation

(nearest 0.1 meter)

(Numeric value) -..--.> Vertical datum category

Guam Mean Sea Level Datum of 1963

Mean sea level (local)

National Geodetic Vertical Datum of 1929

North American Vertical Datum of 1988

Not applicable
Dish

Draw span

Drilling platform

Product

Gas

Oil

Unknown

Relationship to surface

Exposed at surface

Submerged below water surface
Drive-in theater screen

Drydock
A concave object used for transmitting or receiving electronic signals.

The movable portion of a bridge deck.

A raised structure located in a sea equipped for the extraction of petroleum products.
The large, flat, white or silver surface (and supporting structure) upon which a picture is projected for viewing.

An artificial basin fitted with a gate or caisson into which a ves:el may be floated and from which water may be pumped out to expose the bottom of the vessel.

Flotation

Floating

Not floating 
Fish ladder

Directional status

One way

Unknown

Flume

Directional status

One way

Unspecified

Unknown

Operational status

Abandoned

Operational

Under construction

Unknown

Product

Coal

Logs

Oil

Water

Unspecified

Unknown

Gaging station

Gage type
Tidal
Unspecified

Gate

\section{Grave}

Helipad

Gate type
Unspecified

A facility consisting of a series of small pools, each one slightly higher than the preceding, built around a dam to enable fish to make their way upstream.

An open, inclined, artificial channel constructed of wood, metal, or concrete generally elevated and V-shaped that carries liquid for a special purpose.

A structure used to measure the condition of a hydrographic feature.

A structure that may be swung, drawn, or lowered to block an entrance or passageway.

\begin{tabular}{|c|c|c|}
\hline Check------- & $\mid--->$ Text & \\
\hline Flood & i & (Character identifie \\
\hline Head & 1 & Not applicable \\
\hline Road-...... & $\cdots>$ Acces & ss restrictions \\
\hline Sluice & 1 & Private \\
\hline Tidal & I & Toll \\
\hline Unspecified & 1 & Not applicable \\
\hline
\end{tabular}

A place of burial for one person.

A structure used for the landing and takeoff of helicopters.

Name

(Character identifier)

Not applicable

Unknown

Operational status

Abandoned

Operational

Under construction

Unknown

Surface condition

Hard/Paved

Not paved

Unknown 
Historical marker

Name

(Character identifier)

Not applicable

Unknown

Kiln

$$
\begin{aligned}
& \text { Product } \\
& \text { Brick } \\
& \text { Charcoal } \\
& \text { Coke } \\
& \text { Unknown }
\end{aligned}
$$

Launch pad

Name
(Character identifier)
Not applicable
Unknown

Operational status
Abandoned
Operational
Under construction
Unknown

Launching ramp

\section{Ramp type \\ Boat \\ Seaplane}

Lock

Name

(Character identifier)

Not applicable

Unknown

Masonry shore

Mine entrance
Angle of orientation
$0 . . .359$ degrees
Mine entrance type
Adit
Shaft
Name
(Character identifier)
Not applicable
Unknown
Operational status
Abandoned
Operational
Unknown

A structure, not a building, that commemorates people or past events.

Any of various ovens for hardening, burning, or drying substarces.

A structure from which a rocket or missile is launched.

A partially submerged hard surface on a shoreline for launching or retrieving vessels or aircraft.

An enclosure used to raise or lower vessels as they pass from cne level to another.

A structure built of stone, brick, or concrete that borders a body of water.

Passage that affords entry to an underground mine.

Penstock

A closed pipe or channel used to convey water into the turbine of a hydroelectric generating plant. 
Penstock (continued)

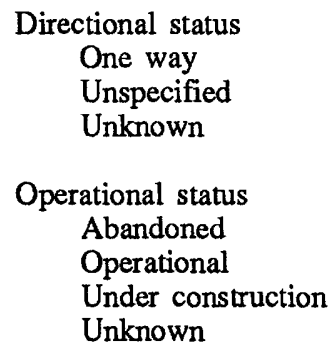

Pier/Wharf

Point monument

Post

Post type

Dolphin

Piling

Prospect
Name
(Character identifier)
Not applicable
Unknown

(Character identifier)

Not applicable

Unknown

Operational

Unknown

Structures to which vessels may be berthed:

Pier: long narrow structure extending into the water

Wharf: parallel to the shoreline and accommodates ships on one side only

A structure noting a spot on a boundary or survey line.

An upright piece of timber or other material, in or adjacent to a body of water, used for mooring ships or supporting other structures.

A marked location where mineral exploration has occurred but no mine has been developed.

Pump

A device that raises, transfers, or compresses fluids or that attenuates gares especially by suction or pressure.

Racetrack

A course laid out for racing.

Name

(Character identifier)

Not applicable

Unknown

Track condition/use

Hard/Paved-Vehicle

Improved/Loose-Vehicle/Animal

Improved-Pedestrian

Improved/Rough-Vehicle

Unknown

Recreational slide

An amusement structure consisting of a smooth, usually inclined surface or track for sliding. 
A constructed basin formed for recreation use, storage, treatment, collection, or processing of water or other liquids.

Covering

Covered

Not covered

Elevation (nearest 0.1 meter)

(Numeric value)-->Vertical datum category

Guam Mean Sea Level Datum of 1963

Mean sea level (local)

National Geodetic Vertical Datum of 1929

Unspecified

North American Vertical Datum of 1988

Unknown

Hydrographic category

Intermittent

Perennial

Not applicable

Unknown

Name

(Character identifier)

Not applicable

Unknown

Operational status

Abandoned

Operational

Under construction

Unknown

Reservoir use

Clarification

Cooling

Debris basin

Evaporator--------.----->Product

Filtration bed

Salt

Fish hatchery Soda

Fishpond Unknown

Guzzler

Industrial processing

Industrial waste

Percolation basin (spreading ground)

Purification

Retardation basin

Settling basin

Sewage disposal

Storage----_-_-------->Liquid contained

Oil

Water

Sump----------------->Liquid contained

Oil

Swimming

Water

Unknown

Runway

A straight path used for landing and takeoff of aircraft.

Operational status

Abandoned

Operational

Under construction

Unknown 
Runway (continued)

Surface condition

Hard/Paved

Not paved

Unknown

Siphon

Ski jump

Spillway

Operational status

Abandoned

Operational

Under construction

Unknown

Directional status

One way

Unspecified

Unknown
A pipe conveying water by gravitational force to a lower level, over an obstruction higher than the intake.

Tank

An inclined structure consisting of a track from which skiers vault.

A passage for surplus water to run over or around a dam.

Elevation (nearest 0.1 meter)

(Numeric value)-->Vertical datum category

Guam Mean Sea Level Datum of 1963

Mean sea level (local)

National Geodetic Vertical Datum of 1929

North American Vertical Datum of 1988

Unspecified

A large container used for storage.

Name

(Character identifier)

Not applicable

Unknown

Tank type

Cistern

General case---.-.---->Product

Chemical

Fuel

Gas

Gasoline

Molasses

Oil

Oxygen

Water

Unspecified

Silo $>$ Product

Grain

Unknown

Storage bin----------->Product

Unspecified

Grain

Unknown

Surge

Unspecified

Taxiway

An improved area providing access to/from runways and the apron.

Tower

A structure designed primarily with a view to elevation, typically higher than wide. 
Tower (continued)

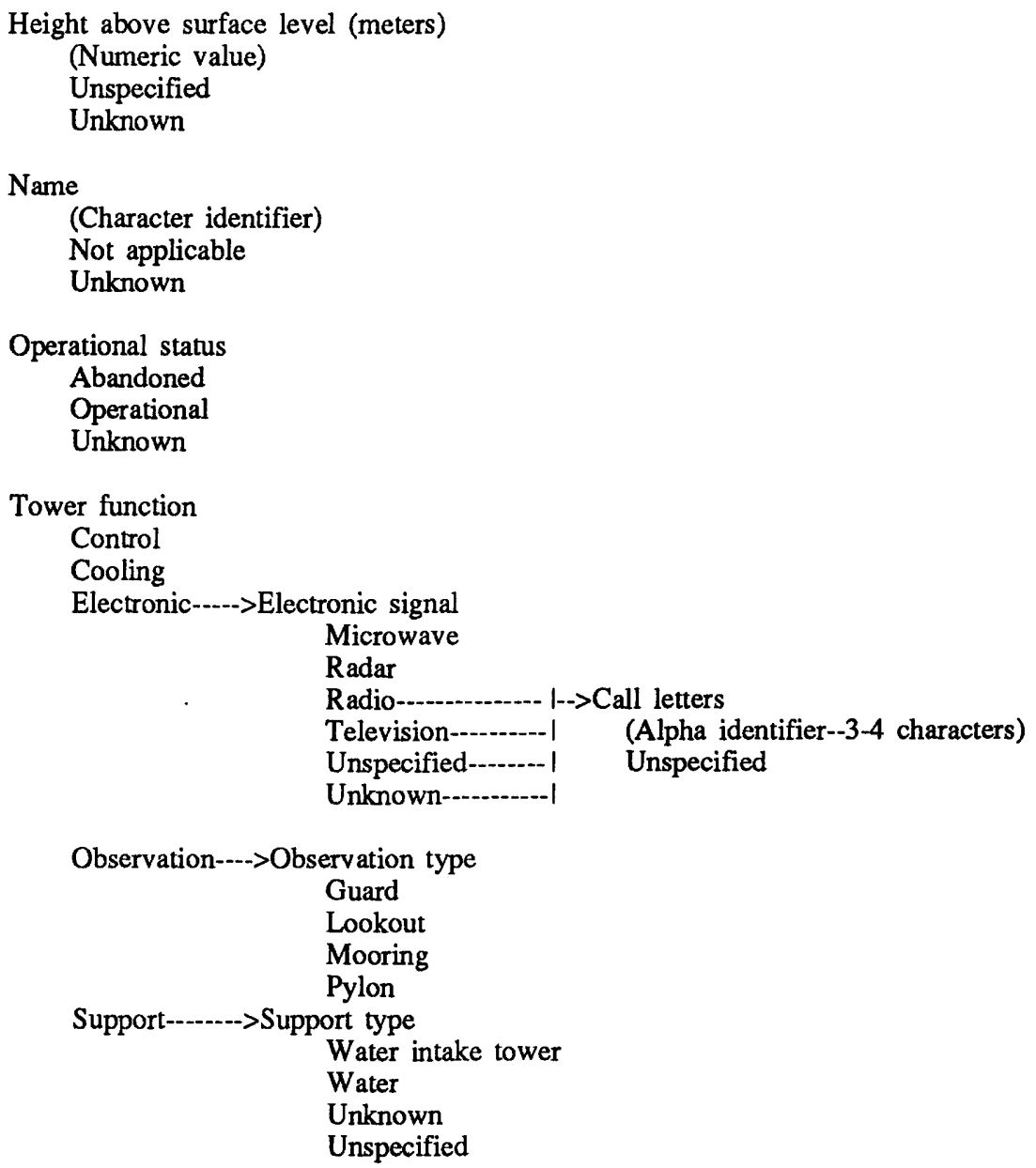

Tunnel

An underground or underwater passage.

Name

(Character identifier)

Not applicable

Unknown

Operational status

Operational

Proposed

Under construction

Unknown

Tunnel entrance

Opening that affords entry to an underground or underwator passage.

Angle of orientation

$0 . . .359$ degrees

Turntable

A rotating platform with railroad tracks used for turning locomotives or cars.

Operational status

Abandoned

Dismantled

Operational

Proposed

Under construction

Unknown 
Wall

An upright structure of masonry, wood, plaster, or other building material serving to enclose, divide, or protect an area.

\section{Wall type \\ General case \\ Sea}

A structure through which water enters or exits a conduit.

Water intake/outflow

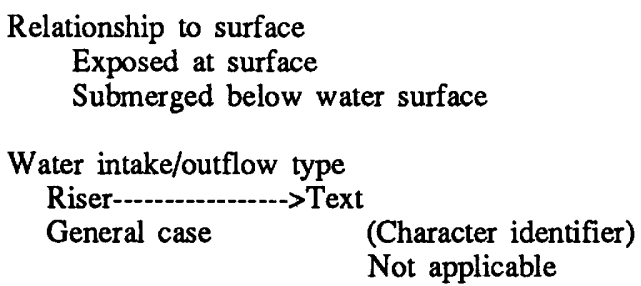

Well

A pit or hole dug or bored into the Earth for the extraction of oil, water, other fluids or gases.

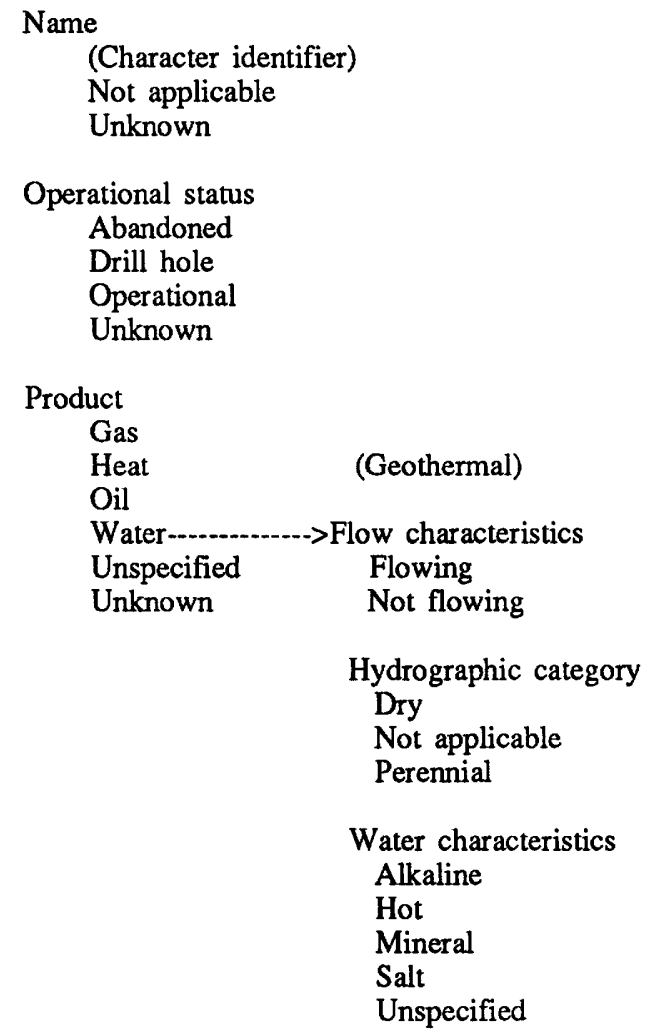

Windmill

A mill or other machine that runs on the energy generated by a wheel of adjustable blades or flats rotated by the wind.
Name
Not applicable
Unknown
Windmill function
Pump
Generator

(Character identifier)
The hulk or the ruins of a disabled vessel which is attached to or foul of the bottom or cast up on the shore. 
Wreck (continued)

Name

(Character identifier)

Not applicable

Unknown

Relationship to surface

Exposed at surface---.-.-.......-->Exposed portion

Submerged below water surface

Mast and(or) funnel

Hull and(or) superstructure

View: Cover Subview 1: Built-up land Subview 2: Complex Subview 3: Agriculture

Fish hatchery

Name

(Character identifier)

Not applicable

Unknown

Holding pen

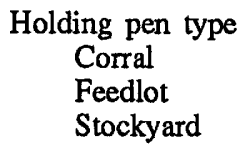

Marine activity site

View: Cover Subview 1: Built-up land Subview 2: Complex Subview 3: Commercial

Shopping center
Name
(Character identifier)
Not applicable
Unknown

View: Cover Subview 1: Built-up land

Archeological site/Ruins

A group of associated structures functioning as a unit used fo fishing, aquaculture, or related activities.

A set of pools of water and related structures used for spawring and growing of fish that are subsequently used to stock lakes and streams.

An enclosed area in which livestock are temporarily kept.

A group of structures used for the sale of products and services.

An area of historical significance containing the deteriorated remains of a

Archeological site/Ruins type

Archeological site

Pictograph

Ruins

Unspecified

Name

(Character identifier)

Not applicable

Unknown

Campground

A designated area on which primitive structure(s) are erected for temporary shelter or where recreational vehicles are temporarily parked. structure(s) or where past human life and activities are under study.

Campsite type

Campground (includes campsite)

Recreational vehicle

Unspecified 
Campground (continued)

Name

(Character identifier)

Not applicable

Unknown

Cemetery

$$
\begin{aligned}
& \text { Name } \\
& \text { (Character identifier) } \\
& \text { Not applicable } \\
& \text { Unknown }
\end{aligned}
$$

Exhibition ground

Name

(Character identifier)

Not applicable

Unknown

Marina

Name

(Character identifier)

Not applicable

Unknown

Outdoor theater

Outdoor theater type

Amphitheater

Aqua

Drive-in

Name

(Character identifier)

Not applicable

Unknown

Park

Park type

Amusement

Botanical

Parade ground

Picnic area

Playground

Zoo

Unspecified

Name

(Character identifier)

Not applicable

Unknown
An area of land for burying the dead with two or more graves.

A public area where outdoor fairs, circuses, and other events are held that also contains structures for the display of livestock, machinery, agricultural produce, etc.

A harbor facility for recreational craft where supplies, repairs, and varions services are available.

An outdoor area consisting of a stage or other focal point, and an area where the audience can be seated to view the performance or event.

A place or area developed for public use or recreation.

Sports site

A field, center, or open area maintained for the purpose of holding sporting events and activities. 
Sports site (continued)

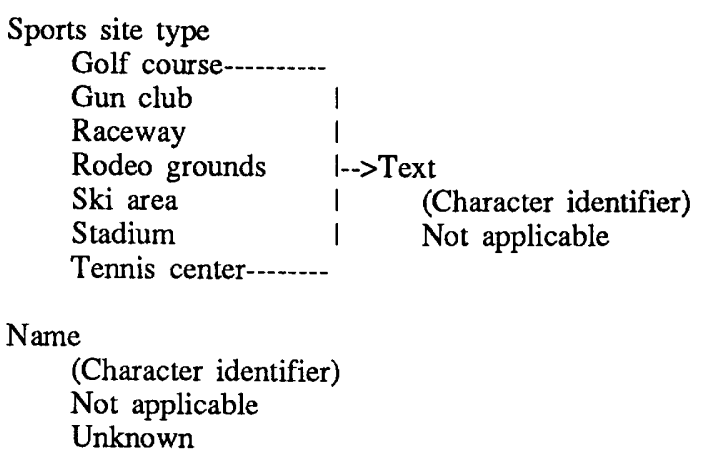

View: Cover

Disposal site

Wrecking yard

View: Cover

Mine

Mine type

Auger borings
Open pit
Pit
Placer
Quarry
Strip

Name

(Character identifier)

Not applicable

Unknown

Operational status

Abandoned

Operational

Reclaimed

Unknown
Abandoned

Unknown nder construction
An area or site engaged in the wrecking and reclamation of discarded products.

(Spoil bank)

(Dump, landfill)

(Mine dump) 
Mine (continued)

Product
Bentonite
Caliche
Chert
Cinders
Clay
Coal
Copper
Gold
Gravel
Pumice
Salt
Sand
Scoria
Shale
Silver
Soil
Uranium
Unspecified
Unknown

Well field

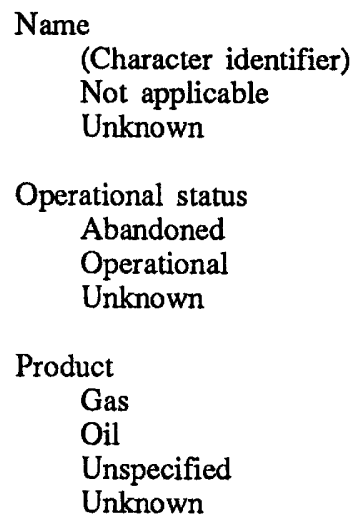

An area where petroleum and(or) natural gas is or was removed from the Earth.

View: Cover Subview 1: Built-up land Subview 2: Complex Subview 3: High Density Building Area

High density building area

A congested, built-up area.

View: Cover Subview 1: Built-up land Subview 2: Complex Subview 3: Industrial

Industrial site

A group of associated structures functioning as a unit used for refining a material or manufacturing a product.

\footnotetext{
Name

(Character identifier)

Not applicable

Unknown

Operational status

Abandoned

Operational

Under construction

Unknown
} 
Industrial site (continued)

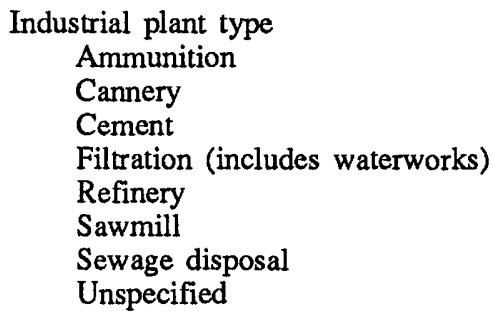

Mineral pile

Proving ground

Name

(Character identifier)

Not applicable

Unknown

Tank farm

Name

(Character identifier)

Not applicable

Unknown

Product

Gas

Oil

Unspecified
A manmade heap of products resulting from mines.

An area set aside for scientific testing.

A set of tanks and related structures used for the storage of liquids and(or) gases.

View: Cover Subview 1: Built-up land Subview 2: Complex Subview 3: Institutional

Institutional site
A group of buildings or associated structures functioning as a unit used predominantly for educational, correctional, governmental, nedical, or religious purposes.

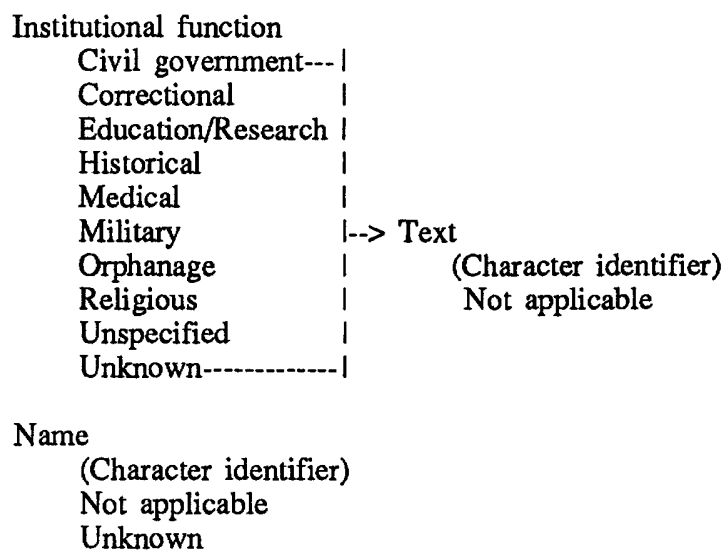

View: Cover Subview 1: Built-up land Subview 2: Complex Subview 3: Residential

Trailer park

An area maintained for the parking of inhabited mobile hores.

Name

(Character identifier)

Not applicable

Unknown 
View: Cover Subview 1: Built-up land Subview 2: Complex Subview 3: Transition

Transition area

Area in transition from one land use activity to another, and characterizet by a lack of information to predict future use or discern past use.

View: Cover Subview 1: Built-up land Subview 2: Complex Subview 3: Transportation

Aircraft facility

Aircraft facility type

Airport

Heliport

Seaplane base

Name

(Character identifier)

Not applicable

Unknown

Operational status

Abandoned

Operational

Under construction

Unknown

Interchange

Interchange designator

(Alphanumeric identifier)

Not applicable

Unknown

Name

(Character identifier)

Not applicable

Unknown

Launch facility

Name

(Character identifier)

Not applicable

Unknown

Operational status

Abandoned

Operational

Under construction

Unknown

Parking site

Railway yard
An area where aircraft can take off and land, usually equipped with associated buildings and facilities.

Facility used primarily by conventional, fixed-wing aircraft.

Facility used primarily by rotary-wing aircraft.

Facility used primarily where water is the landing surface.

An area designated to provide traffic access from one road to another.

An area from which rockets/missiles may be housed and projected, usually equipped with associated buildings and facilities.

A designated area where motor vehicles are set and left temporarily.

An area provided with a system of tracks and associated structures where railway trains are assembled and railway cars are switched, stored, or serviced.

Name

(Character identifier)

Not applicable

Unknown 
Railway yard (continued)
Operational status
Abandoned
Operational
Under construction
Unknown

Rest site
Name
(Character identifier)
Not applicable
Unknown

Toll plaza

Traffic inspection facility
A roadside area usually having facilities for people and(or) vehicles.

An open area having the facility to collect tolls.

An open area having facilities to examine vehicles and(or) their cargo.

Traffic inspection facility type
Agricultural
Customs
Weigh

View: Cover Subview 1: Built-up land Subview 2: Complex Subview 3: Utility

Cable/Pipeline site

Dam site

$$
\begin{aligned}
& \text { Name } \\
& \text { (Character identifier) } \\
& \text { Not applicable } \\
& \text { Unknown } \\
& \\
& \text { Operational status } \\
& \text { Abandoned } \\
& \text { Operational } \\
& \text { Under construction } \\
& \text { Unknown }
\end{aligned}
$$

Pipeline regulation station

$$
\begin{aligned}
& \text { Name } \\
& \text { (Character identifier) } \\
& \text { Not applicable } \\
& \text { Unknown } \\
& \\
& \text { Operational status } \\
& \text { Abandoned } \\
& \text { Operational } \\
& \text { Under construction } \\
& \text { Unknown } \\
& \text { Pipeline regulation station type } \\
& \text { Compressor } \\
& \text { Pumping } \\
& \text { Valve }
\end{aligned}
$$

An ancillary facility along a pipeline route in which the flow of fluids or gases is controlled.
An area where cables or pipelines are located under water.

An area including a dam and associated structures functionin? to control the flow or raise the level of water.
Power site 
Power site (continued)

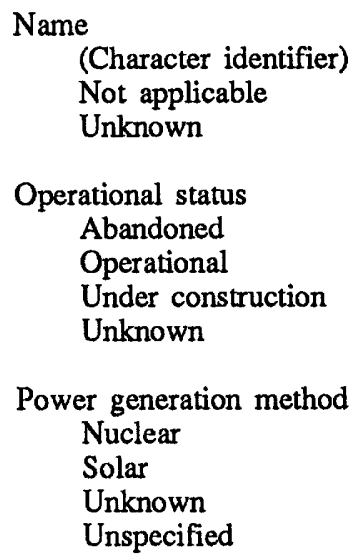

Substation

An ancillary facility along a powerline route in which electric current is transformed.

\author{
Name \\ (Character identifier) \\ Not applicable \\ Unknown \\ Operational status \\ Abandoned \\ Operational \\ Under construction \\ Unknown
}

View: Cover Subview 1: Cultivated cropland

Cultivated cropland

Land that has been plowed or otherwise cultivated for crop production.

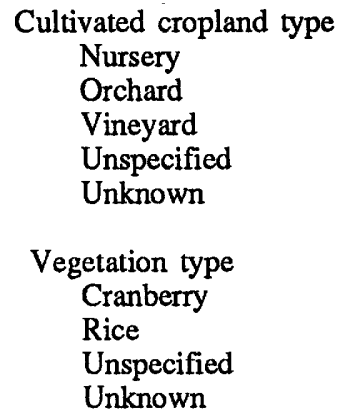

View: Cover Subview 1: Vegetation Subview 2: Grassland

Grassland

An extensive noncultivated area where vegetation is dominated by grases or grass-like plants.

View: Cover Subview 1: Vegetation Subview 2: Shrubland

Shrubland

Areas covered with low-growing or stunted perennial vegetation and usually not mixed with trees. 
View: Cover Subview 1: Vegetation Subview 2: Forestland

Tree

Woody perennial plants having a self-supporting main stem nr trunk and a definite crown. (Used for individual trees having historical or cultural significance.)

Name

(Character identifier)

Not applicable

Unknown

Trees

An extensive area of land covered with woody perennial plarts having a self-supporting main stem or trunk and a definite crown.

Tree category

Deciduous

Evergreen

Vegetation characteristics

Mangrove

Unspecified

Snag/Stump

Relationship to surface

A firmly attached stem or trunk of a tree near the surface of water.

Exposed at surface

Submerged below water surface

View: Cover Subview 1: Water

Area to be Submerged

The known limits of the intended lake that will be created brhind a dam under construction.

Elevation (nearest 0.1 meter)

(Numeric value)-->Vertical datum category

Guam Mean Sea Level Datum of 1963

Mean sea level (local)

National Geodetic Vertical Datum of 1929

Unspecified

North American Vertical Datum of 1988

Unknown

Name

(Character identifier)

Not applicable

Unknown

Bay/Estuary/Inlet

A water area that is an inlet of the sea/ocean.

Name

(Character identifier)

Not applicable

Unknown

Ford

Location in a body of water where the physical characteristic of the bottom, water depth, and approaches permit the passage of vchicles.

Name

(Character identifier)

Not applicable

Unknown

Gut

A narrow natural passage or contracted strait connecting two bodies of water where no flow can be determined. 
Gut (continued)

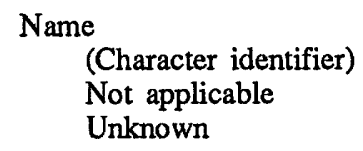

Inundation area An area of land subject to flooding.
Inundation control
Controlled-------->Inundation area use
Dewatering area
Not controlled
Duck pond

Lake/Pond

A standing body of water surrounded by land.

Elevation (nearest 0.1 meter)

(Numeric value)-->Vertical datum category

Guam Mean Sea Level Datum of 1963

Mean sea level (local)

National Geodetic Vertical Datum of 1929

North American Vertical Datum of 1988 $\rightarrow>$ Stage

Average water elevation

High water elevation

Unspecified

Normal pool elevation

Unknown

Hydrographic category

Intermittent

Perennial

Unknown

Name

(Character identifier)

Not applicable

Unknown

Water characteristic

Fresh

Salt

Rapids

Sea/Ocean

Directional status

One way

Unknown

Unspecified

Name

(Character identifier)

Not applicable

Unknown
An area of swift current in a stream or river, characterized by standing waves or by boulders and rocks.

The great body of salt water of the oceans.

Name

(Character identifier)

Not applicable

Unknown

Sea/Ocean type

Reef pool

Unspecified 
Shoreline

Delineation status

$$
\begin{aligned}
& \text { Apparent } \\
& \text { Definite } \\
& \text { Indefinite/ } \\
& \text { Approximate } \\
& \text { Unsurveyed }
\end{aligned}
$$

Spring

Stream/River

Angle of orientation

$$
0 . .359 \text { degrees }
$$

Name

(Character identifier)

Not applicable

Unknown

Water characteristics
Alkaline
Hot
Mineral
Sulfur
Unspecified

A naturally occurring line of contact between a body of water and the land.

A place where water issues from the ground naturally.

A body of flowing water.
Definite
Unsurveyed

Elevation (nearest 0.1 meter)

(Numeric value)-->Vertical datum category

Guam Mean Sea Level Datum of 1963

Mean sea level (local)

National Geodetic Vertical Datum of 1929

North American Vertical Datum of 1988

$->$ Stage

Unspecified

Unknown

Directional status

One way

Unknown

Unspecified

Hydrographic category

Intermittent

Perennial

Unknown

Hydrographic form

Braided

Not braided

\section{Name}

(Character identifier)

Not applicable

Unknown 
Submerged stream (continued)

Name

(Character identifier)

Not applicable

Unknown

Waterfall

A vertical or nearly vertical descent of water over a step or ledge in the bed of a river.

Name

(Character identifier)

Not applicable

Unknown

View: Division Subview 1: Administrative

Reservation

Bounded land set aside for a particular purpose generally having certain use restrictions.

Name

(Character identifier)

Not applicable

Unknown

Reservation class

Forest-.-..-...-..-.-.-1

General case

Grassland

Indian land

Military

Park

Prison

Wilderness

Wildlife

Unknown-.............-.

Reservation use status

National

State

Regional

County

Minor civil unit

City

Private

Unknown

View: Division Subview 1: Boundary

Boundary Line

A separation between divisions of current or past significance.

Delineation status

Definite

Disputed

Historical

Indefinite/Approximate

Proposed-....-.-.-----.- $>$ Text

Protracted-..-....--I (Character identifier)

Unknown Not applicable

Name

(Character identifier)

Not applicable

Unknown 
Boundary point

Boundary point identifier

(Alphanumeric identifier)

Not applicable

Unknown

Fence line

International Date Line

View: Division Subview 1: Census

Census block

Census block number

(Alphanumeric value)

Census block group

Census block group number

(Integer value - 1-9)

Census County Division (CCD)/

Minor Civil Division (MCD)

$\mathrm{CCD} / \mathrm{MCD}$ number

(Integer value - 001-999)

Census tract/Block Numbering Area (BNA)

Census tract/BNA Number

(Numeric value - 0001.01-9989.99)

Metropolitan Statistical Area (MSA)

An area with a population greater than 50,000 .
The primary statistical unit for which census information is collected and published.

An aggregate of census blocks for which statistical information is published.

Subcounty aggregates of census tracts and Block Numbering Areas (BNA's) for which statistical information is published. CCD's are established in areas where MCD's do not exist.

Aggregates of census block groups for which statistical information is published. Tracts occur in MSA's and potential MSA's, and BNA's occur outside MSA's.

A line generally coinciding with the 180 th meridian, modifiet to avoid land, and designated as the place where each calendar day bigins.

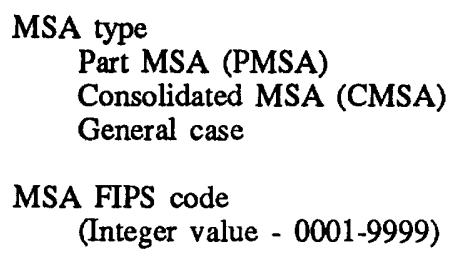

View: Division Subview 1: Hydrologic unit

Hydrologic Unit

\footnotetext{
Region unit code

(Integer value - 01...21)

Subregion unit code

(Integer value - 01...99)

Not applicable
}

Subdivisions used for the collection and organization of data dealing with the properties, distribution, and circulation of water. These codes provide a standardized base for use by water resources organizations in the storage, retrieval, and exchange of hydrologic data; the indexing and inventorying of hydrologic data and information; the cataloging of water data acquisition activities; and a variety of other applications. 
Hydrologic unit (continued)

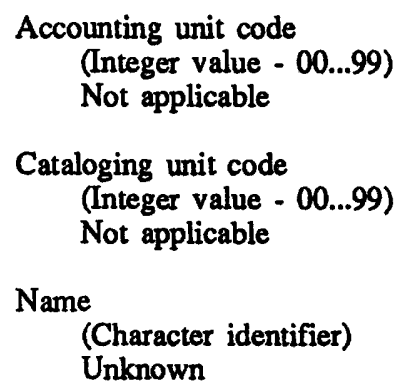

View: Division Subview 1: Land parcel

Land parcel

A tract or plot of the Earth's surface distinguishable by ownership.

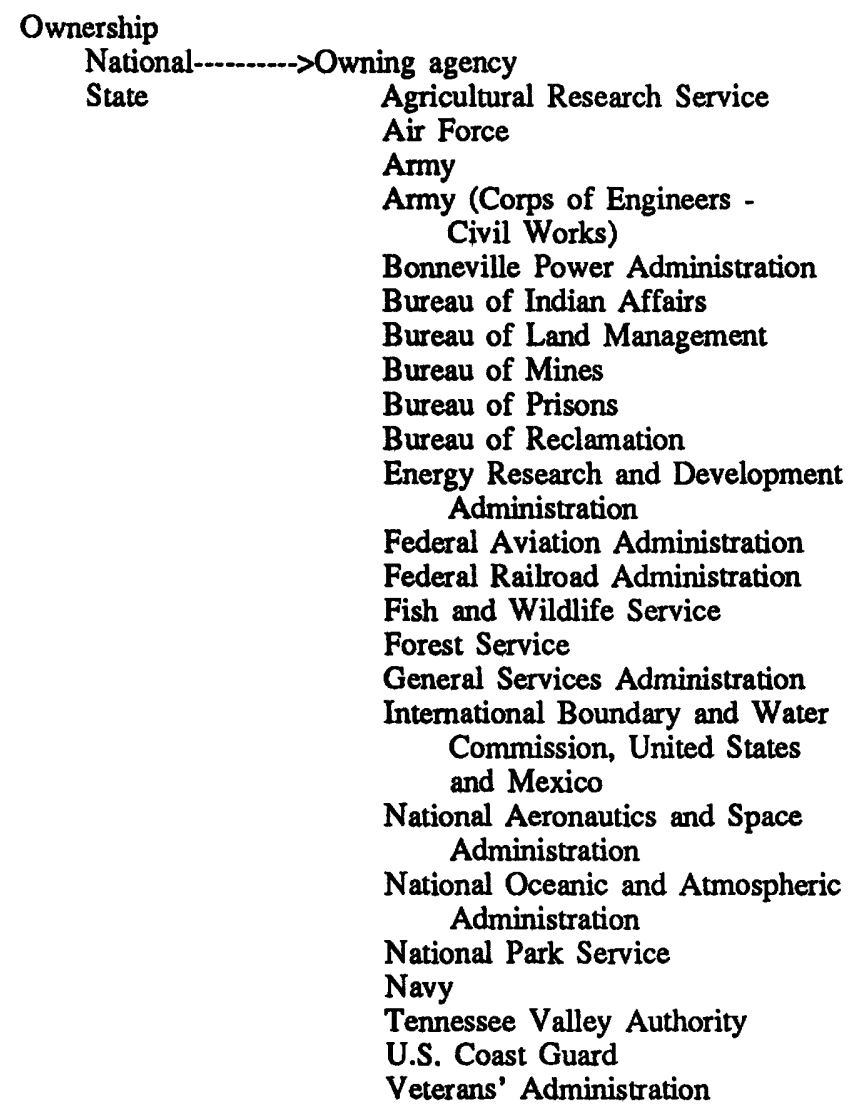

View: Division Subview 1: Locale

Locale

A named place not otherwise categorized.
Name
(Character identifier)
Unknown

View: Division Subview 1: Maritime

An area where a vessel anchors or may anchor, either because of suit bility or designation. 
Anchorage (continued)

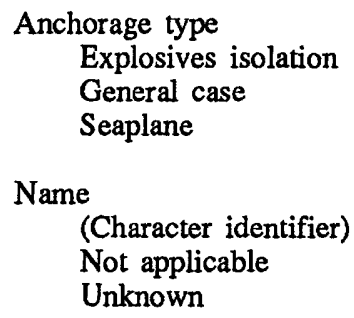

Hazard zone

An area identified as a danger to maritime navigation.

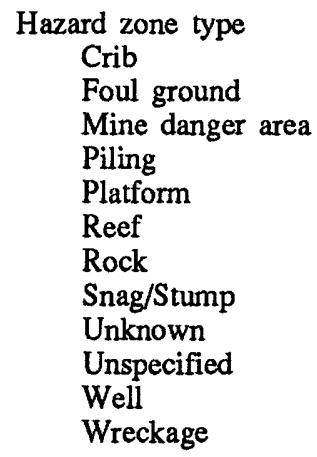

Lane

A prescribed course for ships, boats, or seaplanes.

Lane type

Airboat trail

Dredged channel

Ferry crossing

Seaplane landing/takeoff

Shipping

Name

(Character identifier)

Not applicable

Unknown

Special use zone

An area where distinctive types of shipping activities occur.

Special use activity

Dumping ground for hazardous material

Spoil area

View: Division Subview 1: Political

City

An incorporated populated place such as a village, city, town, borough, or hamlet, and includes an independent city.

Name

(Character identifier)

County

Second-order division of a nation such as parish, borough, county, municipio, or judicial division, and independent cities in Mary' and, Missouri, Nevada, and Virginia.

FIPS code identifier-2nd

(Integer value - 001...999)

Name

(Character identifier) 
Exclusive Economic Zone (EEZ)

Minor civil unit

FIPS code identifier-3rd

(Integer value - 0001...9999)

Not applicable

Name

(Character identifier)

Minor civil subunit

Name

(Character identifier)

Nation

Name

(Character identifier)

State/Territory

FIPS code identifier-1st

(Integer value - 01...99)

Name

(Character identifier)

View: Division Subview 1: Survey system

Baseline

\section{Name}

(Character identifier)

Georgia Survey District

\author{
District number \\ (Integer value - 001...999) \\ Lot number \\ (Integer value - 0001...9999)
}

Homestead entry
A zone contiguous to the territorial sea, including zones contiguous to the territorial sea of the United States, Puerto Rico, the Northern Mariana Islands, and U.S. overseas territories and possessions. The EEZ extends to a distance 200 nautical miles from the baseline from which the breadth of the territorial sea is measured. In cases where the maritime boundary with a neighboring state remains to be determined, the boundary of the EEZ shall be determined by the U.S. and other states concerned in accordance with equitable principles.

Third-order division of a nation such as township, town, district, precinct. and barrio.

Fourth-order division of a nation such as Hawaiian ahupuaas.

An area under the jurisdiction of a sovereign government.

First-order division of a nation.

The line extending east and west from the initial point of a Public Lan' Survey System (PLSS) survey. Townships will be north or south of the baseline.

Public lands surveyed by the State of Georgia from 1805-1832. The land was divided by county into districts and lots. The State contains 389 districts, and each district can have over 1,000 lots. The lots were siz?d according to their perceived value and range from 40 to 490 acres.

Generally these land lines have NOT been shown on 7.5-minute quadrangles except in the Atlanta area. 
Land grant Grants established prior to the original subdivisional public surveys.

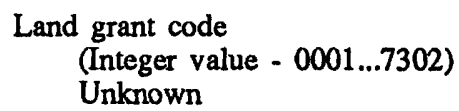

Name

(Character identifier)

Unknown

Principal meridian

The line extending north and south from the initial point of a Public Land Survey System (PLSS) survey. Townships will be east or west of the principal meridian.

Public survey area

An area of the public land survey systems established by publis. private, or combined surveys.

Origin of survey name

(Character identifier)

Origin of survey number

(Integer value - 01...48)

Public survey area type

General case

Donation land claim

Range number

(Numeric value with 1 alpha character $(E / W)$ )

Section number

(Alphanumeric value)

Township number

(Numeric value with 1 alpha character $(\mathrm{N} / \mathrm{S})$ )

Survey corner

A public land survey or other land survey comer.

BLM corner identifier

(Alphanumeric value)

Field identification

Identified

Not identified

Unknown

Name

(Character identifier)

Survey comer type

Arbitrary

Auxiliary meander

Closing

Isolated

Land grant

Meander

Quarter section

Section

Tract

Witness off line

Witness on line

Survey point

A survey location other than a survey corner.

Survey point type

Angle point

Land grant monument

Location monument (includes mineral monument) 
Survey point (continued)

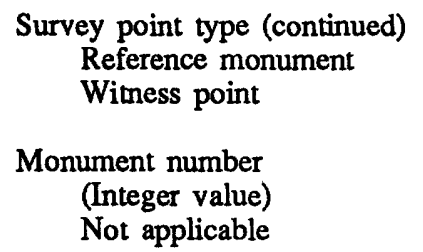

View: Ecosystem

Desert

A region rendered barren or partially barren by environmental extremes, especially by low rainfall.

Name

(Character identifier)

Not applicable

Unknown

Tundra

A treeless, level, or gently rolling plain characteristic of arctic or subarctic regions, having a permanently frozen subsoil, and usually supporting low growing vegetation such as lichens, mosses, and stunted shrubs.

Wetland

A vegetated area that is inundated or saturated by surface or ground water for a significant part of the year. The vegetation is adapted for life in saturated soil conditions.

Name

(Character identifier)

Not applicable

Unknown

View: Geoposition

Contour (bathymetric)

A line connecting points of equal depth with reference to the sounding datum.

Contour symbolization category

Mound

Not applicable

Delineation status

Amended

Definite

Indefinite/

Approximate

Depth (nearest 0.1 meter)

(Positive Numeric Value)----->Bathymetric datum

Gulf Coast low water

Lowest low water

Mean low lake level

Mean low water

Mean lower low water

Mean sea level

Tropic lower low water

Water surface as indicated--->Text

Unknown

(Character identifier) 
Contour symbolization category

Depression

Not applicable

Delineation status

Amended

Definite

Indefinite/

Approximate

Elevation (nearest 0.1 meter)

(Numeric value)-->Vertical datum category

Guam Mean Sea Level Datum of 1963

Mean sea level (local)

National Geodetic Vertical Datum of 1929

North American Vertical Datum of 1988

Control station A point with an accurate position and(or) elevation used as a base for a dependent survey.

Elevation (nearest 0.001 meter)

(Numeric value)-->Vertical datum category

Guam Mean Sea Level Datum of 1963

Mean sea level (local)

National Geodetic Vertical Datum of 1929

Unspecified

North American Vertical Datum of 1988

Horizontal control accuracy

First order

Not applicable

Second order-..-.-.- |-->Control class

Third order--.-.-.-. I Class I

Third order or better Class II

Monument type

No tablet

Tablet

Name

(Character value)

Not applicable

Unknown

Relationship to surface

Elevated above surface

Exposed at surface

Vertical control accuracy

First order-.....-.-.-.

Not applicable $\quad \mid->$ Control class

Second order-.....-. I Class I

Third order Class II

Third order or better

Mile marker

A point on a feature indicating the distance, in miles, measured along the course or path of the feature, from an established origin point $\mathrm{cn}$ the feature.

Mile marker type

Railroad

Watercourse

Mileage number (nearest 0.1 mile)

(Numeric value) 
Spot elevation

A point with a measured vertical position, measured relative to a reference datum, of less than third-order accuracy.

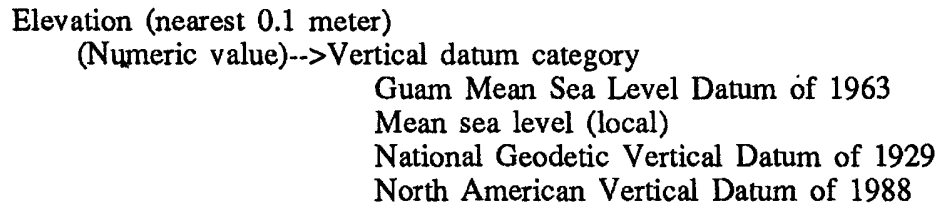

Relationship to surface

Elevated above surface

Exposed at surface

View: Morphology

Arch

A naturally occurring curved structure that supports the weight of material over space.

Name

(Character identifier)

Bar

A natural accumulation of sand, gravel, or other material forming an underwater or exposed embankment.

Bar type

Offshore

Point

Name

(Character identifier)

Not applicable

Basin

A bowl-shaped depression in the surface of the land or ocean floor.

\author{
Basin type \\ Carolina Bay \\ Crater--.----->Crater type \\ Unspecified \\ Bomb \\ Meteoric \\ Volcanic
}

Name

(Character identifier)

Beach

The gently sloping shore that is washed by waves, usually composed of sand and pebbles.

Name

(Character identifier)

Bend

Name

The land within the curve of a stream sometimes including the course of the stream.

(Character identifier)

Cape

A projection of land extending into a body of water that prominently marks a change in or interrupts the coastal trend of that water body.

Name

(Character identifier)

Cave

A naturally formed, subterranean open area or chamber.

Name

(Character identifier) 
Cave entrance

$$
\begin{aligned}
& \text { Angle of orientation } \\
& 0 . . .359 \text { degrees } \\
& \text { Name } \\
& \text { (Character identifier) }
\end{aligned}
$$

Cliff

$$
\text { Name }
$$

(Character identifier)

\section{Crevasse}

Disturbed surface

Dunes

$$
\begin{aligned}
& \text { Name } \\
& \text { (Character identifier) } \\
& \text { Not applicable } \\
& \text { Stability } \\
& \text { Stable } \\
& \text { Shifting }
\end{aligned}
$$

Embankment

$$
\begin{aligned}
& \text { Embankment type } \\
& \text { Levee } \\
& \text { Redoubt }
\end{aligned}
$$

Fault

Name

(Character identifier)

Not applicable

Flat

Flat type

$$
\text { Playa }
$$

Tidal

Name

(Character identifier)

Not applicable

Foreshore

Fumarole

Name

(Character identifier)

Not applicable

Gap

\footnotetext{
Name

(Character identifier)

Not applicable
}

Passage that affords entry to a naturally formed, subterranean open area or chamber.

A high vertical, near-vertical, or overhanging face of rock, earth, or ice.

A deep fissure in the surface of the Earth caused by breaking or parting.

An area that is broken into a chaotic pattern of elevations and depressions.

Hills of sand piled up by the wind.

A raised, solid-fill linear mound.

A fracture in the Earth's crust accompanied by a displacement of one side of the fracture with respect to the other.

A level tract of land.

The part of a seashore between high-water and low-water mark:

A hole in the Earth's crust from which steam and gases are emitted.

A low point or opening between mounts or in a ridge. 
Geyser

Name

(Character identifier)

Not applicable

Unknown

Iceberg

Iceberg tongue

Incline/Flow

Name

(Character identifier)

Island

Name

(Character identifier)

Not applicable

Isthmus

Name

(Character identifier)

Moraine

Name

(Character identifier)

Not applicable

Mount

Mount type
General case
Hummocked ice
Ice dome
Indian mound
Pingo
Name
(Character identifier)

Pinnacle

Name

(Character identifier)

Plain

\section{Name}

(Character identifier)

Range

\section{Name}

(Character identifier)
A natural intermittent fountain of hot water ejected with force into the aifrom a hole in the Earth's crust.

Large mass of floating or stranded ice of greatly varying shape, more than 5 meters above sea level, which has broken away from a glacier.

A major accumulation of icebergs projecting from the coast, held in place by grounding and joined together by fast ice.

A feature characterized by a sloping surface or a formation resulting from movement down a sloping surface.

An area of dry or relatively dry land surrounded by water or low wetlard.

A narrow strip of land, bordered on both sides by water that connects two larger land areas.

An accumulation of earth and stones carried and deposited by a glacier.

A landmass that projects conspicuously above its surroundings.

A vertical, standing, often spire-shaped natural rock formation.

A region of general uniform slope, comparatively level and of considerable extent.

A chain of mounts. 
Name

(Character identifier)

Not applicable

Ridge

Name

(Character identifier)

Ridge line

\section{Name}

(Character identifier)

Rock

Sastrugi

Sink

Name

(Character identifier)

Not applicable

Summit

$$
\text { Name }
$$

(Character identifier)

Terrace

Name

(Character identifier)

Trench

Valley

Name

(Character identifier)

Wash

Name

(Character identifier)

Not applicable

Exposed at surface
A long and narrow upland with steep sides.

The line separating drainage basins.

Submerged below water surface

A concreted mass of stony material.

Sharp, irregular ridges formed on a snow surface by wind erosion and deposition. The ridges are parallel to the direction of the prevailing wind.

The place at which a stream disappears underground in a karst area.

The peak of a mount or ridge.

A step-like land surface between higher and lower ground.

A long cut in the surface created through excavation.

An elongated depression in the Earth's surface that generally sl ’pes from one end to the other.

The dry portion of a bed of a stream that contains water only during or after a local rainstorm or heavy snowmelt. 


\section{ALPHABETIC LIST OF DLG-E ATTRIBUTES AND ASSOCIATED ATTRIBUTE VALUES}

This section lists alphabetically all DLG-E attributes and all possible attribute values and identifies the features to which a value is associated. For example, the entry for the attribute "water characteristics" appears as follows:

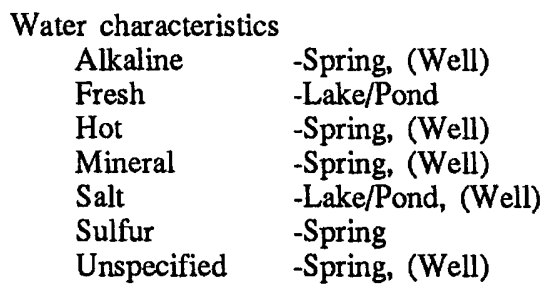

The attribute "water characteristics" will be found for the features Lake/Pond, Spring, and (Well). The feature "well" is in parentheses to indicate that the attribute "water characteristics" is an attribute of an attribute value included under the feature "well" (it is not directly an attribute of the feature itself).

The attribute values of "water characteristics" are different for each of the features listed above.

$\begin{array}{lll}\text { Feature: } & \text { Lake/Pond } \\ \text { Attribute: } & \text { Water characteristics } \\ \text { Values: } & \text { Fresh and Salt } \\ & \\ \text { Feature: } & \text { Spring } \\ \text { Attribute: } & \text { Water characteristics } \\ \text { Values: } & \text { Alkaline, Hot, Mineral, Sulfur, Unspecified } \\ & \text { (Well) } & \\ \text { Feature: } & \text { Product } & \\ \text { Attribute: } & \text { Water---.-->Attribute: Water characteristics } \\ \text { Value: } & \text { Value: } & \text { Alkaline } \\ & & \text { Hot } \\ & & \text { Mineral } \\ & & \text { Salt } \\ & & \text { Unspecified }\end{array}$

Access restrictions

$\begin{array}{ll}\text { None } & \text {-Road, Trail } \\ \text { Private } & \text {-(Gate), Road, Trail } \\ \text { Restricted } & \text {-Road, Trail } \\ \text { Toll } & \text {-(Gate), Road, } \\ \text { Not applicable } & \text {-(Gate) } \\ \text { Unknown } & \text {-Road, Trail }\end{array}$

Accounting unit code

(Integer value $(00 . . .99)$ ) -Hydrologic Unit

Not applicable

Aircraft facility type
Airport
-Aircraft facility
Heliport
Seaplane base

Anchorage type

Explosives isolation -Anchorage

General case

Seaplane

Angle of orientation
$0 . . .89$
$0 . .359$
-Building
Not applicable -Building 
Archeological site/Ruins type

Archeological site -Archeological site/Ruins

Pictograph

Ruins

Unspecified

Athletic field type

Archery range -Athletic field

Ball

Equestrian

Pistol range

Polo

Rifle range

Unspecified

Bar type

Offshore -Bar

Point

Basin type

Carolina bay -Basin

Crater

Unspecified

Boundary point identifier

(Alphanumeric identifier) -Boundary point

Not applicable

Unknown

Building class

Class 1

Class 2

Bureau of Land Management (BLM) identification number

(Alphanumeric value) -Survey comer

Building class

Class 1 -Building

Class 2

Cableway type

Logging -Cableway

Ski lift

Ski tow

Tramway

Unknown

Campsite type

Campground -Campground

Recreational vehicle

Unspecified

Canal/Ditch category

$$
\text { Canal -Canal/Ditch }
$$

Ditch

Unspecified

Cataloging unit code

(Integer value (00...99)) -Hydrologic unit

Not applicable

Census block group number

(Integer value - 1-9) -Census block group

Census block number

(Alphanumeric value) -Census block 
Census County Division (CCD)/

Minor Civil Division (MCD) number

(Integer value - 001-999) -CCD/MCD

Census tract/Block Numbering Area (BNA) number

(Numeric value - 0001.01-9989.99) -Census tract/BNA

Chimney type

Flare pipe -Chimney

Stack

Unknown

Contour symbolization category

Depression -Contour (land)

Mound -Contour (bathymetric)

Not applicable -Contour (bathymetric), Contour (land)

Covering

Covered -Bridge, Reservoir

Not covered

Cultivated cropland type

Nursery -Cultivated cropland

Orchard

Vineyard

Unspecified

Unknown

Delineation status

Amended -Contour (bathymetric), Contour (land)

Apparent -Shoreline

Definite -Boundary line, Contour (bathymetric), Contour (land), Shoreline, Stream/River

Disputed -Boundary line

Historical -Boundary line

Indefinite/

Approximate -Boundary line, Contour (bathymetric), Contour (land), Shoreline

Proposed -Boundary line

Protracted -Boundary line

Unsurveyed -Shoreline, Stream/River

Unknown -Boundary line

Depth

(Positive numeric value) -Contour (bathymetric)

Discarded substance

Dredged material -Disposal site

Garbage

Slag pile

Tailings

Waste rock

Unspecified

Unknown

District number

(Integer value - 001...999) -Georgia Survey District

Earth composition
Gravel
-Barren land
Rock
Salt
Sand
Shell
Silt
Unspecified 
Elevation

(Numeric value -nearest 0.001 meter)

(Numeric value -nearest 0.1 meter)

Unspecified

Unknown

Embankment type

Levee -Embankment

Redoubt

FIPS code identifier-1st

(Integer value - 01...99) -State/Territory

FIPS code identifier-2nd

(Integer value - 001...999) -County

FIPS code identifier-3rd

(Integer value - 0001...9999) -Minor Civil Unit

Not applicable

Field identification

Identified

Not identified

Unknown

Flat type

Playa

Tidal

Flotation

Floating -Drydock

Not floating

Directional status

Alternating

Bidirectional

One way

Unspecified

Unknown

Gage type

Tidal

Unspecified

Gate type

Check

Flood

Head

Road

Sluice

Tidal

Unspecified

Hazard zone type

Crib

Foul ground

Mine danger area

Piling

Platform

Reef

Rock

Snag/Stump

Unknown

\section{-Survey corner}

-Flat

-Road, Trail

-Road, Trail Trail Trail Trail

-Gaging station
-Control station

-Area to be submerged, Contour (land), Lake/Pond, Reservcir, Spillway, Spot elevation, Stream/River

-Area to be submerged, Control station, Lake/Pond, Reservcir, Spillway, Stream/River

-Area to be submerged, Lake/Pond, Reservoir, Stream/River

-Aqueduct, Canal/Ditch, Fish ladder, Flume, Penstock, Rapids, Road, Siphon, St $\div a m / R i v e r$,

-Aqueduct, Canal/Ditch, Fish ladder, Flume, Penstock, Rapids, Road, Siphon, St־am/River

-Aqueduct, Canal/Ditch, Fish ladder, Flume, Penstock, Rapids, Road, Siphon, Stream/River, 
Hazard zone type (continued)

Unspecified

Well

Wreckage

Height above surface level (meters)

(Numeric value) -Tower

Unspecified

Unknown

Historical significance

Not significant -Trail

Significant

Unknown

Holding pen type

Corral

Feedlot

-Holding pen

Stockyard

Horizontal control accuracy

1st order -Control station

2nd order

3 rd order

3rd order or better

Not applicable

Hydrographic category
Dry
-(Well)
Intermittent -Canal/Ditch, Lake/Pond, Reservoir, Stream/River
Perennial -Canal/Ditch, Lake/Pond, Stream/River, (Well)
Not applicable -Reservoir, (Well)
Unknown -Canal/Ditch, Lake/Pond, Reservoir, Stream/River

Hydrographic form
Braided
-Stream/River

Not braided

Ice mass type
Alpine glacier
-Ice mass
Continental glacier
Pack ice
Snowfield
Ammunition -Industrial site
Cannery
Cement
Filtration
Refinery
Sawmill
Sewage disposal
Unspecified

Industrial plant type

Institutional function

Civil government -Institutional site

Correctional

Education/Research

Historical

Medical

Military

Orphanage

Religious

Unspecified

Unknown 
Interchange designator

(Alphanumeric identifier) -Interchange

Not applicable

Unknown

Inundation control

Controlled -Inundation area

Not controlled

Land grant code

(Integer value - 0001...7302) -Land grant

Unknown

Lane type

Airboat trail

Dredged channel

Ferry crossing

Seaplane landing/takeoff

Shipping

Lot number

(Integer value - 0001-9999) -Georgia Survey District

Material composition

Earthen

-Dam/Weir

Masonry

Unspecified

Median category

With median

Without median

$-\operatorname{Road}$

Metropolitan Statistical Area FIPS code

(Integer value - 01-9999) -Metropolitan Statistical Area (MSA)

Metropolitan Statistical Area (MSA) type

Part MSA (PMSA) -Metropolitan Statistical Area (MSA)

Consolidated MSA (CMSA)

General case

Mile marker type

Railway

Watercourse

-Mile marker

Mileage number

(Numeric value) -Mile marker

Mine entrance type

Adit

-Mine entrance

Shaft

Mine type

Auger borings -Mine

Open pit

Pit

Placer

Quarry

Strip

Monument number

(Integer value) -Survey point

Not applicable

Monument type

No tablet

-Control station

Tablet 
Mount Type

General case -Mount

Hummocked ice

Ice dome

Indian mound

Pingo

Name

(Character

identifier)

Not applicable

Unknown

-Aircraft facility, Anchorage, Aqueduct, Arch, Archeological site/Ruins, Area to be submerged, Athletic field, Bar, Baseline, Basin, Bay/Estuary/Inlet, Beach, Beacon, Bend, Boardwalk, Boundary line, Breakwater/Jetty, Bridge, Building, Cableway, Campground, Canal/Ditch, Cape, Cave, Cave entrance, Cemetery, City, Cliff, Cliff dwelling, Control station, County, Cul de sac, Dam site, Dam/Weir, Desert, Dunes, Exhibition ground, Fault, Fish hatchery, Flat, Ford, Fumarole, Gap, Geyser, Gut, Helipad, Historical marker, Hydrologic unit, Ice mass, Incline/Flow, Industrial site, Institutional site, Interchange, Island, Isthmus, Lake/Pond, Land grant, Lane, Launch facility, Laun:h pad, Locale, Lock, Marina, Mine, Mine entrance, Minor Civil Unit, Minor Civil Subunit, Moraine. Mount, Nation, Outdoor theater, Park, Pier/Wharf, Pinnacle, Pipeline, Pipeline regulation station, Plain, Power site, Prospect, Proving ground, Racetrack, Railway yard, Range, Rapids, Reef, Reservation, Reservoir, Rest site, Ridge, Ridge line, Road, Sea/Ocean, Shopping center, Sink, Spo-ts site, Spring, State/Territory, Storage site, Stream/River, Submerged stream, Substation, Summit, Survey corner, Tank, Tank farm, Terrace, Tower, Trail, Trailer park, Tree, Tunnel, Valley, Wash, Waterfall, Well, Well field, Wetland, Windmill, Wreck

Navigation type

Aeronautical -Beacon

Nautical

Unspecified

Unknown

Number of decks

(Integer value) -Bridge

Not applicable

Unspecified

Unknown

Number of lanes or tracks

(Integer value) -Railway, Road

Unspecified

Unknown

Operational status

Abandoned

Dismantled

Drill hole

Operational

-Aircraft facility, Aqueduct, Beacon, Bridge, Building, Cableway, Canal/Ditch, Dam site, Disposal site, Flume, Helipad, Industrial site, Launch facility, Launch pad, Mine, Mine entrance, Penstock, Pipeline, Pipeline regulation station, Power site, Railway, Railway yard. Reservoir, Road, Runway, Siphon, Substation, Tower, Tumtable, Well, Well field -Bridge, Cableway, Railway, Turntable

-Well

-Aircraft facility, Aqueduct, Beacon, Breakwater/Jetty, Bridge, Building, Cableway, Canal/Ditch, Dam site, Dam/Weir, Disposal site, Flume, Helipad, Industrial site, Launch facility, Launch pad, Mine, Mine entrance, Penstock, Pier/Wharf, Pipeline, Pipeline regulation station, Power site, Railway, Railway yard, Reservoir, Road, Runway, Siphon, Substation, Tower, Transmission line, Tunnel, Turntable, Well, Well field

Proposed

Reclaimed

Ruined -Bridge, Canal/Ditch, Dam/Weir, Pipeline, Road, Tunnel, Turntable

-Mine

Under construction

-Breakwater/Jetty, Building, Pier/Wharf

-Aircraft facility, Aqueduct, Bridge, Canal/Ditch, Dam site, Dam/Weir, Disposal site, Flume. Helipad, Industrial site, Launch facility, Launch pad, Penstock, Pipeline, Pipeline regulatior station, Power site, Railway, Railway yard, Reservoir, Road, Runway, Siphon, Substation, Transmission line, Tunnel, Turntable

Unknown -Aircraft facility, Aqueduct, Beacon, Breakwater/Jetty, Bridge, Building, Cableway, Canal/Ditch, Dam site, Dam/Weir, Disposal site, Flume, Helipad, Industrial site, Launch facility, Launch pad, Mine, Mine entrance, Penstock, Pier/Wharf, Pipeline, Pipeline regulation station, Power site, Railway, Railway yard, Reservoir, Road, Runway, Siphon, Substation, Transmission line, Tower, Tunnel, Turntable, Well, Well field

Origin of survey name

(Character identifier)

-Public survey area 
Origin of survey number

(Integer value - 01...48) - Public survey area

Outdoor theater type

Amphitheater -Outdoor theater

Aqua

Drive-in

Ownership

National -Land parcel

State

Park type

Amusement -Park

Botanical

Parade ground

Picnic area

Playground

Zoo

Unspecified

Pipeline regulation station type

Compressor -Pipeline regulation station

Pumping

Valve

Post type

Dolphin -Post

Piling

Power generation method
Nuclear
-Power site
Solar
Unspecified
Unknown

Product

Bentonite -Mine

Brick -Kiln

Caliche -Mine

Charcoal -Kiln

Chemical -(Tank)

Chert -Mine

Cinders -Mine

Clay -Mine

Coal -Flume, Mine, Pipeline

Coke -Kiln

Copper -Mine

Fuel -(Tank)

Gas -Drilling platform, (Tank), Tank farm, Well, Well field

Gasoline -(Tank)

Gold -Mine

Grain -(Tank)

Gravel -Mine

Heat -Well

Logs -Flume

Molasses -(Tank)

Oil -Drilling platform, Flume, (Tank), Tank farm, Well, Well field

Oxygen - (Tank)

Pumice -Mine

Salt -Mine, (Reservoir)

Sand -Mine

Scoria -Mine

Sewage -Pipeline

Shale -Mine

Silver -Mine

Soda -(Reservoir)

Soil -Mine 
Product (continued)

Uranium

Water

-Mine

Unspecified

-Flume, Pipeline, Reservoir, (Tank), Well

Unknown

-Flume, Mine, Pipeline, (Tank), Tank farm, Well, Well Field

-Drilling platform, Flume, Kiln, Mine, Pipeline, (Reservoir), (Tank), Well, Well field

Public survey area type

General case

-Public survey area

Donation land claim

Railway category

General case

-Railway

Inclined railway

Logging

Rapid transit

Unknown

Railway gauge

Narrow -Railway

Standard

Monorail

Unknown

Railway type

Mainline -Railway

Siding

Ramp type

Boat -Launching ramp

Seaplane

Range number

(Numeric value with 1 alpha character (E/W)) -Public service area

Region unit code

(Integer value (01...21)) -Hydrologic unit

Relationship to surface

Awash

Elevated above surface

Exposed at surface

Submerged below water surface

Under ground surface

-Rock

-Control station, Pipeline, Spot elevation, Transmission line

-Control station, Drilling platform, Pier/Wharf, Rock, Snag/Stump, Spot elevation,

Water intake/outflow, Wreck

-Drilling platform, Pier/Wharf, Pipeline, Rock, Snag/Stump, Transmission lire,

Water intake/outflow, Wreck

-Pipeline, Transmission line

Reservation class

Forest

-Reservation

General case

Grassland

Indian land

Military

Park

Prison

Wilderness

Wildlife

Unknown

Reservation use status

National -Reservation
State
Regional
County
Minor Civil Unit
City
Private
Unknown



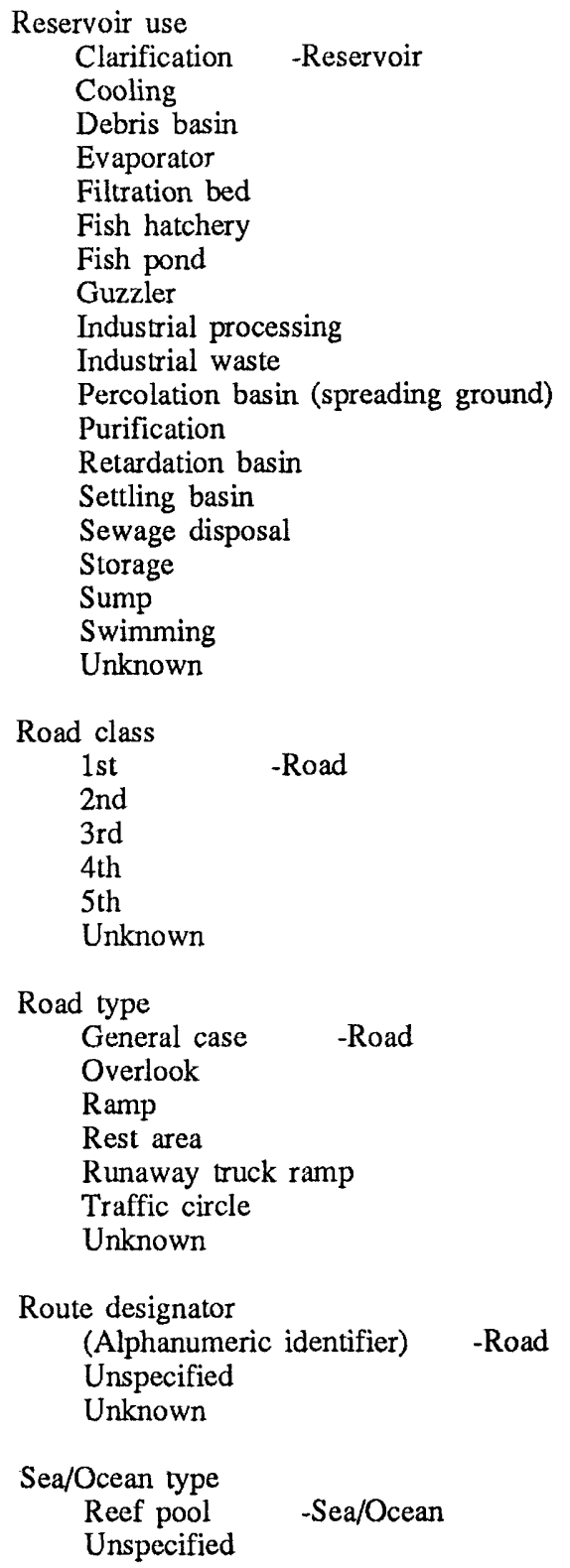

Section number

(Alphanumeric value) -Public survey area

Signaling method

Daybeacon -Beacon
Lighted
Radio
Unspecified
Unknown

Special use activity

Dumping ground for hazardous material -Special use zone Spoil area

Spillway elevation

(Numeric value) -Dam/Weir

Not applicable 
Sports site type

Golf course -Sports site

Gun club

Raceway

Rodeo grounds

Ski area

Stadium

Tennis court

Stability

Stable -Dune

Shifting

Subregion unit code

(Integer value (01-99)) -Hydrologic unit

Not applicable

Surface condition

Hard/Paved

Not paved

-Heliped, Runway

Unknown

Survey corner type
Arbitrary
Auxiliary meander
Closing
Isolated
Land grant
Meander
Quarter section
Section
Tract
Witness off line
Witness on line

Survey point type

Angle point

Land grant monument

-Survey point

Location monument (includes mineral monument)

Reference monument

Witness point

Tank type

Cistern -Tank

General case

Silo

Storage bin

Surge

Tower function

Control

-Tower

Cooling

Electronic

Observation

Mooring

Pylon

Support

Water

Unspecified

Unknown

Township number

(Numeric value with 1 alpha character (N/S)) - Public survey area

Track condition/Use

Hard/Paved-Vehicle

Improved/Loose-Vehicle/Animal

Improved-Pedestrian 
Track condition $\backslash$ Use (continued)

Improved/Rough-Vehicle

Unknown

Traffic inspection facility type

Agricultural - Traffic inspection facility

Customs

Weigh

Trail type

Bicycle -Trail

Bridle

Marked

Pack

Pedestrian

Portage

Ski

Snowmobile

Winter

Not applicable

Unknown

Transmission use

Power

-Transmission line

Telegraph

Telephone

Unknown

Tree category

Deciduous -Trees

Evergreen

Vegetation characteristics

Mangrove

-Trees

Unspecified

Vegetation type

Cranberry

-Cultivated cropland

Rice

Unspecified

Unknown

Vertical control accuracy

1 st order

2nd order

3 rd order

3 rd order or better

Not applicable

Wall type

General case -Wall

Sea

Water characteristics

Alkaline

Fresh

-Spring, (Well)

Hot

Mineral

Salt

Sulfur

-Control station

$\begin{array}{ll}\text { Sulfur } & \text {-Spring } \\ \text { Unspecified } & \text {-Spring, (Well) }\end{array}$

Water intake/outflow type

Riser

-Water intake/outflow

General case 
Width (meters)

(Integer value) -Road

Unspecified

Windmill function

Pump

-Windmill

Generator 


\section{ALPHABETIC LIST OF DLG-E ATTRIBUTES OF ATTRIBUTE VALUES}

Attribute: Access restrictions

$$
\begin{aligned}
& \text { Private } \\
& \text { Toll } \\
& \text { Not applicable }
\end{aligned}
$$

Attribute: Bathymetric datum

Gulf Coast low water Lowest low water Mean low lake level Mean low water Mean lower low water Mean sea level Tropic lower low water Water surface as indicated Unknown

Attribute: Call letters
(Alpha identifier
3-4 characters)
Not applicable

Attribute: Continental glaciation type

Inland ice sheet

Ice shelf

Attribute: Control class

Class I

Class II

Attribute: Crater type

Bomb

Meteoric

Volcanic

Attribute: Electronic signal
Microwave
Radar
Radio
Television
Unspecified
Unknown

Attribute: Exposed portion

Mast and/or Funnel Hull and/or Super-

$$
\text { Structure }
$$

Attribute: Flow characteristics

Flowing

Not flowing of Feature: Gate

Attribute: Gate type

Value: Road

of Feature: Contour (bathymetric)

Attribute: Depth

Value: Positive numeric value) of Feature: Tower

Attribute: Electronic signal

Value: Radio

Television

Unspecified

Unknown

of Feature: Ice mass

Attribute: Ice mass type

Value: Continental glacier

of Feature: Control station

Attribute: Horizontal control accuracy

Value: $\quad$ 2nd order

3rd order

of Feature: Control station

Attribute: Vertical control accuracy

Value: 1 st order

2nd order

of Feature: Basin

Attribute: Basin type

Value: Crater

of Feature: Tower

Attribute: Tower function

Value: Electronic

of Feature: Wreck

Attribute: Relationship to surface

Value: $\quad$ Exposed at surface

of Feature: Well

Attribute: Product

Value: Water 
Attribute: Hydrographic category

$\begin{array}{ll}\text { of Feature: } & \text { Well } \\ \text { Attribute: } & \text { Product } \\ \text { Value: } & \text { Water }\end{array}$

Dry

Perennial

Water

Not applicable

Attribute: Inclined railway type

Cable

Cog

Unspecified

Attribute: Inundation area use

Dewatering area

Duck pond

Attribute: Lighthouse presence

With lighthouse

Without lighthouse

of Feature: Railway

Attribute: Railway category

Value: Inclined railway

of Feature: Inundation area

Attribute: Inundation control

Value: Controlled

of Feature: Beacon

Attribute: Signaling method

Value: Lighted

Attribute: Liquid contained

Oil

Water

of Feature: Reservoir

Attribute: Reservoir use

Value: Storage

of Feature: Reservoir

Attribute: Reservoir

Value: Sump

Atribute: Observation type

of Feature: Tower

Attribute: Tower function

Guard

Value:

Observation

Lookout

Attribute: Owning agency

Agricultural Research Service

of Feature: Land parcel

Attribute: Ownership

Air Force

Value: National

Army

Army (Corps of Engineers - Civil Works)

Bonneville Power Administration

Bureau of Indian Affairs

Bureau of Land Management

Bureau of Mines

Bureau of Prisons

Bureau of Reclamation

Energy Research and Development Administration

Federal Aviation Administration

Federal Railroad Administration

Fish and Wildlife Service

Forest Service

General Services Administration

International Boundary and Water Commission,

United States and Mexico

National Aeronautics and Space Administration

National Oceanic and Atmospheric Administration

National Park Service

Navy

Tennessee Valley Authority

U.S. Coast Guard

Veterans' Administration

Attribute: Product

Salt

of Feature: Reservoir

Attribute: Reservoir use

Soda

Value: Evaporator

Unknown 


\section{Product \\ Chemical \\ Fuel \\ Gas \\ Gasoline \\ Molasses \\ Oil \\ Oxygen \\ Water \\ Unspecified}

Product

Grain

Unspecified

Unknown

Product

Grain

Unspecified

Unknown

Attribute: Rock type

\section{Coral}

Lava

Unspecified

Unknown

Attribute: Route type
Altemate
Business
Bypass
Connector
Loop
Spur
Truck
Unspecified

Attribute: Support type

Water intake tower

Attribute: Stage

Average water elevation

High water elevation

Normal pool elevation

Attribute: Text

(Character

Not applicable

(Character

identifier)

Not applicable

(Character identifier)

Not applicable of Feature: Tank

Attribute: Tank type

Value: General case

of Feature: Tank

Attribute: Tank type

Value: Silo

of Feature: Tank

Attribute: Tank type

Value: Storage bin

of Feature: Barren land

Attribute: Earth composition

Value: Rock

of Feature: Road

Attribute: Route designator

Value: (Alphanumeric identifier) of Feature: Tower

Attribute: Tower function

Value: Support

of Feature: Lake/Pond

Attribute: Elevation

Value: (Numeric value)

of Feature: Beacon

Attribute: Navigation type

Value: All entries

of Feature: Boundary line

Attribute: Delineation status

Value: Proposed

Protracted

of Feature: Building

Attribute: Building class

Value: Class 1

Class 2 
Attribute: Text (continued)

(Character
identifier)
Not applicable

(Character
identifier)
Not applicable
(Character
identifier)
Not applicable
(Character
identifier)
Not applicable
(Character
identifier)
Not applicable
(Character
identifier)
Not applicable
(Character
identifier)
Not applicable

Attribute: Vertical datum category

Guam Mean Sea Level Datum of 1963

Mean sea level (local)

National Geodetic Vertical Datum of 1929

North American Vertical Datum of 1988

\author{
of Feature: Contour (bathymetric) \\ Attribute: Bathymetric datum \\ Value: Water surface as \\ indicated \\ of Feature: Gate \\ Attribute: Gate type \\ Value: All entries \\ of Feature: Institutional site \\ Attribute: Institutional function \\ Value: All entries \\ of Feature: $\quad$ Reservation \\ Attribute: Reservation class \\ Value: All entries \\ of Feature: Sports site \\ Attribute: Sports site type \\ Value: All entries \\ of Feature: Tower \\ Attribute: Tower type \\ Value: All entries \\ of Feature: Water intake/outflow \\ Attribute: Water intake/outflow type \\ Value: $\quad$ Riser
}

of Feature: Dam/Weir

Attribute: Spillway elevation

Value: (Numeric value)

of Feature: Reservoir

Attribute: Elevation

Value: (Numeric value)

\begin{tabular}{|c|c|}
\hline $\begin{array}{l}\text { of Feature: } \\
\text { Attribute: } \\
\text { Value: }\end{array}$ & $\begin{array}{l}\text { Spillway } \\
\text { Elevation } \\
\text { (Numeric value) }\end{array}$ \\
\hline $\begin{array}{l}\text { of Feature: } \\
\text { Attribute: } \\
\text { Value: }\end{array}$ & $\begin{array}{l}\text { Area to be submerged } \\
\text { Elevation } \\
\text { (Numeric value) }\end{array}$ \\
\hline $\begin{array}{l}\text { of Feature: } \\
\text { Attribute: } \\
\text { Value: }\end{array}$ & $\begin{array}{l}\text { Lake/Pond } \\
\text { Elevation } \\
\text { Numeric value) }\end{array}$ \\
\hline $\begin{array}{l}\text { of Feature: } \\
\text { Attribute: } \\
\text { Value: }\end{array}$ & $\begin{array}{l}\text { Stream/River } \\
\text { Elevation } \\
\text { (Numeric value) }\end{array}$ \\
\hline $\begin{array}{l}\text { of Feature: } \\
\text { Attribute: } \\
\text { Value: }\end{array}$ & $\begin{array}{l}\text { Contour (land) } \\
\text { Elevation } \\
\text { (Numeric value) }\end{array}$ \\
\hline $\begin{array}{l}\text { of Feature: } \\
\text { Attribute: } \\
\text { Value: }\end{array}$ & $\begin{array}{l}\text { Control station } \\
\text { Elevation } \\
\text { (Numeric value) }\end{array}$ \\
\hline $\begin{array}{l}\text { of Feature: } \\
\text { Attribute: } \\
\text { Value: }\end{array}$ & $\begin{array}{l}\text { Spot elevation } \\
\text { Elevation } \\
\text { (Numeric value) }\end{array}$ \\
\hline
\end{tabular}


Attribute: Water characteristics

Alkaline

Hot

Mineral

Salt

Unspecified of Feature: Well

Attribute: Product

Value: 


\section{APPENDIX B \\ DLG-E EXAMPLE DATA SET}

\section{Section}

1. DLG-E example data set B-1

2. Source materials B-2

3. DLG-E feature data specifications B-4

4. Instance count summary B-19

5. Graph plots B-20

6. DLG-O+ relational tables for use with DLG-E data B-22

7. Case examples B-32 



\title{
APPENDIX B
}

\section{DLG-E EXAMPLE DATA SET}

\author{
OVERVIEW
}

To apply the concepts discussed in the body of this report, a contrived comprehensive example DLG-E data set was developed. This example is intended to show the relationships between original source materials (used to construct the DLG-E data) and the feature/attribute definitions, delineation rules, data extraction specifications, and data representation rules. The example also illustrates how these specifications would contribute to the definition and building of a DLG-1: data set. It is critical to note that a DLG-E data set, even a contrived one, cannot be built without these supporting specifications. The example is designed to show not only possible data content and structure for DLG-E data, but also the content and structure of the supporting specification documents.

The example strives to be highly deterministic by specifying how the various preliminary rule sets are to be applied. The intent in any data exchange scheme is to communicate an understanding of the phenomena being represented. In the DLG-E case, this requires that the data user understand the feature definitions, extraction specifications, meanings of attributes, attribute values, digital object representations and their relationship to features, and so forth, used by the National Mapping Division. The ultimate goal is to have these specifications defined so precisely, that, given the same original source materials, two trained individuals could produce identical digital representations of a given phenomena by strictly adhering to all the definitions and rules. It is realized that this degree of precision may not be attainable, but nonetheless that should not deter the attempt to strive for this level.

The procedures used to develop the example DLG-E data set were as follows:

1. Building on the feature definitions and attribute lists in appendix A and the general representation rules in chapter 4, candidate "DLG-E feature data specifications" (including delineation, data extraction, and representation rules) were. developed for 24 selected DLG-E features in the example data set. It is important to note here that the rules developed in this step should be considered very preliminary; meant for illustration and experimentation purposes only. Actual DLG-E feature data specifications are currently being developed.

2. A contrived graphic map and field notes were generated to illustrate possible source materials. It was decided to develop contrived materials (instead of using an actual real-world example) in order to include as many of the selected features and special cases as possible.

3. Using the feature definitions in appendix A (plus four additional feature constructs developed for modeling purposes) and the specifications developed in step 1, the ground phenomena described in the source materials were categorizid as DLG-E feature instances. Specifically, a total of 67 feature instances of 24 DLG-E features were found.

4. Using the representation rules from step 1, a planar graph, representative of the DLG-E feature instances found in step 3, was abstracted from the graphic map. This linear graph was digitized as a set of topologically integrated nodes, points, chains, and polygons (the DLG-E spatial objects).

5. Each feature instance was encoded as a feature object, attributed, and related to other feature objects (if appropriat?) and to the digitized spatial objects by building a set of relational tables.

\section{THE DLG-O+ IMPLEMENTATION}

The DLG-E example has been implemented using a specific data and file structure. It is important to remember that the same data and data model may be implemented using different structures within other environments. In fact, the plannad distribution format for DLG-E data will be an implementation of the Spatial Data Transfer Specification (see appendix C), not what has been used for this example. The data structure is used here for illustration and experimentation purposes only. It includes the familiar DLG-3 structure (see USGS Data Users Guide 2, pages 2-3) for the implementation of the DLG-E spatial objects, attributes (location) and topological relationships. DLG-3 nodes, lines, and areas ar: used to represent DLG-E nodes, chains, and polygons, respectively. (Note: a DLG-E point is implemented as a DLG-3 "degenerate" line with node.) Feature objects, attributes, attribute values, and relationships are implemented as a set of relational tables.

DLG-O+ is the file structure chosen for the DLG-E example. DLG-O+ consists of two parts: the "DLG-O" part and the "+" part. The DLG-O part is simply a Digital Line Graph in Optional distribution format that holds the spatial object as "topological elements." Neither attribute codes nor text are associated with the topological elements--just coordinate data and topological relationships. The specifications for the "DLG-O" part are well documented in the current Standerds for Digital Line Graphs (see USGS Data Users Guide 2, appendix B), and need not be repeated here. 
The " + " part of DLG-O+ consists of "flat files" associated with a DLG-O file. In the case of our example, the " + " part is a set of eight relational tables, each table implemented as a single flat file. These tables serve to hold data representing the feature objects, nonspatial attribute values, and feature-to-feature and feature-to-spatial object relations of the DLG-E. The following named tables have been specified for use with DLG-E data:

1. Feature Object table provides a summary of the information carried in the other tables. There is one record in this table for each feature object.

2. Entity Label table serves to store the actual entity labels (i.e., DLG-E feature terms) associated with feature objects. There is one record in this table for each unique entity label assigned to one or more feature objects.

3. Attribute Definition table provides the means for interpreting attribute values in the Attribute Value table, and text in the Name/Text table. There is one record in this table for each unique attribute term in the data set.

4. Relationship Definition table provides information for interpreting Relationship Tuple records. There is one record in this table for each unique type of relationship in the data set (for DLG-E data, these relationships are listed in table 4, page 5 of this circular).

5. Attribute Value table serves to store the actual attribute values of attributes associated with (1) feature objects, (2) other attribute values, or (3) relationships.

6. Name/Text table serves to store names and text strings associated with (1) feature objects, (2) attribute values, or (3) relationships.

7. Attribute Assignment table provides the means by which (1) attribute values, and (2) names/text, are assigned to (a) feature objects. (b) relationships (as instanced in the Relationship Tuple records), (c) attribute assignments (as instanced in the records of this table), (d) other attribute values, and (e) other feature names/text. Also, this table can associate entity labels with feature objects.

8. Relationship Tuple table is an object linkage table. Feature and topological objects are related to feature objects through named relationships (defined in the Relationship Definition table).

These tables will be described in more detail in Section 6.

\section{SOURCE MATERIALS}

Source materials are the actual materials used for compilation of the DLG-E data set. All information in th: DLG-E must be traceable to the set of source materials. Sources may consist of graphic maps, imagery, field notes, or any other ancillary information containing name, boundary, or other information. For the example, a contrived graphic map and field classification notes were used.

\section{Contrived Field Classification Notes}

- Entire extent of U.S. 63 on map is Alternate U.S. 63 and also is named Bishop Avenue (from Highway Department).

- The four-lane portion of Alternate U.S. 63 is also known as Memorial Drive (from local residents and 1'"sinessmen).

- The entire extent of the map is in Township 6 South (from Bureau of Land Management).

- The spillway elevation for the dam on East Fork Lake is 974 feet (from County Engineer).

- The trail connecting the large part of Lane Spring State Park with the smaller south portion of the park is also part of the park (from Park Administrative Office). 
Contrived Source Map Graphic

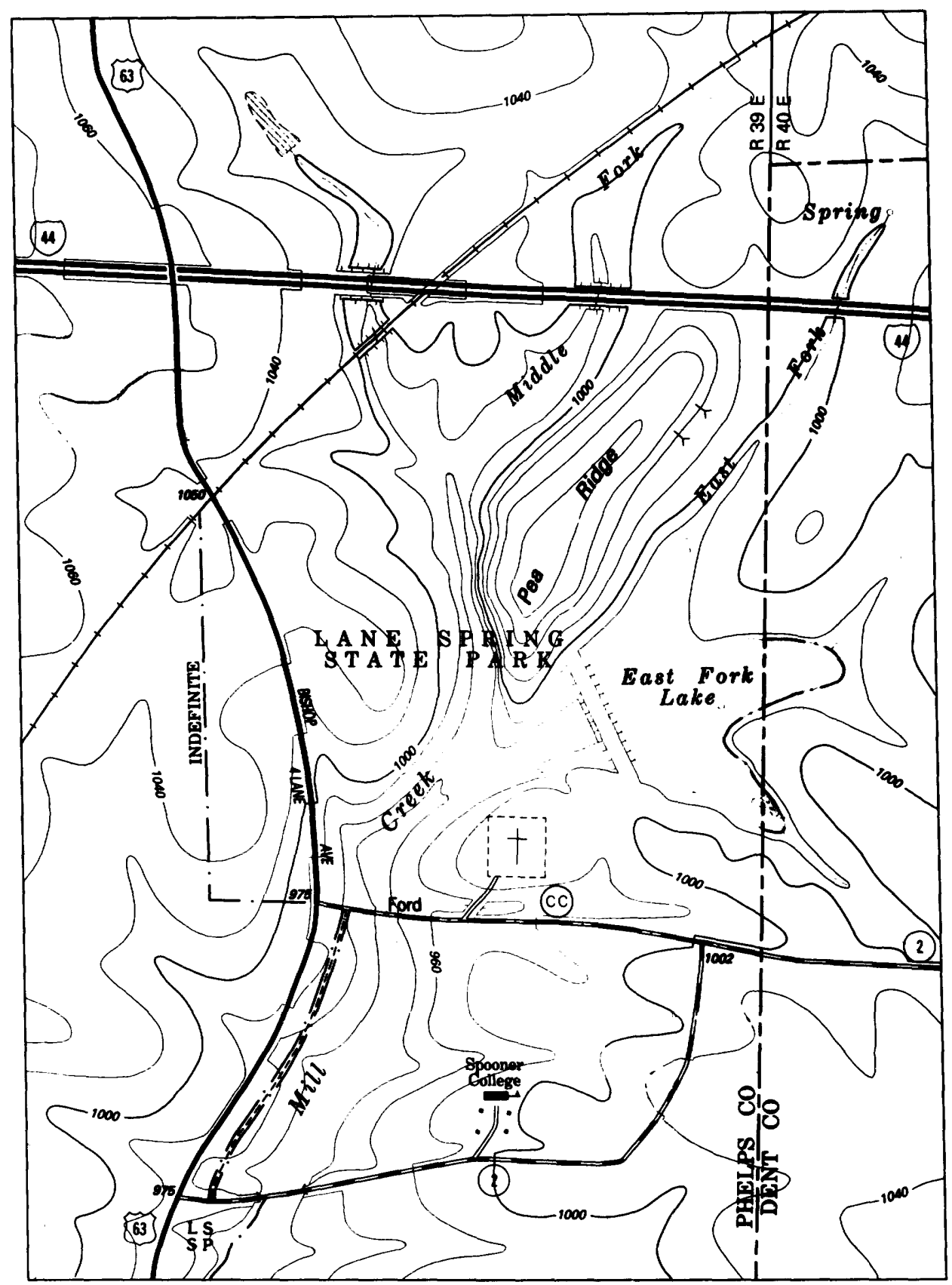




\section{DLG-E FEATURE DATA SPECIFICATIONS}

The feature data specifications define the domain of features that may be represented in DLG-E data. An at'empt will be made to extract occurrences or "instances" of these features from the source material provided. For this reason, the portions of the DLG-E feature data specifications related to this task are referred to as data extraction specifisations. Features meeting the capture conditions defined in the data extraction specifications and discernible from the source will be present in the DLG-E. All remaining ground phenomena will not be represented.

For each feature in the DLG-E feature data specification, a domain of attributes is defined. Each attribute is assigned a value, taken from the domain of values specified by the attribute definition authority. All attributes and attribute values used in the example are taken from the DLG-E features list (appendix A).

Attributes are used to describe characteristics of features as well as attribute values. In addition, multivalued attributes are demonstrated. While the DLG-O+ relational table specifications allow for several rather abstract forms of attribution, such as attributing the assignment of an attribute or relationship, the example demonstrates only the more common applications of attributes.

This section presents a number of the DLG-E feature data specifications used to build the DLG-E example data set from the contrived source materials in the previous section. Each DLG-E feature data specification is presented using the following generic template:

\section{DLG-E FEATURE DATA SPECIFICATION}

FEATURE - definition as documented in DLG-E domain of features.

ATTRIBUTE/ATTRIBUTE VALUE LIST -

Attribute definitions of attributes and values

Value (those common to more than one feature are generic definitions)

DELINEATION - (ground truth) - what the feature looks like on the ground.

\section{DATA EXTRACTION -}

Capture Condition - criteria for determining when a feature is to be captured for inclusion in the dita base. This is independent of source.

Source Interpretation Guidelines - criteria for extracting ground truth, for those situations that are ambiguous, from various sources (image, field, graphic, DLG-3).

Valid Attributes - which attributes are valid for a given scale.

\section{REPRESENTATION RULES-}

Composition Rules - under these conditions, feature has these relationships (allowed relationships may not always occur).

If (feature) is (condition), (feature) is composed of/part of...., bounded by/bounds..... inflows to/outflows from...., connected to, and vertically related to....

Delimiting Rules - definition of feature instance based on global rules.

Special Conditions - specific definition rules which are peculiar to a specific feature.

Vector Model Consideration - TBR

On the next several pages, the very preliminary DLG-E feature specifications for the following DLG-E featres are presented: stream/river, spring, road, underpass, junction, shoreline, reservation, boundary line, and ridge. 
STREAM/RIVER - A body of flowing water.

ATTRIBUTE/ATTRIBUTE VALUE LIST -

Delineation status -

Apparent

Definite

Not applicable

Directional status -

Alternating

Bidirectional

Not applicable

One way

Unknown

Unspecified

Elevation -

(Numeric value)
The level of confidence with which a feature can be defined.

Conditions prevent the feature from being confidently defined because of obscuring vegetation or shadov's. Conditions permit the feature to be confidently defined.

The state of movement along the feature.

Movement occurs in both directions, however only one way at a time.

Movement occurs in both directions simultaneousl:.

Movement occurs in only one direction.

The vertical distance of a feature above a given datum. Increment: 0.1 feet

-->Vertical Datum Category The base elevation used as a reference from which to

Mean Sea Level (Local) reckon heights or depths.

The average height of the surface of the sea for $\& 11$ stages of the tide, usually determined by averagin? height readings observed hourly over a 19-year period.

National Geodetic Vertical Datum of 1929

A fixed reference adopted as a standard geodetic datum for heights, derived for land surveys from a geieral adjustment of first order land nets of both the United States and Canada.

North American Vertical Datum of 1988

As of 2/89 this proposed vertical datum has not been defined.

Normal Pool Elevation

The height of water surface above the vertical datum.

High water elevation

The normal stage of water that prevails for most of the year for a controlled body of water.

Unknown

A stage of water that prevails when the feature is at or near capacity.

Not applicable

Hydrographic category -

Intermittent

Perennial

Unknown

Hydrographic form -

Braided

Not braided

The portion of the year the feature contains water. Contains water for only part of the year, but mor? than just after rainstorms and at snowmelt (see feature WASH).

Contains water throughout the year, except for infrequent periods of severe drought.

The pattern of channels.

Feature has a stream course which is not filled at normal flow, and that subdivides into interlacing channels.

Feature has a stream course that is filled at normal flow and that does not subdivide into interlacing chanrels. 
Name -

(Character identifier)

Not applicable

Unknown

\section{DELINEATION -}

The proper name, specific term, or expressinn by which the feature is known.

The upper limit of a stream is determined to be the point at which the feature first becomis evident as a channel.

The limits of a perennial stream are determined to be the height on the banks when water is at average water elevation.

The limits of an intermittent stream are determined to be the height of the banks when w'ter is at high water.

The lower limit of areal streams entering into bays, estuaries, gulfs, oceans, or seas is defined at the place where the stream reaches a width of 1 nautical mile with no further constrictions, if the land and water do not otherwise make the division obvious.

DATA EXTRACTION at $1: 24,000$ scale -

Capture Condition -

All streams are captured to within $0.5^{\prime \prime}$ of saddles or divides.

Capture all tributaries with a length of 1.25 " or longer.

Capture additional tributaries less than 1.25" in length if needed for contour portrayal.

If overedge source is not available to make length determination, all streams intersecting cell boundaries will be captured, regardless of length.

Capture all streams that are connected to springs or ponds.

Capture only the above-ground portion of streams. See feature SINK for those streams which disappear in karst areas.

Capture a representative pattern for braided streams: always collect perennial streams, alv'ays collect double-line streams, always collect streams which form bounding limits.

\section{Source Interpretation Guidelines -}

All sources -

If a stream/river is controlled by locks, a normal pool elevation is required. Water surface elevations are given to the nearest whole foot. Artificial lakes formed by water impounded by a da $\eta$ are considered under the feature LAKE/POND.

Dry washes, arroyos, dry gulches, and ephemeral streams are considered under the feature WASH.

Image -

If image shows a lower than average water elevation, look for evidence of water marks, delineate at that level.

If image shows higher than average water elevation, the mean water level must be obtained from ancillary sources.

Graphic -

Approximate, indefinite, and unsurveyed streams/rivers have a delineation status of "appar nnt."

Braided stream - capture all channels.

DLG-3 -

Approximate, indefinite, and unsurveyed streams/rivers have a delineation status of "apparont."

Valid Attributes -

All attributes are valid. 
Composition Rules -

If stream is linear, stream is composed of sequenced, directed chain(s).

If stream is areal, stream is composed of area bounded by shoreline(s), with inflow to/outflow from junction, vertically related to other feature.

Delimiting Rules - delimit instance using rules for network links.

Special Conditions -

The stream representation will change from the linear representation to areal representation when the stream width becomes greater than 0.02".

To accommodate variations in stream width:

if stream (area) becomes

less than 0.02 " but greater than 0.01 " for greater than 2.64 ", represent feature as an area

less than 0.02 " but greater than 0.01 " for less than 2.64 ", represent feature as a line less than $0.01 "$ regardless of distance, represent as a line

if stream (line) becomes

greater than 0.02 " but less than 0.03 " for less than 2.64 ", represent as a line

greater than 0.02 " but less than 0.03 " for greater than $2.64 "$, represent as an area greater than 0.03 " regardless of distance, represent as an area.

Transitional tapering from linear representation to areal representation will take place over a distance of $0.15^{\prime \prime}$ prior to the 0.02 " width requirement, and vice versa. 
SPRING - A place where water issues from the ground naturally.

ATTRIBUTE/ATTRIBUTE VALUE LIST -

Angle of orientation -

The angular measurement of a feature, calculated from true north ( 0 degrees), clockwise to the mejor axis of the feature.

0 - 359 degrees

Increment: 1 degree

Name -

Not applicable

The proper name, specific term, or expressinn by which the feature is known.

(Character identifier)

Not applicable

Unknown

Water characteristics -

The distinctive properties of the water.

Alkaline
Hot
Sulfur
Unspecified

Water shows evidence of alkali salts.

Water temperature is higher than that of the human body (98 degrees).

Water shows evidence of enough hydrogen sulfide to smell and/or taste.

DELINEATION -

A spring is an area, bounded by the edges of the place where water issues from the ground.

DATA EXTRACTION at $1: 24,000$ scale -

Capture Condition -

All required

Source Interpretation Guidelines -

All sources -

The major axis for angle of orientation on isolated springs is along its downward slope.

Springs located within stream/river or lake/pond do not require angle of orientation.

DLG-3 -

If the DLG-3 descriptive code is 050.0615 (mineral or hot), the compiler must reference the source graphic to determine the attribute value.

Field -

Evidence of alkali salts is determined by observation of alkali residue around the spring.

Valid Attributes -

All attributes are valid.

REPRESENTATION RULES at 1:24,000 scale -

Composition Rules -

If spring is located within a stream, spring is composed of a node.

If spring is not located within a stream, spring is composed of a point.

Delimiting Rules -

Special Conditions . 
UNDERPASS - The occurrence of an intersection of two feature instances with a vertical relationship.

ATTRIBUTE/ATTRIBUTE VALUE LIST - None

DELINEATION - Not applicable

DATA EXTRACTION at 1:24,000 scale -

Capture Condition -

Use when features carrying traffic or having flow pass under other features and the relative vertical information cannot be determined by other information.

Source Interpretation Guidelines -

Not applicable

Valid Attributes -

Not applicable

\section{REPRESENTATION RULES at 1:24,000 scale -}

Composition Rules -

When the overpassing/underpassing features are both chains, and not coincident, underpass is composed of a node, vertically related to other features.

When the overpassing/underpassing features are both chains, and are coincident, underpass is comprosed of chains, vertically related to other features.

When one of the overpassing/underpassing features is a chain and the other is an area, underpass is composed of a chain, vertically related to other features.

When the overpassing/underpassing features are both areas, underpass is composed of an area, vertically related to other features.

\section{Delimiting Rules -}

Special Conditions -

Only two features may be vertically related with the feature "underpass." In the case of three or more features overpassing each other at the same spatial location, only vertically adjarent features shall be referenced in the "underpass" feature. Thus, a triple overpass shall gen rate two underpass instances - one for the top and middle features and another for the middle and bottom features. 
JUNCTION - The occurrence of an intersection of two areal features having flow.

ATTRIBUTE/ATTRIBUTE VALUE LIST - None

DELINEATION - Not applicable

DATA EXTRACTION at $1: 24,000$ scale -

Capture Condition -

Use when one areal network link with flow joins another or when an areal network link with flow intersects the cell boundary.

Source Interpretation Guidelines -

Not applicable

Valid Attributes -

Not applicable

REPRESENTATION RULES at 1:24,000 scale -

Composition Rules -

Junction is composed of chains, with inflow to/outflow from other areal features.

Delimiting Rules -

Special Conditions - 
SHORELINE - A naturally occurring line of contact between a body of water and land.

ATTRIBUTE/ATTRIBUTE VALUE LIST -

Delineation status -

Apparent

Definite
The level of confidence with which a feature can be defined.

Conditions prevent the feature from being confidently defined because of obscuring vegetation or shadows.

Conditions permit the feature to be confidently definet.

DELINEATION -

The definite shoreline is the line of contact between water and land. The apparent shoreline in tidal areas is the seaward edge of marine vegetation where that limit would reasonably appear as the shoreline to the mariner. The apparent shoreline for inland areas is the estimated line of contact between water and land.

DATA EXTRACTION at 1:24,000 Scale -

Capture Condition -

Capture all natural shorelines bounding other features that meet minimum capture conditions.

Source Interpretation Guidelines -

Image - The position of a shoreline is interpreted at a water level defined by the feature to be bounded.

Graphic - All shorelines are captured as shown on graphic. Shorelines shown as indefinite, approximate, or unsurveyed will be captured as with a delineation status of "apparent."

DLG-3 - The following attributes will convert to the DLG-E feature shoreline:

0500200 Shoreline - collect as definite shoreline

0500203 Indefinite Shoreline - collect as apparent shoreline

0500207 Apparent Shoreline - collect as apparent shoreline

0500201 Manmade Shoreline becomes a feature in DLG-E.

Valid Attributes -

All attributes are valid.

REPRESENTATION RULES at $1: 24,000$ scale -

Composition Rules - shoreline is composed of chain(s), bounds lake/pond, sea/ocean, stream/river, areas to be submerged, bay/estuary/inlet, inundation area.

Delimiting Rules - Delimit instances using the rules for network links. Special Conditions - 
RESERVATION - Bounded land set aside for a particular purpose, generally having certain use restrictions.

\section{ATTRIBUTE/ATTRIBUTE VALUE LIST -}

Name -

(Character identifier)

Not applicable

Unknown

Reservation class -

Forest

General case

Grassland

Indian land

Military

Park

Prison

Wilderness

Wildlife

Unknown

Reservation administrative status -

National

State

Regional

County

City

Unknown
The proper name, specific term, or expression by which the feature is known.

The primary use associated with the reservation.

Area primarily for the management of forest resources.

Area primarily for the management of native grasses. As defined by Bureau of Indian Affairs.

Area primarily for military activities and purooses.

Area primarily for preservation of a cultural or natural resource.

Area for housing persons convicted or accised of crimes.

Area virtually unsettled and uncultivated (ratural); includes areas designated by an administrative group as wilderness, primitive, wild and scenic, or similar designation.

Area primarily for wildlife management or preservation; includes the following areas: conservation, game, hunting/fishing, preserve, or other area wit' "wildlife" in name.

Managing authority.

Group of State, county, and/or city govern nents.

\section{DELINEATION -}

The reservation area is delineated by the boundary line that surrounds the reservation. Th ? area is usually defined by law, proclamation, or ownership.

DATA EXTRACTION at $1: 24,000$ scale -

Capture Condition -

Capture all reservations.

Nonproclaimed inholdings greater than $.05 "$ in the shortest dimension should be excluded from the reservation.

Source Interpretation Guidelines -

Graphic - capture limits (boundaries) of area as shown on graphic. Update as current dercription indicates.

DLG-3 - capture area attribute codes:

0900103 through 0111,0129 through 0134,0150 - compiler must reference the source graphic to determine appropriate reservation class.

0900420 (cemetery) with coincidence code 2090009 - this indicates National remetery. 
Field - contact administrative group and obtain legal description. When bounded by a road, determine whether the reservation extends to the center of the road or to the edge of the road. The description. should be used to verify other sources.

Valid Attributes -

all attributes are valid.

REPRESENTATION RULES at 1:24,000 scale -

Composition Rules -

Reservation is composed of area, bounded by boundary line.

Delimiting Rules -

Special Conditions - 
BOUNDARY LINE - A separation between divisions of current or past significance.

ATTRIBUTE/ATTRIBUTE VALUE LIST -

Delineation status -

Approximate/Indefinite

Definite

Disputed

Historical

Protracted

Name -

(Character identifier)

Not applicable

Unknown
The level of confidence with which a feature can be defined.

Conditions prevent the feature from being located to meet NMAS.

Conditions permit the feature to be confidertly defined. The location of State, county or national reservation boundary is in controversy because of conflinting or unclear legal definitions.

The location can be confidently defined but has lost its original significance.

Boundary line is extended from or fit between established surveyed points pending actual grount survey.

The proper name, specific term, or expressinn by which a particular geographic entity is known.

\section{DELINEATION -}

Boundary lines are delineated as defined by law or proclamation.

DATA EXTRACTION at 1:24,000 scale -

Capture Condition -

Capture all established civil boundaries.

Source Interpretation Guidelines -

Graphic -

Interpret as shown and adjust to legal description if required.

DLG-3 -

Capture following line attribute codes:

090.0201 becomes Indefinite/Approximate.

090.0202 becomes Disputed.

090.0203 becomes Historical.

If line in DLG-3 boundary category does not carry any of the above descriptive codes, atribute value becomes Definite.

300.0202 becomes Protracted.

300.0205 becomes Definite.

Field -

Obtain legal descriptions. Determine whether boundary lines are coincident with centerlines or edges of features, such as roads, railroads, and streams.

Valid Attributes -

All attributes are valid.

REPRESENTATION RULES at 1:24,000 scale -

Composition Rules -

Boundary line is composed of ordered chains, bounds other features.

Delimiting Rules -

Special Conditions - 
RIDGE - A long and narrow upland with steep sides.

ATTRIBUTE/ATTRIBUTE VALUE LIST -

Name -

(Character identifier)
The proper name, specific term, or expression by whith the feature is known.

DELINEATION -

The limits of the ridge are defined by the break in slope between the steep sides of the feature and the relatively flat terrain at the base of the feature.

DATA EXTRACTION at $1: 24,000$ scale -

Capture Condition -

All ridges and associated generics contained in the Geographic Names Information System Phase II listing are required.

Source Interpretation Guidelines -

Valid Attributes -

All attributes are valid.

REPRESENTATION RULES at 1:24,000 scale -

Composition Rules -

A ridge is composed of an area.

Delimiting Rules -

Special Conditions - 
ROAD - An open way for the passage of vehicles.

\section{ATTRIBUTE/ATTRIBUTE VALUE LIST -}

Access restrictions -

Private

Restricted

Toll

Unknown

Unspecified

Directional status -

Alternating

Bidirectional

Not applicable

One way

Unknown

Unspecified

Median category -

With median

Without median

Name -

(Character identifier)

Not applicable

Unknown

Number of lanes or tracks -

(Integer value)

Unspecified

Unknown

Operational status -

Abandoned

Operational

Proposed

Under construction

Unknown

Road class -

1 st

2nd

3rd
The constraints on use.

Maintained by private funds and not open to the public.

Designated for official use only.

Controlled by payment of fee for travel.

The state of movement along the feature.

Movement occurs in both directions, however only one way at a time.

Movement occurs in both directions simultareously.

Movement occurs in only one direction.

The existence of a median.

Curbs or median strips separate opposing traffic lanes.

Traffic lanes are not separated by curbs or redian strips.

The proper name, specific term, or expressicn by which the feature is known.

The state or condition.

Intact but not maintained or intended for use.

Usable and intended for use.

Planned in detail, but construction not starte-1.

Construction started, but not complete.

The classification of roads based on design, weatherability, governmental designation, and the Department of Transportation functional classification system.

Hard-surface highways including interstate and U.S. numbered highways (including alternates, primary State routes, and all controlled access highways).

Hard-surface highways including secondary State routes, primary county routes, and other highways that connect principal cities and towns, and link these places with the primary highway system.

Hard-surface highways not included in a hicher class and improved, loose-surface roads passable in all kinds of weather. These roads are adjuncts to the primary and secondary highway systems. Also inclyded are important private roads such as main loggins or industrial roads which serve as connecting links to the regular road network. 
Improved, loose-surface roads passable only in fair weather.

5th

\section{Unknown}

Road type -

General case

Overlook

Ramp

Rest area

Runaway truck ramp

Traffic circle

Unknown

Route designator -

(Alphanumeric identifier)

$\rightarrow$ Route type
Alternate
Business
Bypass
Connector
Loop
Spur
Truck
Unspecified

Unspecified

Unknown

Width -

(Integer value)

Unspecified

Unknown
Unimproved roads passable only with four-wheel-drivo vehicles. Included are one-lane roads on levees, and maintenance roads along transmission and other simi 1 ir features.

The purpose or function.

Common use.

A pull-off area designated as scenic, having definite entrance and exit points that are separated from the roadway.

An inclined road connecting roads of differing levels.

An access road to service facilities such as service stations, weigh stations, comfort stations, restaurants, and parking areas.

A short inclined road constructed of unconsolidated material that exits gradually from and runs adjacent to the right lane of a descending highway, for stopping runaway trucks.

A junction of roads that forms a circle around whicl traffic moves in one direction.

The official alphanumeric identifier.

DELINEATION -

A road is delineated by the edge of all traffic lanes, excluding the shoulders.

DATA EXTRACTION at $1: 24,000$ scale -

Capture Condition -

All roads are captured, excluding driveways that are less than .25". 
Source Interpretation Guidelines -

All sources -

Hard-surface construction is generally concrete, asphaltic concrete, or bituminous macadam. Surfaces are waterproof. Minimum maintenance is required.

Improved, loose-surface construction is on light foundation and is usually gravel or stone surface, or of some stable material, such as selected sand-clay, treated oil gravel, or light tar-bound macadam. The roads are generally drained and graded, but the surface is not waterproof. Periodic mainten nnce is required.

Unimproved-surface construction is usually stabilized soil, sand-clay, or disintegrated rock with poor or no foundation. The road is sometimes drained or graded. If the roads are maintained at al' continual maintenance is required.

Only class 3 roads are designated to have an access restriction of "private."

Route designators are captured for Interstate highways, U.S. numbered highways, and State highways.

Names are captured for expressways and turnpikes, historical names required to preserve continuity of a feature, all streets in urban areas, and well-known or posted roads in rural areas.

Image -

For dual highways less than or equal to $.035^{\prime \prime}$ in overall width, capture the median centerlin:, with median category value of "with median" and width with a value for the extent of the road including the median.

For dual highways greater than $.035 "$ in overall width, capture the centerline of each roadwev, with median category value of "with median" and width with a value for the width of each roadray.

REPRESENTATION RULES at 1:24,000 scale -

Composition Rules -

If width is less than or equal to $.05 "$, road is composed of ordered chain(s), vertically relatef to other feature.

If width is greater than $.05 "$, road is composed of area, connected to junction, with inflow toloutflow from junction, vertically related to other feature.

Delimiting Rules - Delimit instances using rules for network links. Special Conditions - 


\section{INSTANCE COUNT SUMMARY}

For the example DLG-E feature data specification, 24 features were selected from the 202 features defined in the DLG-E features list (and four additional modeling constructs). Note: only nine of the feature data specifications are actually documented in this appendix. A total of 67 feature instances (of the 24 features) were discernible from the source material provided and met the capture conditions specified in the DLG-E feature data specification. The instance count summary details how many instances occurred for each feature and the number of attributes for each feature.

\begin{tabular}{|c|c|c|c|}
\hline Feature & $\begin{array}{l}\text { Number of Feature } \\
\text { Instances (A) }\end{array}$ & $\begin{array}{l}\text { Number of } \\
\text { Attributes (B) }\end{array}$ & $A \times B$ \\
\hline Named Feature & 7 & 1 & 7 \\
\hline Road & 15 & 7 & 105 \\
\hline Railway & 1 & 4 & 4 \\
\hline Stream & 8 & 3 & 24 \\
\hline Lake & 1 & 2 & 2 \\
\hline Spring & 1 & 2 & 2 \\
\hline Dam & 1 & 3 & 3 \\
\hline Shoreline & 2 & 1 & 2 \\
\hline Junction & 1 & 0 & 0 \\
\hline Nation & 1 & 1 & 1 \\
\hline State Territory & 1 & 2 & 2 \\
\hline County & 2 & 2 & 4 \\
\hline Domain & 1 & 0 & 0 \\
\hline Public Survey Area & 2 & 3 & 6 \\
\hline Ridge & 1 & 1 & 1 \\
\hline Cemetery & 1 & 1 & 1 \\
\hline Institutional Site & 1 & 2 & 2 \\
\hline Reservation & 3 & 3 & 9 \\
\hline Bridge & 1 & 4 & 4 \\
\hline Building & 5 & 2 & 10 \\
\hline Underpass & 4 & 0 & 0 \\
\hline Trail & 1 & 3 & 3 \\
\hline Ford & 1 & 1 & 1 \\
\hline Boundary Line & 5 & 1 & 5 \\
\hline TOTALS & $\begin{array}{l}67 \text { instances } \\
\text { (counted) }\end{array}$ & & $\begin{array}{l}198 \\
\text { computed } \\
\text { attribute } \\
\text { values }\end{array}$ \\
\hline
\end{tabular}




\section{GRAPH PLOTS}

Plots of the resultant DLG-O are provided to identify the spatial objects referenced by the Relationship Tuple Table. For clarity, two plots were produced. Chain (line) and point ID's are labeled on the first plot. Area ID's are lab?led on the second plot. Arrows on the chain plot indicate the direction of each chain.

\section{Chains and Points with ID Numbers}

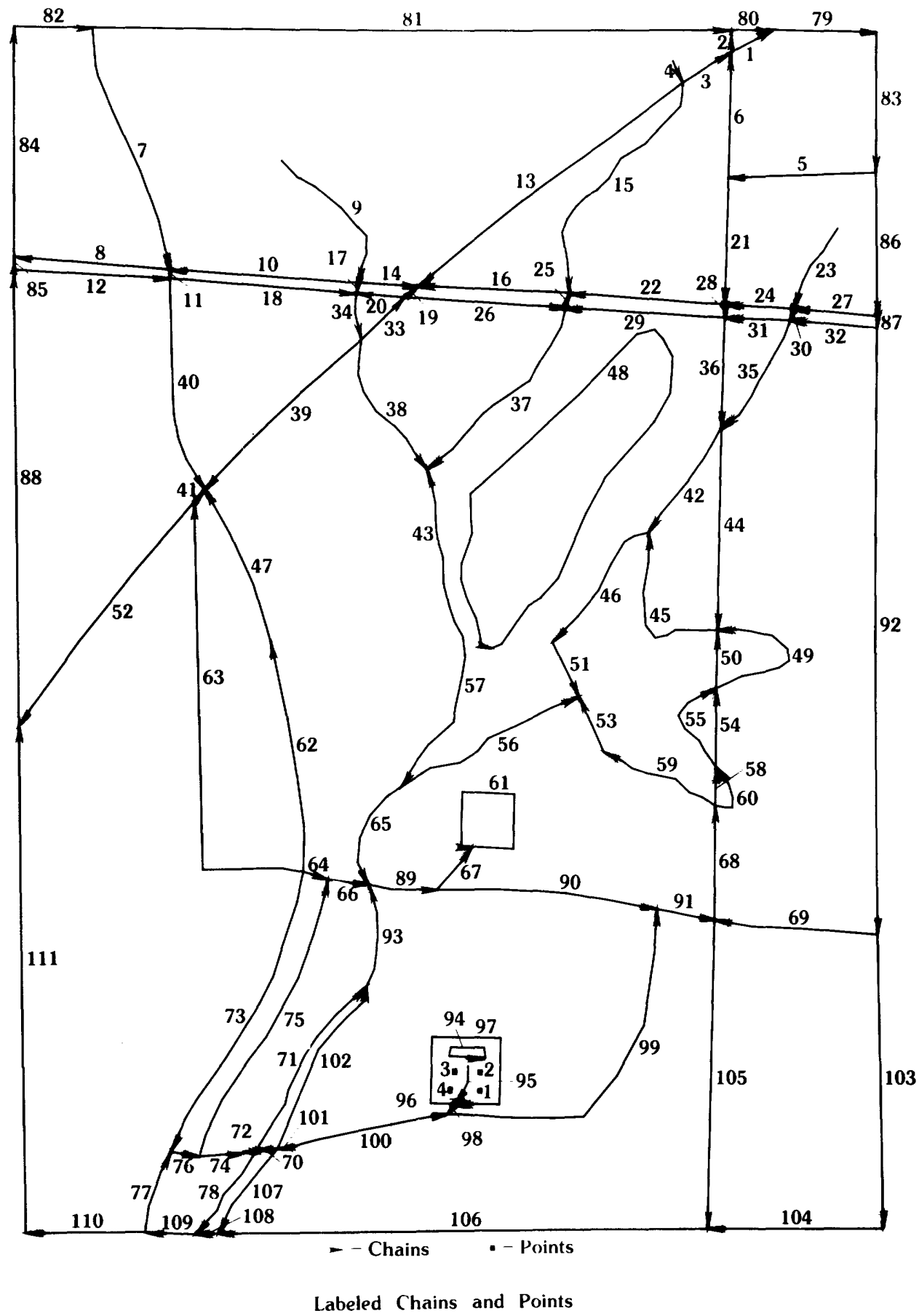


Areas with ID Numbers

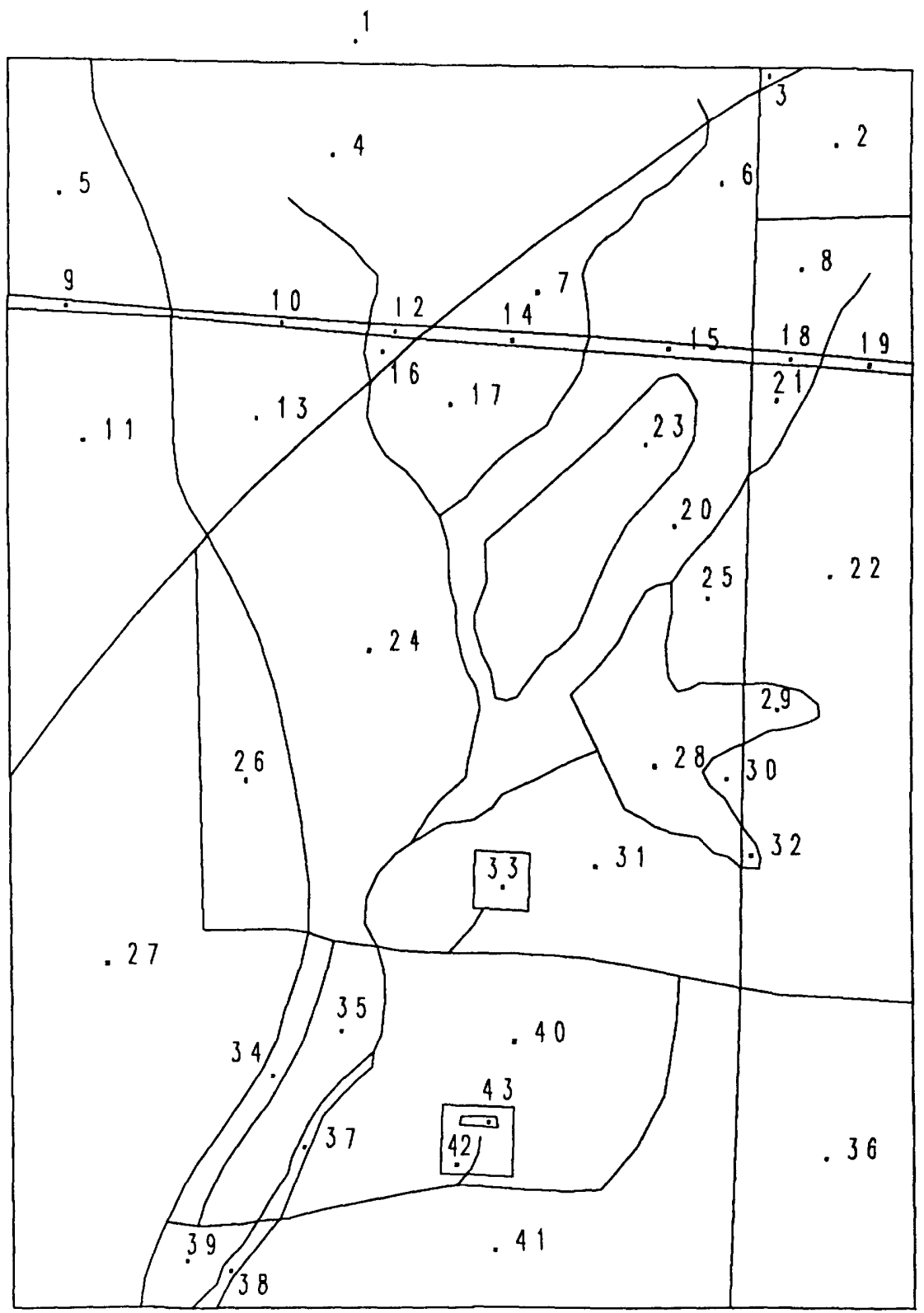




\section{DLG-0+ RELATIONAL TABLES FOR USE WITH DLG-E DATA}

Explanations of the eight relational tables designed for use with DLG-E data are presented. Definitions of tre fields (domains) of the tables are given, distinguishing key fields, foreign ID fields, and "other" fields. The information provided in this section is necessary for the reader to understand the case examples which follow.

This section presents the design of a set of DLG-O+ tables or "flat files" for use in implementing DLG-E features, nonspatial (nonlocational) attributes and values, and nontopological relationships. In a DLG-O+ data set, DLG-E data are separated into spatial and nonspatial components. A DLG-O file, without attributes or text, carries the spatia'

information. DLG-O+ flat files carry the nonspatial information. This organization is much like that employed by a number of currently available commercial geographic information systems. ARC/INFO, for example, stores s'atial data in ARC files and nonspatial data in related INFO (a commercial relational data base management system) files.

The following named tables have been specified for use with DLG-E data:

1. Feature Object table

2. Entity Label table

3. Attribute Definition table

4. Relationship Definition table

5. Attribute Value table

6. Name/Text table

7. Attribute Assignment table

8. Relationship Tuple table

\section{THE USE AND STRUCTURE OF "OBJECT" KEYS AND FOREIGN IDENTIFIERS}

In a DLG-O file, each topological object has an associated key by which it may be uniquely identified and referenced. In the tables presented below, each feature object instance, attribute value (including name/text) instance (or set--see below), entity label, attribute value assignment, and relationship tuple instance (or set) also has such a key. When referenced from other records, these keys are termed "foreign identifiers" (foreign ID). In the tables, a given foreign ID field may reference more than one type of object, attribute value, or relationship instance. For this reason, $t$; structure of these keys and foreign ID's must be identical.

Each object key/foreign ID begins with a single letter indicating object type, followed by a five-digit integer unique within that object type and data set. The following letters, used throughout the remainder of this section to refer to object types, tables, and types of foreign identifiers, indicate object type:

"A" indicates an Area (polygon),

" $\mathrm{C}$ " indicates a Chain,

"N" indicates a Node,

"P" indicates a Point,

"F" indicates a Feature object,

" $E$ " indicates an Entity label,

"V" indicates an Attribute value,

"T" indicates a Name/Text,

"S" indicates an Attribute assignment, and

" $R$ " indicates a Relationship tuple.

The first four object types are the topological objects in the DLG-O file; the five digit integers identifying t ase objects are the same as the "element internal ID" numbers in the DLG-O Area, Line, and Node Identification records. The remaining six "object" types are represented by the records of the tables of the same name. Note that attribite labels and relationship labels also have unique keys (in the Attribute Definition and Relationship Definition tables, respectively), but these are referenced from specific foreign ID fields reserved just for them (in the $V, T$, and $R$ tables). Thes? keys therefore need not have the same structure as the "object" keys.

\section{MINIMUM FOUR-TABLE SET PLUS FOUR}

A minimum set of tables, designed to carry all the nonspatial components of the DLG-E model could consist of just four tables. Two tables, (1) Attribute Definition and (2) Relationship Definition, carry definitional data, and two tables, (3) Attribute Value and (4) Relationship Tuple, carry instance data. The Attribute Definition table would carry a record for each unique attribute label (term) in the data set (with special records for "Entity Label" and "Comment"). The Attribute Value table carries the actual attribute values (as well as entity labels, names, and comment text). In order to interpret the attribute values correctly, each Attribute Value record carries the foreign ID of the appropriate Attribute 
Definition record. Likewise, the Relationship Definition table carries a record for each unique relationship in the data set (with a special record for an "Attributed by" relationship). The Relationship Tuple table carries the actual pair-wise object-to-object instances of these relationships.

For efficiency (e.g., DLG-O+ must implement these tables as fixed-length fields and records) and other reasons, additioral tables are developed here. To the minimum four, four tables are added: (5) Entity Label, (6) Name/Text, (7) Attribute Assignment, and (8) Feature Object. No new information is handled by these tables, but rather information which might have been carried in the minimum table set is separated out and placed in the additional tables. The Entity Label and Name/Text tables contain, in essence, special case records from the Attribute Value table. The Attribute Assignment talle contains all the "Attributed by" records from the Relationship Tuple table. The Feature Object table summarizes certain feature object data.

The reason for adding the Name/Text table is for storage efficiency. When implementing tables within a fixed-length record environment, the length of the Value field in Attribute Value table would have to be set to the longest name or text string value. Instead we will remove those names and long text strings and keep the Value field only large enougr to handle single numbers and short alphanumeric codes (e.g., 24 bytes). The Name/Text table has the identical structure as the Attribute Value table, but with a much larger value field for handling names and other long textual attribute values.

The reason for adding the Entity Label, Attribute Assignment, and Feature Object tables is for clarity. To have a more explicit structural equivalence to components of the DLG-E data model and the entity/attribute feature definition model, Entity Labels are distinguished from Attributes (by the Entity Label table), and Entities and Attributes are distinguished from Relationships (by the Attribute Assignment table). And finally the Feature Object table provides feature objects with their own "starting place" access table with records keyed by feature object ID (without this table, feature objects would be the only "objects" without a table explicitly keyed to their ID's).

\section{A DESCRIPTION OF FOLLOWING SUBSECTIONS}

The remainder of this section consists of three subsections.

Full Descriptions of DLG-O+ Tables for Use with DLG-E:

Five numbered items describe each of the eight tables:

1. Name of Table;

2. Purpose - a brief summary description;

3. Key field:

Name - always the name of the table followed by "Key,"

Unique? - "YES" or "NO" (if "NO" (for Attribute Value, Name/Text, Attribute Assignment, and Relationship Tuple tables), then a secondary field named "Order Sequence Number" is concatenated with the key field to provide a unique key for each record), and

Construction - "[object type letter]" + 5 digits, except for the Attribute Definition and Relationship Definition tables;

4. Foreign ID field(s) - for each foreign ID field, its full name is given followed by a description, including purpose and what records (by object type if appropriate) may be referenced; and

5. Other fields - for each of the remaining fields, its full name is given followed by a description, including purpose and a definition of possible data item contents.

Table/Field Summary:

For each table, a FORTRAN record format is given (these are what have been used for this example only--other formats may be developed for more voluminous datasets). Then for each field, its full name is equated to a short three- to five-character mnemonic and its byte (column) position within the record. This summary is meant to provide a user with the means to read individual records in the case examples (section B.7) and to allow short field names to be used in discussions which follow (and in programming languages).

Foreign ID's Pointing to "Object" Keys:

This subsection presents a discussion of how the records of the various DLG-O+ tables interrelate through the use of foreign ID's. Specifically, for each table (except the Entity Label, Attribute Definition, and Relationship Definition tables, which do not have foreign ID fields), each foreign ID field is related to the key field(s) of other table records to which the foreign ID may refer. 


\section{Full Descriptions of DLG-O+ Tables for Use with DLG-E}

1. Name of Table: Feature Object

2. Purpose: This table provides a summary of the information carried in the other tables about each featur? object.

3. Key field name: Feature Object Key

Unique?: YES.

Construction: "F" +5 digits.

4. Foreign ID field(s):

Primary Entity Label - this field carries the foreign ID of the primary entity label (in the Entity Label table) of this object. Usually one and only one entity label is assigned a given feature object. If no entity label is assigned to a feature object, this field shall be null. If more than one entity label is assigned a given featur: object, one of the labels must be chosen as the "primary" label.

5. Other fields:

(a) Dimensionality -- indicates the spatial dimension of the feature object; must be one of the following characters: "0" (point features),

"1" (linear features),

"2" (areal features),

"M" (mixed), or

"U" (unknown).

(b) Composition -- indicates the type of objects which comprise this feature object. This is defined by the object type code of those objects recorded as second tuple elements in Relationship Tuple records with the defined relationship being "Composed of" and this feature object as first tuple element. In addition to the type codes F, $A, P, N$, and $C$, the contents of this field may be:

"S" to indicate a mixed spatial object (A, P, N, and C type objects) composition,

" $M$ " to indicate a mixed feature and spatial object composition (F plus $A, P, N$, and/or $C$ type objects), or "U" for unknown composition.

(c) Contiguous? -- indicates whether the objects which comprise this feature are spatially contiguous or disjoint. The contents of this field may be "Y" (yes, they are contiguous), "N" (no), or "U" (unknown).

(d) Number of Unique Relationships -- this is defined as the number of unique Relationship Tuple Key"s of all Relationship Tuple records with this feature object as the first tuple element.

(e) Number of Relationship Tuple records -- the actual number of Relationship Tuple records with this feature object as the first tuple element.

(f) Number of Entity Labels Assigned -- indicated by the number (normally one) of Attribute Assignmant records with an entity label assigned to this feature object.

(g) Number of Attribute Values (or Value Sets) Assigned -- indicated by the number of Attribute Assignment records with Attribute Value foreign ID's (one ID may reference one Attribute Value record or a s $\$$ of records with the same key representing an attribute value set) assigned to this feature object.

(h) Number of Name/Text Strings (or String Sets) Assigned -- indicated by the number of Attribute Assignment records with Name/Text foreign ID's (one ID may reference one Name/Text record or a set of recnrds with the same key representing a name/text string set) assigned to this feature object.

1. Name of Table: Entity Label

2. Purpose: This table serves to store the actual entity labels associated with feature objects. There is on? record in this table for each unique entity label assigned to one or more of feature objects.

\section{B-24 An Enhanced Digital Line Graph Design}


3. Key field name: Entity Label Key

Unique?: YES--as opposed to Attribute Value records, each of which may carry an individual value of a multivalred attribute value set, Entity Label records must always be referenced individually.

Construction: "E" +5 digits.

4. Foreign ID field: none.

5. Other fields:

(a) Entity Label -- the actual alphanumeric text which is a feature/entity term (e.g., "Road").

(b) Definition Authority - Source of the definition for this feature/entity term (e.g., "USGS/NMD, DLG-E").

1. Name of Table: Attribute Definition

2. Purpose: This table provides the means for interpreting attribute values in the Attribute Value and Name/Text tablas.

3. Key field name: Attribute Definition Key.

Unique: YES.

Construction: "AD" +4 digits.

4. Foreign ID field(s): none.

5. Other fields:

(a) Attribute Label - Name given to this attribute (e.g., "Width").

Note that if the minimum table set were used, "Entity Label" would be a special reserved attribute label indicating that the Attribute Value field is to be read as a feature/entity term; an Entity Label table, if present. obviates the need for this special attribute label.

(b) Attribute Definition Authority - Source of the definition for this attribute (e.g., "USGS/NMD, DLG-E").

(c) Attribute Value Format - How to read the values assigned to this attribute; must be one of the following (Not: coding should follow ISO-6093, etc. standards):

A ("printable" ASCII characters)

I (implicit-point--integer),

$\mathrm{R}$ (explicit-point unscaled--real without exponent),

$S$ (explicit-point scaled--real with exponent),

$B$ (bitfield data), or

C (character-mode bitfield).

(d) Attribute Value Measurement Units (e.g., "meters") - this field may be null for nonnumeric attribute values.

Further Comments:

The Attribute Definition table will carry one record for each defined nonlocational attribute used in the DLG-E data set. The meaning of the actual labels (in the Attribute Label field) and values (in the Attribute Value and Name/Text tables--see below) are defined by some authority (e.g., USGS/NMD, DLG-E), but this meaning is not repeated here. The Attribute Authority field is meant as a reference for such definition.

Note also that a given attribute label, including "Entity Label," is not necessarily unique. Different authorities may" be used to define feature/entity terms or different meanings to attributes of the same name. The combination of attribute label and attribute authority is what makes an attribute unique.

\section{Name of Table: Relationship Definition}

2. Purpose: provides information for interpreting Relationship Tuple records.

3. Key field name: Relationship Definition Key

Unique?: yes. Construction: "RD" +2 digits. 


\section{Foreign ID field(s): none.}

5. Other fields:

(a) Relationship Label - Name given to this relationship (e.g., "Composed of"). Note that in the minimum table set, a special relationship label, "Attributed by," is reserved to relate Attribute Value records to their owner(s) (objects, attribute values, or relationships)--it is not used when an Attribute Assignment table is present.

(b) Reverse Relationship Label - Name given to the reverse relationship (e.g., "Part of"). Note that if the relationship is symmetrical (the order of the elements of the tuple is not significant), this name would be the same as the forward Relationship Label.

(c) Relationship Authority - Source of the definition for this relationship (e.g., "USGS/NMD, DLG-E").

(d) Domain of the First Tuple Element - indicates what type of objects may participate as the first elem ant in the Relationship Tuple table. One of the single character "object" type codes listed above is carried in this field. In the minimum table set, this be may be F, V, or R. However, when an Attribute Assignment tab'e is present, only feature objects may be first tuple elements; this field will always carry "F." It is therefore unnecessary, but we keep it for compatibility with the minimum table set and for future expansion.

(e) Domain of the Second Tuple Element - indicates what type of objects may participate as the second element in the Relationship Tuple table. In the minimum table set, the following single character "object" type codes may be present in this field: P, N, C, A, F, V, or R. When an Attribute Assignment table is present, only true object codes (P, N, C, A, and F) may be present.

(f) Ordered? - must be Y (yes), N (no) or E (either).

(g) Directed? - this field is important only with Ordered relationships; if $Y$ (yes), then the order of secrnd tuple elements indicates a "ground" direction important to the composition of the real-world entity represented by the first tuple element (e.g., a Stream has a direction of flow).

(h) Flag Field Meaning - this defines the meaning of the contents of the flag field in the Relationship t"ple records (e.g., a negative sign in the field indicates the coordinate string of the referenced chain is to be reversed for this relationship).

\section{Name of Table: Attribute Value}

2. Purpose: This table serves to store the actual attribute values of attributes associated with (1) feature obiacts, (2) other attribute values, or (3) relationships.

3. Key field name: Attribute Value Key

Unique?: NO--a set of attribute values (one value per record) may be referenced as a whole (by one foreign identifier) if needed and there is no need to reference each individual value of the set.

To produce a unique key for the Attribute Value records, the Order Sequence Number field (5.(b) below) is concatenated to the Attribute Value Key field.

Construction: "V" +5 digits.

4. Foreign ID field:

Attribute Definition Key (to the Attribute Definition table).

5. Other field:

(a) Attribute Value -- the actual attribute value data item (as a set of bytes, which are to be interpreted per the Attribute Value Format field of the referenced Attribute Definition record).

(b) Order Sequence Number - if the value is part of a set (and the records have the same Attribute Value Key), this field provides sequencing data (an integer from 1 to $\mathrm{N}$, the number of values in the set). Also, this field concatenated with the Attribute Value Key field yields a unique key for an individual record. 
1. Name of Table: Name/Text

2. Purpose: This table serves to store the actual "long" alphanumeric attribute values of attributes associated with (1) feature objects, (2) other attribute values, or (3) relationships. Examples of these "long" attribute values are those assigned to the attributes labeled "Name" or "Comment" (in the Attribute Label field of the Attribute Definition table).

3. Key field name: Name/Text Key

Unique?: NO--a set of alphanumeric strings (one string per record) may be referenced as a whole (by one foreign identifier) if needed and there is no need to reference each individual string of the set. In this manner, for example, a single attribute may be valued by a very long text passage entered as a set of text lines, one line per Feature Name/Text record, and the entire record set would be identified by a single key shared by all the records of the set. To produce a unique key for the Name/Text records, the Order Sequence Number field (5(b) below) is concatenated to the Name/Text Key field.

Construction: "T" +5 digits.

4. Foreign ID field:

Attribute Definition Key (to the Attribute Definition table).

5. Other fields:

(a) Name/Text String -- the actual alphanumeric text string comprising the value of the referenced Attribute (e.g., Name).

(b) Order Sequence Number - if the string is part of a set, this field provides sequencing data (an integer from $1 \mathrm{~h}$ $\mathrm{N}$, the number of strings in the set). Also, this field concatenated with the Name/Text Key field yields a unique key for an individual record.

1. Name of Table: Attribute Assignment

2. Purpose: This table provides the means by which (1) attribute values, and (2) names/text, are assigned to (a) feature objects, (b) relationships (as instanced in the Relationship Tuple records), (c) attribute assignments (as instanced in the records of this table), (d) other attribute values, and (e) other feature names/text. This table also provides the means by which entity labels are assigned to only feature objects.

3. Key field name: Attribute Assignment Key

Unique?: NO--a set of tuples (one pair per record) may be referenced as a whole (by one foreign identifier) if needed and there is no need to reference each individual record of the set.

To produce a unique key for the Attribute Assignment records, the Order Sequence Number field ( 5 below) is concatenated to the Atribute Assignment Key field.

Construction: "S" +5 digits.

4. Foreign ID field(s):

(a) Element ID - the Feature Object, Relationship Tuple, Attribute Assignment, Attribute Value, or Feature Name/Text record key of the element to which the attribute is assigned.

(b) Attribute ID - the Attribute Value, Name/Text, or Entity Label record key of the value(s), name/text, or entity label assigned to the element identified by the Element ID.

5. Other field:

Order Sequence Number - if an Attribute Assignment record is part of a set (with a common Attribute Assignment Key), this field provides sequencing data (an integer from 1 to $\mathrm{N}$, the number of records in $t^{\text {the }}$ set). Also, this field concatenated with the Attribute Assignment Key field yields a unique key for an individual record. 
1. Name of Table: Relationship Tuple

2. Purpose: This is an object linkage table. Feature and topological objects are related to feature objects t'rough named relationships (defined in the Relationship Definition table).

3. Key field name: Relationship Tuple Key

Unique?: NO--a set of tuple records may and should be referenced as a whole (by one foreign identifie-) if the set of Second Tuple Elements instance a one-to-many relationship to the feature object identified in the First Tuple Element.

To produce a unique key for the Relationship Tuple records, the Order Sequence Number field (5(b) below) is concatenated to the Relationship Tuple Key field.

Construction: "R" +5 digits.

4. Foreign ID field(s):

(a) Relationship Definition Key - to the Relationship Definition Table.

(b) First Tuple Element - the feature object ID of the first element in this relationship tuple.

(c) Second Tuple Element - the object (feature or topological) ID of the second element of this relatiorship tuple.

5. Other fields:

(a) Flag - this field may be used to attach a simple qualifier to this relationship. For example, a sign may be included in this field to indicate the direction of a chain coordinate string included in a linear feature.

(b) Order Sequence Number - if a set of Second Tuple Elements (in records with identical Relationship Tuple Keys) instance a one-to-many relationship to the feature object identified in the First Tuple Element and t i relationship is an ordered one, this field provides sequencing data (an integer from 1 to $\mathrm{N}$, number of reco-ds in the set), and when concatenated with the Relationship Tuple Key field yields a unique key for an indiv: Hual record.

\section{$\underline{\text { Table/Field Summary }}$}

The following summarizes the record layout of each table, including a FORTRAN record format and an itemized field list. For each field, a short mnemonic is given as well as the full field name and fixed field byte positions within the record.

Feature Object Table:

((A1,I5),1X,(A1,I5),1X,I1,1X,A1,1X,A1,1X,I2,1X,I3,1X,I1,1X,I2,1X,I2)

$\begin{array}{lll}\text { Mnemonic } & & \text { Cols. } \\ \text { FKEY } & & 1-6 \\ \text { PEID } & & 8-13 \\ \text { DIMN } & & 15 \\ \text { COMP } & & 17 \\ \text { CNTG } & & 19 \\ \text { NREL } & & 21-22 \\ \text { NRTR } & & 24-26 \\ \text { NELB } & & 28 \\ \text { NAVS } & & 30-31 \\ \text { NNTS } & & 34-34\end{array}$

Full Field Name

Feature Object Key

Primary Entity Label Foreign ID

Dimensionality

Composition

Contiguous?

Number of Relationships

Number of Relationship Tuple Records

Number of Entity Labels Assigned

Number of Attribute Value( Set)s Assigned

Number of Name/Text String( Set)s Assigned

Entity Label Table:

((A1,I5),1X,A22,1X,A8)

\begin{tabular}{lll}
\cline { 1 - 1 } Mnemonic & & Cols. \\
EKEY & & $1-6$ \\
ELABL & & $8-29$ \\
EAUTH & & $31-38$
\end{tabular}

Full Field Name

Entity Label Key

Entity Label

Definition Authority 
Attribute Definition Table:

((A2,I4), 1X,A36,1X,A8,1X,A1,1X,A8)

Mnemonic Cols.

$\begin{array}{ll}\text { ADKEY } & 1-6 \\ \text { ALABL } & 8-43 \\ \text { AAUTH } & 45-52 \\ \text { AVFMT } & 54 \\ \text { UNITS } & 56-63\end{array}$

Full Field Name

Attribute Definition Key

Attribute Label

Attribute Definition Authority

Attribute Value Format

Attribute Value Measurement Units

Relationship Definition Table:

((A2,I4),2X,A22,1X,A24,1X,A5,1X,A1,1X,A1,1X,A1,1X,A1,1X,A56)

\begin{tabular}{lll} 
Mnemonic & & Cols. \\
\cline { 3 - 3 } RDKEY & & $1-6$ \\
RLABL & & $9-30$ \\
REVLB & & $32-55$ \\
RAUTH & & $57-61$ \\
DOMN1 & 63 \\
DOMN2 & 65 \\
ORD & & 67 \\
DIR & 69 \\
MNG & $71-126$
\end{tabular}

Full Field Name

Relationship Definition Key

Relationship Label

Reverse Relationship Label

Relationship Definition Authority

Domain, First Tuple Element

Domain, Second Tuple Element

Ordered?

Directed?

Flag Meaning

Attribute Value Table:

((A1,I5),1X,(A2,I4),1X,A18,1X,I3)

Mnemonic Cols.

\section{Full Field Name}

$\begin{array}{ll}\text { VKEY } & 1-6 \\ \text { ADID } & 8-13 \\ \text { AVAL } & 15-32 \\ \text { SEQN } & 34-36\end{array}$

Attribute Value Key

Attribute Definition Foreign ID

Attribute Value (Note: actual format of this field is in the AVFMT field in the Attribute Definition table.)

Order Sequence Number

Name/Text Table:

((A1,I5),1X,(A2,I4), 1X,A60,1X,I3)

Mnemonic Cols.

TKEY $1-6$

ADID 8-13

TEXT 15-74

SEQN $\quad 75-77$

Attribute Assignment Table:

$((\mathrm{A} 1, \mathrm{I} 5), 1 \mathrm{X},(\mathrm{A} 1, \mathrm{I} 5), 1 \mathrm{X},(\mathrm{A} 1, \mathrm{I5}), 1 \mathrm{X}, \mathrm{I3})$

$\begin{array}{lll}\text { Mnemonic } & & \text { Cols. } \\ \text { SKEY } & & 1-6 \\ \text { EFID } & & 8-13 \\ \text { AFID } & & 15-20 \\ \text { SEQN } & & 22-24\end{array}$

\section{Full Field Name}

Name/Text Key

Attribute Definition Foreign ID

Name/Text String

Order Sequence Number

\section{Full Field Name}

Attribute Assignment Key

Element (object types F, E, V, T, R, S) Foreign ID

Attribute ("object" types E, V, T) Foreign ID

Order Sequence Number 
Relationship Tuple Table:

$((\mathrm{A} 1, \mathrm{I}), 1 \mathrm{X},(\mathrm{A} 2, \mathrm{I} 4), 1 \mathrm{X},(\mathrm{A} 1, \mathrm{I5}), 1 \mathrm{X},(\mathrm{A} 1, \mathrm{I5}), 1 \mathrm{X}, \mathrm{A} 1,1 \mathrm{X}, 13)$

$\begin{array}{lll}\text { Mnemonic } & & \text { Cols. } \\ \text { RKEY } & & 1-6 \\ \text { RDID } & & 8-13 \\ \text { E1ID } & & 15-20 \\ \text { E2ID } & & 22-27 \\ \text { FLAG } & & 29 \\ \text { SEQN } & & 31-33\end{array}$

Full Field Name

Relationship Tuple Key

Relationship Definition Foreign ID

First Tuple Element (object type F) Foreign ID

Second Tuple Element (types F, P, N, A, C) Foreign ID

Flag

Order Sequence Number

\section{Foreign ID's Pointing to "Object" Keys}

The following diagrams are meant to show how the contents of foreign identifier fields in the DLG-O+ table records point to the key fields of other records. The Feature Object table is a special case in that many of its fields (with the exception of Primary Entity ID field--PEID) do not necessarily point other records, but they do provide counts and other summary information about the records in other tables (namely the Attribute Assignment and Relationship Tuple tables).

An attempt has been made to illustrate cross-references between fields of the different tables by listing the fields of a given table first, followed by a listing of the fields of each of the tables to which the records of the first table may point. Exact field-to-field references are shown by using different highlighting techniques (i.e. bold, italics, underline, and shadow).

Feature Object Table:

RIKEYY PEID DIMN COMP CNTG NREL NRTR NELB NAVS NNTS

Entity Label Table:

EKEY ELABL EAUTH

Relationship Tuple Table:

RKEY RDID BIID E2ID FLAG SEQN

Attribute Assignment Table:

SKEY EIFIDD AFID SEQN

PEID (Feature Object table) points to EKEY (Entity Label table).

DIMN COMP CNTG NREL NRTR summarize information in those Relationship Tuple Table records where $\mathbb{B} \mathbb{I I D}=\mathbb{F} \mathbb{R} \mathbb{R} Y$.

NELB NAVS NNTS count the number of unique SKEY values in those Attribute Assignment Table records

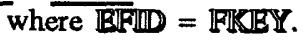

Relationship Tuple Table:

RKEY RDID E1ID E2ID FLAG SEQN

Relationship Definition Table:

RDKEY RLABL REVLB RAUTH DOMN1 DOMN2 ...

Feature Object Table:

FKEY PEID DIMN COMP CNTG $\ldots$

Node, Area, and Line Id Records in DLG-O file:

(Record Type, Element ID number) ...

$R D I D$ points to $R D K E Y$ (Relationship Definition table).

E1ID points to FKEY (Feature Object table). 
E2ID may point to FKEY (Feature Object table), or to Record Type + Element ID number in a DLG-O Node, Line, or Area Id Record.

Attribute Assignment Table:

SKEY EFID AFID SEQN

Feature Object Table:

FKEY PEID DIMN COMP CNTG ...

Relationship Tuple Table:

RKEY RDID E1ID E2ID FLAG SEQN

Attribute Assignment Table (other records):

SKEY EFID AFID SEQN

Attribute Value Table:

VKEY ADID AVAL SEQN

Name/Text Table:

TKEY ADID TEXT SEQN

Entity Label Table:

EKEY ELABL EAUTH

EFID may point to any of the key fields (i.e. FKEY, RKEY, SKEY, VKEY, TKEY, or EKEY) of the six tables listed.

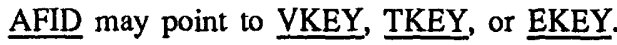

Attribute Value Table:

VKEY ADID AVAL SEQN

Attribute Definition Table:

ADKEY ALABL AAUTH AVFMT UNITS

$A D I D$ points to $A D K E Y$ (Attribute Definition table).

Name/Text Table:

TKEY ADID TEXT SEQN

Attribute Definition Table:

ADKEY ALABL AAUTH AVFMT UNITS

$A D I D$ points to $A D K E Y$ (Attribute Definition table). 


\section{CASE EXAMPLES}

Several examples illustrate how the source, product specification, and representation rules work together to froduce digital representations of features in the DLG-O+ data set. The examples lead the reader through many of the relational tables, showing how information is stored and linked.

This section presents a number of individual cases illustrating how DLG-E features are represented in the $\Gamma^{\top} . G-E$ example data set. Feature instances, summarized in section 4, have been extracted from the source material in section 2 based upon the feature and attribute definitions in appendix $A$ and the DLG-E feature data specifications in section 3. The representations of these feature instances, also based on rules in section 3 , have been implemented usin? the DLG-O+ relational tables defined in section 6, and an associated DLG-O file as plotted in section 5 . As c?n be seen, all parts of this appendix are required to follow the examples in this section.

In pursuing a given example, the reader is encouraged to gather in front of him or her the source graphic (page B-3), the graph plots (pages B-20 and B-21), and the five full DLG-O+ relational tables below (pages B-33 through B-37). The Table/Field Summary (pages B-28 through B-30) can serve as reference for the full field names of the tables.

Each of the examples presents one primary feature instance from the source graphic and follows its represertation through the DLG-O+ relational tables and the DLG-O chain and area plots. In the process, related feature instance; where found, are also discussed. In this manner, instances of both the Road and Underpass features are included in the first example; instances of the Stream/River, Shoreline, and Junction features are presented in the second example; and instances of the Reservation and Boundary Line features are covered in the third example.

As discussed in section 6, the DLG-O+ relational tables make extensive use of "object" keys and foreign II's. Each of the table records has its object key by which it can be referenced by foreign ID's in other table records (se: pages B-30 to B-31). When discussing the case examples, the primary focus is on feature instances. As such, the path through the relational tables begins with a record in the Feature Object table, and following the foreign ID pointers, proseeds as follows:

1. The Feature Object record contains the key value ("F" + ID number) for the instance and points to it: Entity Label (i.e. feature term) in the Entity Label table (as well as summarizes related records in the Attribute As ₹ignment and Relationship Tuple tables);

2. The Attribute Assignment table assigns Attribute Value and Name/Text records to the feature object (and to other "objects" (e.g., other attribute values) as well);

3. The Attribute Value and Name/Text records contain actual values and text strings; each of these records points to its Attribute Label (i.e. attribute term) and associated value format in a record of the Attribute Definition table.

4. The Relationship Tuple records relate objects in the DLG-O file (points, nodes, chains, and areas), as well as other feature objects, if appropriate, to feature objects. Each Tuple record also points to a Relationship Definition table record which defines which relationship is being instanced.

\section{FULL DLG-E EXAMPLE DATA SET TABLES}

Five of the eight DLG-O+ relational tables defined for DLG-E data are relatively brief for the DLG-E example data set. The Entity Label, Attribute Definition, Relationship Definition, Attribute Value, and Name/Text tables are ircluded here in their entirety for use by each of the examples to follow. For the Feature Object, Attribute Assignment, anc Relationship Tuple tables, those records (and only those records) pertaining to the actual case examples will be presented within the context of the discussion of the example. Note: the column headings in each of the example tables are the field mnemonics presented in the Table/Field Summary in section 6 (pages B-28 to B-30). 
Entity Label Table (in its entirety):

$\begin{array}{lll}\text { EKEY } & \text { ELABL } & \text { EAUTH } \\ \text { E00001 } & \text { NAMED FEATURE } & \text { USGS/NMD } \\ \text { E00002 } & \text { ROAD } & \text { USGS/NMD } \\ \text { E00003 } & \text { RAILWAY } & \text { USGS/NMD } \\ \text { E00004 } & \text { STREAM } & \text { USGS/NMD } \\ \text { E00005 } & \text { LAKE } & \text { USGS/NMD } \\ \text { E00006 } & \text { SPRING } & \text { USGS/NMD } \\ \text { E00007 } & \text { DAM } & \text { USGS/NMD } \\ \text { E00008 } & \text { SHORELINE } & \text { USGS/NMD } \\ \text { E00009 } & \text { JUNCTION } & \text { USGS/NMD } \\ \text { E00010 } & \text { NATION } & \text { USGS/NMD } \\ \text { E00011 } & \text { STATE/TERRITORY } & \text { USGS/NMD } \\ \text { E00012 } & \text { COUNTY } & \text { USGS/NMD } \\ \text { E00013 } & \text { DOMAIN } & \text { USGS/NMD } \\ \text { E00014 } & \text { PUBLIC SURVEY DOMAIN } & \text { USGS/NMD } \\ \text { E00015 } & \text { RIDGE } & \text { USGS/NMD } \\ \text { E00016 } & \text { CEMETERY } & \text { USGS/NMD } \\ \text { E00017 } & \text { INSTITUTIONAL SITE } & \text { USGS/NMD } \\ \text { E00018 } & \text { RESERVATION } & \text { USGS/NMD } \\ \text { E00019 } & \text { BRIDGE } & \text { USGS/NMD } \\ \text { E00020 } & \text { BUILDING } & \text { USGS/NMD } \\ \text { E00021 } & \text { UNDERPASS } & \text { USGS/NMD } \\ \text { E00022 } & \text { TRAIL } & \text { USGS/NMD } \\ \text { E00023 } & \text { FORD } & \text { USGS/NMD } \\ \text { E00024 } & \text { BOUNDARY LINE } & \text { USGS/NMD }\end{array}$

This table is a list of the 24 DLG-E features (types, not instances) found in the contrived source materials. Each feat Te instance is represented by a feature object. Each Feature Object record contains a pointer to one record in the Entity Label table, indicating which type of feature is being instanced. The Attribute Assignment table also contains records which relate Entity Labels to Feature Objects (as such these records are redundant when only one Entity Label is assigned to a given Feature Object). 
Attribute Definition Table (in its entirety):

\begin{tabular}{|c|c|c|c|c|}
\hline ADKEY & $\underline{A L A B L}$ & AAUTH & AVFMT & UNITS \\
\hline AD0001 & ACCESS RESTRICTION & USGS/NMD & A & \\
\hline AD0002 & NAME & USGS/NMD & A & \\
\hline AD0003 & ROUTE DESIGNATOR & USGS/NMD & A & \\
\hline AD0004 & OPERATIONAL STATUS & USGS/NMD & A & \\
\hline AD0005 & ROAD CLASS & USGS/NMD & A & \\
\hline AD0006 & TRAFFIC DIRECTION & USGS/NMD & A & \\
\hline AD0007 & NUMBER OF LANES OR TRACKS & USGS/NMD & I & \\
\hline AD0008 & RAILWAY GAUGE & USGS/NMD & A & \\
\hline AD0009 & HYDROGRAPHIC CATEGORY & USGS/NMD & A & \\
\hline $\mathrm{AD} 0010$ & WATER CHARACTERISTIC & USGS/NMD & A & \\
\hline AD0011 & MATERIAL COMPOSITION & USGS/NMD & A & \\
\hline AD0012 & SPILLWAY ELEVATION & USGS/NMD & I & FEET \\
\hline AD0013 & DELINEATION STATUS & USGS/NMD & A & \\
\hline AD0014 & FIPS CODE IDENTIFIER FIRST & USGS/NMD & A & \\
\hline AD0015 & FIPS CODE IDENTIFIER SECOND & USGS/NMD & A & \\
\hline AD0016 & ORIGIN OF SURVEY NAME & USGS/NMD & A & \\
\hline AD0017 & RANGE & USGS/NMD & A & \\
\hline AD0019 & TOWNSHIP & USGS/NMD & A & \\
\hline AD0020 & INSTITUTIONAL FUNCTION & USGS/NMD & A & \\
\hline AD0021 & RESERVATION TYPE & USGS/NMD & A & \\
\hline $\mathrm{AD} 0022$ & RESERVATION USE STATUS & USGS/NMD & A & \\
\hline AD0023 & COVERING & USGS/NMD & A & \\
\hline AD0024 & NUMBER OF DECKS & USGS/NMD & I & \\
\hline AD0025 & ANGLE OF ORIENTATION & USGSNMD & I & DEGREES \\
\hline AD0026 & BUILDING CLASS & USGS/NMD & A & \\
\hline AD0027 & TRAIL TYPE & USGS/NMD & A & \\
\hline AD0029 & ROUTE TYPE & USGS/NMD & A & \\
\hline AD0030 & COMMENT & USGS/NMD & A & \\
\hline
\end{tabular}

This table contains a record for each unique Attribute Label term used in the DLG-E example data set. Each Attribute Value and Name/Text record contains a pointer to a record in this table, indicating which Attribute is being valued. Also, the AVFMT field in this table indicates how to read the AVAL field in the Attribute Value record, and for numeric attribute values, the UNITS field indicates the units of measure. 
Relationship Definition Table (in its entirety):

\begin{tabular}{|c|c|c|c|c|c|c|c|c|}
\hline RDKEY & $\underline{\text { RLABL }}$ & $\underline{\text { REVLB }}$ & RAUTH & DOMN1 & DOMN2 & ORD & DIR & MNG \\
\hline RD0001 & Composed of & Part of & DLG-E & $\mathrm{F}$ & $\mathbf{p}$ & $\mathrm{N}$ & $\mathrm{N}$ & \\
\hline RD0002 & Composed of & Part of & DLG-E & F & $\mathbf{N}$ & $\mathrm{N}$ & $\mathbf{N}$ & \\
\hline RD0003 & Composed of & Part of & DLG-E & F & C & $\mathbf{N}$ & $\mathbf{N}$ & \\
\hline RD0004 & Composed of & Part of & DLG-E & $\mathrm{F}$ & A & $\mathbf{N}$ & $\mathbf{N}$ & \\
\hline RD0005 & Composed of & Part of & DLG-E & F & $\mathrm{F}$ & $\mathbf{N}$ & $\mathbf{N}$ & \\
\hline RD0006 & Composed of & Part of & DLG-E & $\mathrm{F}$ & C & $\mathrm{Y}$ & $\mathbf{N}$ & F1 \\
\hline RD0007 & Composed of & Part of & DLG-E & F & $\mathrm{F}$ & $\mathrm{Y}$ & $\mathrm{N}$ & \\
\hline RD0008 & Composed of & Part of & DLG-E & F & C & 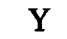 & $\mathbf{Y}$ & F1 \\
\hline RD0009 & Composed of & Part of & DLG-E & F & F & $Y$ & $\mathbf{Y}$ & F1 \\
\hline RD0010 & Bounded by & Bounds & DLG-E & F & $\mathrm{F}$ & $\mathrm{E}$ & $\mathbf{Y}$ & $\mathrm{F} 2$ \\
\hline RD0011 & Vert. relates & Vert. related by & DLG-E & $\mathrm{F}$ & F & $\mathrm{Y}$ & $\mathbf{N}$ & $\mathrm{O} 1$ \\
\hline RD0013 & Flows to & Flows from & DLG-E & F & F & $\mathrm{N}$ & $\mathbf{Y}$ & \\
\hline RD0014 & Connects to & Connects to & DLG-E & $\mathrm{F}$ & F & $\mathrm{E}$ & $\mathrm{Y}$ & \\
\hline
\end{tabular}

Each Relationship Tuple record contains a pointer to a record in this table indicating what relationship is being instanced. The relationships are those listed as "nontopological" in table 4 in "Concepts of DLG-E Design," page 5, with added distinctions made to the "composed of/part of" relationship (by object types, ordering of members of a relationship tupl: set, and "ground" significance of direction).

Note that the Flag Meaning field (MNG) has been shortened to allow listing here. The following explains how the Flag Meaning field (MNG) indicates the meaning of the Relationship Tuple record FLAG and/or SEQN field contents:

F1 Flag Meaning \#1

"+" in the FLAG field of the Relationship Tuple record indicates that the direction defined by the order of the coordinates of the one-dimensional object referenced by E2ID (chain for RD0006 and RD0008, and feature for RD0009) matches the direction of the feature object referenced by E1ID.

"-" in the FLAG field indicates that the direction defined by the order of the coordinates of the onedimensional object referenced by E2ID is the opposite of the direction of the feature object referenced by E1ID.

F2 Flag Meaning \#2

" + in the FLAG field of the Relationship Tuple record indicates that the direction of the one-dimensioral feature object referenced by E2ID is clockwise around the bounded two-dimensional feature object referenced by E1ID (area is to the right).

"-" in the FLAG field indicates that the direction of the one-dimensional feature object referenced by E2ID must be reversed to allow the bounded object referenced by E1ID to be to the right.

O1 Order Meaning \#1

"1" in the SEQN field of the Relationship Tuple record indicates that the feature object referenced by E2ID is the "above" feature

"2" in the SEQN field indicates that the E2ID feature is "below." 
Attribute Value Table (in its entirety):

\begin{tabular}{|c|c|c|c|}
\hline VKEY & $\underline{\mathrm{ADID}}$ & AVAL & [SEQN is not used] \\
\hline V00001 & AD0001 & NONE & \\
\hline V00004 & AD0004 & OPERATIONAL & \\
\hline V00005 & $\mathrm{AD} 0005$ & $1 \mathrm{ST}$ & \\
\hline V00006 & $\mathrm{AD} 0006$ & TWO WAY & \\
\hline V00007 & AD0007 & & 2 \\
\hline V00014 & AD0007 & & 4 \\
\hline V00031 & $\mathrm{AD} 0003$ & US63 & \\
\hline V00041 & AD0006 & ONE WAY & \\
\hline V00052 & $\mathrm{AD} 0003$ & I-44 & \\
\hline V00061 & $\mathrm{AD} 0005$ & 2ND & \\
\hline V00087 & $\mathrm{AD} 0003$ & ROUTE CC & \\
\hline V00115 & $\mathrm{AD} 0003$ & ROUTE 2 & \\
\hline V00121 & AD0027 & UNKNOWN & \\
\hline V00124 & AD0007 & & 1 \\
\hline V00126 & $\mathrm{AD} 0008$ & STANDARD & \\
\hline V00129 & AD0003 & \#UNSPECIFIED & \\
\hline V00131 & $\mathrm{AD} 0005$ & 3RD & \\
\hline V00141 & AD0009 & PERENNIAL & \\
\hline V00147 & $\mathrm{AD} 0009$ & INTERMITTENT & \\
\hline V00162 & $\mathrm{AD} 0010$ & UNSPECIFIED & \\
\hline V00163 & AD0011 & EARTHEN & \\
\hline V00165 & AD0012 & & 974 \\
\hline V00166 & $\mathrm{AD} 0013$ & DEFINITE & \\
\hline V00167 & $\mathrm{AD} 0010$ & FRESH & \\
\hline V00174 & $\mathrm{AD} 0014$ & 34 & \\
\hline V00176 & $\mathrm{AD} 0015$ & 101 & \\
\hline V00178 & $\mathrm{AD} 0015$ & 102 & \\
\hline V00179 & AD0016 & USGLO & \\
\hline V00180 & $\mathrm{AD} 0017$ & $39 \mathrm{E}$ & \\
\hline V00182 & $\mathrm{AD} 0019$ & $6 \mathrm{~S}$ & \\
\hline V00184 & AD0017 & $40 \mathrm{E}$ & \\
\hline V00189 & $\mathrm{AD} 0020$ & EDUCATION & \\
\hline V00190 & $\mathrm{AD} 0022$ & STATE & \\
\hline V00192 & $\mathrm{AD} 0023$ & NOT COVERED & \\
\hline V00194 & $\mathrm{AD} 0024$ & & 1 \\
\hline V00195 & AD0026 & 1 & \\
\hline V00196 & $\mathrm{AD} 0025$ & & 0 \\
\hline V00204 & $\mathrm{AD} 0013$ & INDEFINITE & \\
\hline V00231 & $\mathrm{AD} 0021$ & PARK & \\
\hline V00240 & AD0029 & ALTERNATE & \\
\hline V00241 & AD0029 & UNSPECIFIED & \\
\hline
\end{tabular}

This table contains a record for each unique attribute value assigned (by the Attribute Assignment table) to ore or more feature objects or to other attribute values. The ADID field points to an Attribute Definition record indicating how to read the value. 
Name/Text Table (in its entirety):

$\begin{array}{lll}\text { TKEY } & \text { ADID } & \text { TEXT } \\ \text { T00001 } & \text { AD0002 } & \text { BISHOP AVENUE } \\ \text { T00002 } & \text { AD0002 } & \text { \#UNKNOWN } \\ \text { T00003 } & \text { AD0002 } & \text { UNITED STATES OF AMERICA } \\ \text { T00004 } & \text { AD0002 } & \text { SPOONER COLLEGE } \\ \text { T00010 } & \text { AD0002 } & \text { LANE SPRINGS STATE PARK } \\ \text { T00011 } & \text { AD0002 } & \text { EAST FORK LAKE } \\ \text { T00012 } & \text { AD0002 } & \text { MEMORIAL DRIVE } \\ \text { T00014 } & \text { AD0030 } & \text { From the County Engineer } \\ \text { T00015 } & \text { AD0030 } & \text { From local residents and businessmen } \\ \text { T00016 } & \text { AD0030 } & \text { From the Highway Department } \\ \text { T00017 } & \text { AD0030 } & \text { From Park Admin Office: trail is part of the park. } \\ \text { T00152 } & \text { AD0002 } & \text { MIDDLE FORK } \\ \text { T00158 } & \text { AD0002 } & \text { EAST FORK } \\ \text { T00160 } & \text { AD0002 } & \text { MILL CREEK } \\ \text { T00173 } & \text { AD0002 } & \text { MISSOURI } \\ \text { T00175 } & \text { AD0002 } & \text { PHELPS } \\ \text { T00177 } & \text { AD0002 } & \text { DENT } \\ \text { T00187 } & \text { AD0002 } & \text { PEA RIDGE } \\ \text { T00188 } & \text { AD0002 } & \text { \#UNSPECIFIED } \\ \text { T00244 } & \text { AD0002 } & \text { \#NOT APPLICABLE }\end{array}$

This table contains a record (with ADID = "AD0002") for each unique name assigned (by the Attribute Assignment talle) to a feature object. Special records with the contents of the TEXT field beginning with "\#" are used to indicate the status of assigning a name, rather than a name itself (an actual name is not recorded).

This table also contains comments (ADID = "AD0030") which may be assigned to any nontopological "object." In the DLG-E example data set, three such records indicate the source of an attribute value assignment, and a fourth comments a relationship tuple record. 


\section{ROAD AND UNDERPASS EXAMPLE}

U.S. 63 is a feature instance running north-south through the source graphic. The contrived field notes indicate that the route is actually Alternate U.S. 63. This instance is obviously a road, but along its length, some of its attribrte values (e.g., number of lanes) change. Each of the coherent parts of Alternate U.S. 63 with consistent attribute values is therefore recorded as an individual road feature instance. There are four such road instances, with object ID's F00001 through F00004. Feature object F00005, composed of F00001 through F00004 (the Relationship Tuple set with RKEY = "R00005" tells us this), represents the entire length of Alternate U.S. 63. Since the representation rules for "Poad" $(E K E Y=$ "E00002") dictate that a road instance can only be composed of chains or areas, however, F00005 is classified as a "Named Feature" (EKEY = "E00001") instance instead.

The first road feature object (F00001) of Alternate U.S. 63 is also related to other feature objects through Rel rionship Tuple records (with RKEYs = "R00064" and "R00065" directly to F00057, F00058, F00006, and F00007, and with RKEY = "R00008" indirectly to F00008). All Feature Object records related to this example then are as follcws:

Feature Object Table (road and underpass example):

\begin{tabular}{|c|c|c|c|c|c|c|c|c|c|}
\hline FKEY & PEID & DIMN & COMP & CNTG & NREL & NRTR & NELB & NAVS & NNTS \\
\hline F00001 & $\mathrm{E} 00002$ & 1 & $\mathrm{C}$ & Y & 1 & 4 & 1 & 6 & 1 \\
\hline F00002 & $\mathrm{E} 00002$ & 1 & C & Y & 1 & 1 & 1 & 6 & 1 \\
\hline F00003 & $\mathrm{E} 00002$ & 1 & C & Y & 1 & 1 & 1 & 6 & 1 \\
\hline F00004 & $\mathrm{E} 00002$ & 1 & C & $\mathrm{Y}$ & 1 & 1 & 1 & 6 & 1 \\
\hline F00005 & $\mathrm{E} 00001$ & 1 & $\mathrm{~F}$ & $\mathrm{Y}$ & 1 & 4 & 1 & 0 & 1 \\
\hline F00006 & $\mathrm{E} 00002$ & 1 & C & $\mathrm{Y}$ & 1 & 7 & 1 & 5 & 1 \\
\hline F00007 & $\mathrm{E} 00002$ & 1 & C & $Y$ & 1 & 7 & 1 & 5 & 1 \\
\hline F00008 & E00001 & 1 & F & $\mathrm{N}$ & 1 & 2 & 1 & 3 & 0 \\
\hline F00057 & $\mathrm{E} 00021$ & 0 & $\mathrm{~N}$ & $\mathrm{Y}$ & 2 & 3 & 1 & 0 & 0 \\
\hline F00058 & $\mathrm{E} 00021$ & 0 & $\mathrm{~N}$ & $\mathrm{Y}$ & 2 & 3 & 1 & 0 & 0 \\
\hline
\end{tabular}

F00005 and F00008 are both one-dimensional "Named Features" consisting of individual "Road" feature object- F00005 is contiguous and is composed of an ordered set (but with no ground significance to the order). Its one-dimersional road feature objects (F00001 through F00004) consist of ordered sets of chains (also with no ground significance to the order). F00008 on the other hand, representing I-44, is composed of a noncontiguous, unordered set consisting of F00n06 (eastbound lanes) and F00007 (west-bound lanes). Each of these objects consists of an ordered set of chains, with ground significance (traffic travels in the direction specified by the order of the coordinates of the chains, as modified by the FLAG field). F00057 and F00058 are zero-dimensional "Underpass" features (EKEY = "E00021") each compcred of a node. F00001 is vertically related to (placed above) F00006 and F00007 at these underpass features (U.S. 63 passes over I-44). The Relationship Tuple records related to this example then are:

Relationship Tuple Table (Road and Underpass Example):

$\begin{array}{llllcc}\text { RKEY } & \text { RDID } & \text { E1ID } & \text { E2ID } & \text { FLAG } & \text { SEQN } \\ \text { R00001 } & \text { RD0006 } & \text { F00001 } & \text { C00007 } & + & 1 \\ \text { R00001 } & \text { RD0006 } & \text { F00001 } & \text { C00011 } & + & 2 \\ \text { R00001 } & \text { RD0006 } & \text { F00001 } & \text { C00040 } & + & 3 \\ \text { R00001 } & \text { RD0006 } & \text { F00001 } & \text { C00047 } & - & 4 \\ \text { R00002 } & \text { RD0006 } & \text { F00002 } & \text { C00062 } & - & 1 \\ \text { R00003 } & \text { RD0006 } & \text { F00003 } & \text { C00073 } & + & 1 \\ \text { R00004 } & \text { RD0006 } & \text { F00004 } & \text { C00077 } & - & 1 \\ \text { R00005 } & \text { RD0007 } & \text { F00005 } & \text { F00001 } & + & 1 \\ \text { R00005 } & \text { RD0007 } & \text { F00005 } & \text { F00002 } & + & 2 \\ \text { R00005 } & \text { RD0007 } & \text { F00005 } & \text { F00003 } & + & 3 \\ \text { R00005 } & \text { RD0007 } & \text { F00005 } & \text { F00004 } & + & 4 \\ \text { R00006 } & \text { RD0008 } & \text { F00006 } & \text { C00012 } & + & 1 \\ \text { R00006 } & \text { RD0008 } & \text { F00006 } & \text { C00018 } & + & 2 \\ \text { R00006 } & \text { RD0008 } & \text { F00006 } & \text { C00020 } & - & 3 \\ \text { R00006 } & \text { RD0008 } & \text { F00006 } & \text { C00026 } & + & 4 \\ \text { R00006 } & \text { RD0008 } & \text { F00006 } & \text { C00029 } & - & 5 \\ \text { R00006 } & \text { RD0008 } & \text { F00006 } & \text { C00031 } & - & 6 \\ \text { R00006 } & \text { RD0008 } & \text { F00006 } & \text { C00032 } & - & 7 \\ \text { R00007 } & \text { RD0008 } & \text { F00007 } & \text { C00027 } & + & 1\end{array}$




\begin{tabular}{llllll} 
RKEY & RDID & E1ID & E2ID & FLAG & SEQN \\
\cline { 3 - 4 } R00007 & RD0008 & F00007 & C00024 & + & 2 \\
R00007 & RD0008 & F00007 & C00016 & + & 4 \\
R00007 & RD0008 & F00007 & C00022 & + & 3 \\
R00007 & RD0008 & F00007 & C00014 & - & 5 \\
R00007 & RD0008 & F00007 & C00010 & + & 6 \\
R00007 & RD0008 & F00007 & C00008 & + & 7 \\
R00008 & RD0005 & F00008 & F00006 & & 1 \\
R00008 & RD0005 & F00008 & F00007 & & 2 \\
R00060 & RD0002 & F00057 & N00012 & & \\
R00061 & RD0002 & F00058 & N00016 & \\
R00064 & RD0011 & F00057 & F00001 & 1 \\
R00064 & RD0011 & F00057 & F00007 & & 2 \\
R00065 & RD0011 & F00058 & F00001 & & 1 \\
R00065 & RD0011 & F00058 & F00006 & & 2
\end{tabular}

Specifically, to trace the attribution of Alternate U.S. 63 (F00005):

1. S00010 assigns T00001, the name "Bishop Avenue"

2. Names (AD0002) and "Number of Lanes" (AD0007) change over the length of Alternate U.S. 63, so these attributes are valued at the road feature instance level represented by objects F00001 through F00004.

a) V00007, valuing "Number of Lanes" at 2, is assigned to F00001, F00003, and F00004 (by S00008, S00025, and S00033 respectively).

b) V00014, valuing "Number of Lanes" at 4, is assigned to F00002 by S00017.

c) F00002 is named "Memorial Drive" (S00011 assigning T00012). S00271 identifies the source for naming F00002 "Memorial Drive" by assigning a comment (T00015--"From local residents and businessmen") to S00011.

3. The following attribute values are assigned to the road feature instances (objects F00001 through F00004):

a) V00001, which values "Access Restriction" (AD0001) as "None."

b) V00004, which values "Operational Status" (AD0004) as "Operational."

c) V00005, which values "Road Class" as "1st."

d) V00006, which values "Traffic Direction" as "Two way."

e) V00031, which values "Route Designator" as "US63."

4. S00261 further attributes V00031 ("US63") by assigning V00240, which values "Route Type" (AD0029) as "Alternate."

5. S00273 further comments on the source of "Alternate" by assigning T00016 ("From the Highway Department") tc S00261.

The Attribute Assignment records listed below also include records for feature objects representing I-44 (F00006, F00007, and F00008) and for the two Underpass features (no attribute values are assigned, just the E00021 entity label). The Attribute Assignment records related to this example then are as follows:

Attribute Assignment Table (Road and Underpass Example):

[Note: to save space, the records are listed here in two columns; there are only three fields per record (SEQN is not used).]

$\begin{array}{llllll}\text { SKEY } & \text { EFID } & \text { AFID } & \text { SKEY } & \text { EFID } & \text { AFID } \\ \text { S00001 } & \text { F00001 } & \text { E00002 } & \text { S00026 } & \text { F00004 } & \text { E00002 } \\ \text { S00002 } & \text { F00001 } & \text { V00001 } & \text { S00028 } & \text { F00004 } & \text { T00002 } \\ \text { S00003 } & \text { F00001 } & \text { T00002 } & \text { S00033 } & \text { F00004 } & \text { V00007 } \\ \text { S00005 } & \text { F00001 } & \text { V00004 } & \text { S00034 } & \text { F00005 } & \text { E00001 } \\ \text { S00006 } & \text { F00001 } & \text { V00005 } & \text { S00035 } & \text { F00001 } & \text { V00031 } \\ \text { S00007 } & \text { F00001 } & \text { V00006 } & \text { S00036 } & \text { F00006 } & \text { E00002 } \\ \text { S00008 } & \text { F00001 } & \text { V00007 } & \text { S00037 } & \text { F00006 } & \text { V00001 } \\ \text { S00009 } & \text { F00002 } & \text { E00002 } & \text { S00038 } & \text { F00006 } & \text { T00002 } \\ \text { S00010 } & \text { F00005 } & \text { T00001 } & \text { S00040 } & \text { F00006 } & \text { V00004 } \\ \text { S00011 } & \text { F00002 } & \text { T00012 } & \text { S00041 } & \text { F00006 } & \text { V00005 } \\ \text { S00017 } & \text { F00002 } & \text { V00014 } & \text { S00042 } & \text { F00006 } & \text { V00041 } \\ \text { S00018 } & \text { F00003 } & \text { E00002 } & \text { S00043 } & \text { F00006 } & \text { V00007 } \\ \text { S00020 } & \text { F00003 } & \text { T00002 } & \text { S00044 } & \text { F00007 } & \text { E00002 } \\ \text { S00025 } & \text { F00003 } & \text { V00007 } & \text { S00046 } & \text { F00007 } & \text { T00002 }\end{array}$




$\begin{array}{llllll}\text { SKEY } & \text { EFID } & \text { AFID } & \text { SKEY } & \text { EFID } & \text { AFID } \\ \text { S00050 } & \text { F00007 } & \text { V00041 } & \text { S00281 } & \text { F00002 } & \text { V00006 } \\ \text { S00051 } & \text { F00007 } & \text { V00007 } & \text { S00282 } & \text { F00002 } & \text { V00031 } \\ \text { S00052 } & \text { F00008 } & \text { E00001 } & S 00283 & \text { F00003 } & \text { V00001 } \\ \text { S00053 } & \text { F00008 } & \text { V00052 } & \text { S00284 } & \text { F00003 } & \text { V00004 } \\ \text { S00248 } & \text { F00057 } & \text { E00021 } & \text { S00285 } & \text { F00003 } & \text { V00005 } \\ \text { S00249 } & \text { F00058 } & \text { E00021 } & S 00286 & \text { F00003 } & \text { V00006 } \\ \text { S00261 } & \text { V00031 } & \text { V00240 } & S 00287 & \text { F00003 } & \text { V00031 } \\ \text { S00262 } & \text { V00052 } & \text { V00241 } & S 00288 & \text { F00004 } & \text { V00001 } \\ \text { S00271 } & \text { S00011 } & \text { T00015 } & S 00289 & \text { F00004 } & \text { V00004 } \\ \text { S00272 } & \text { S00261 } & \text { T00016 } & S 00290 & \text { F00004 } & \text { V00005 } \\ \text { S00274 } & \text { F00008 } & \text { V00006 } & \text { S00291 } & \text { F00004 } & \text { V00006 } \\ \text { S00275 } & \text { F00008 } & \text { V00014 } & S 00292 & \text { F00004 } & \text { V00031 } \\ \text { S00278 } & \text { F00002 } & \text { V00001 } & S 00293 & \text { F00007 } & \text { V00001 } \\ \text { S00279 } & \text { F00002 } & \text { V00004 } & S 00294 & \text { F00007 } & \text { V00004 } \\ \text { S00280 } & \text { F00002 } & \text { V00005 } & \text { S00295 } & \text { F00007 } & \text { V00005 }\end{array}$

\section{STREAM/RIVER, SHORELINE, AND JUNCTION EXAMPLE}

Mill Creek is a "Stream/River" (EKEY = "E00004") feature instance discernible on the source graphic, beginning north of I-44 at the discharge of an intermittent pond. It proceeds as an intermittent stream until a point near Pea Ridgo. As Mill Creek continues southward, it becomes wide enough to be displayed as an areal feature (a water body bounded by a "Shoreline" (EKEY = "E00008")). This water body flows "out" of the map area at the south neatline. The indication of the direction of stream flow is carried by the modified (by the FLAG field) order of coordinates of the chains comprising the stream/river feature objects. When a stream is represented by an area, however, a "Junction" (EKEY = "EN0009") feature object is often required to participate with the areal stream object in a "Flows to/flows from" relationship.

The following Feature Object records relate to this Mill Creek example:

Feature Object Table:

\begin{tabular}{|c|c|c|c|c|c|c|c|c|c|}
\hline FKEY & PEID & DIMN & COMP & CNTG & NREL & NRTR & NELB & NAVS & NNTS \\
\hline $\mathrm{F} 00022$ & E00004 & 2 & A & Y & 3 & 4 & 1 & 1 & 0 \\
\hline F00023 & E00004 & 1 & C & $\mathrm{Y}$ & 1 & 2 & 1 & 1 & 0 \\
\hline F00024 & $\mathrm{E} 00004$ & 1 & C & $\mathrm{Y}$ & 1 & 1 & 1 & 1 & 0 \\
\hline F00025 & E00004 & 1 & C & $\mathrm{Y}$ & 1 & 1 & 1 & 1 & 0 \\
\hline F00026 & E00004 & 1 & C & $\mathrm{Y}$ & 1 & 4 & 1 & 1 & 0 \\
\hline F00032 & $\mathrm{E} 00001$ & M & $\mathrm{F}$ & $\mathrm{Y}$ & 1 & 5 & 1 & 0 & 1 \\
\hline F00036 & $\mathrm{E} 00009$ & 1 & C & $\mathrm{Y}$ & 1 & 1 & 1 & 0 & 0 \\
\hline F00037 & E00008 & $i$ & C & $\mathrm{Y}$ & 1 & 4 & 1 & 1 & 0 \\
\hline
\end{tabular}

Feature Object F00032, classified as a "Named Feature" (EKEY = "E00001"), represents all of Mill Creek within the source map. It is composed of five stream/river feature objects differentiated from one another based upon (a) composition (chains vs. areas), (b) attribute values (perennial vs. intermittent), and (c) junctions with other stream/river nbjects. F00022 represents the areal part of Mill Creek; F00023, the linear part downstream from the junction with East Fork; F00024, the perennial part upstream from East Fork; F00025, the intermittent part downstream from Middle For': and F00026 represents Mill Creek upstream from Middle Fork.

Feature Object F00022, the areal part of Mill Creek, is composed of two DLG-O areas. It is bounded, to the right, by (relationship RD0010) feature object F00037, representing a shoreline feature instance composed of ordered chains. F00022 also flows into (relationship RD0013) object F00036, representing a junction feature instance.

Objects F00023, F00024, F00025, and F00026 are each composed of an ordered set of chains (actually F00024 and F00025 consist of only one chain each). The order of the coordinates of these chains, as modified by the FLAG field ("+" or "-"), represents the direction of stream flow. 
The Relationship Tuple records related to this example are as follows:

Relationship Tuple Table (Stream/River, etc., example):

\begin{tabular}{llllll} 
RKEY & RDID & E1ID & E2ID & FLAG & SEQN \\
\hline 900022 & RD0004 & F00022 & A00037 & & 1 \\
R00022 & RD0004 & F00022 & A00038 & & 2 \\
R00023 & RD0008 & F00023 & C00093 & - & 1 \\
R00023 & RD0008 & F00023 & C00065 & + & 2 \\
R00024 & RD0008 & F00024 & C00057 & + & \\
R00025 & RD0008 & F00025 & C00043 & - & \\
R00026 & RD0008 & F00026 & C00038 & + & 1 \\
R00026 & RD0008 & F00026 & C00034 & + & 2 \\
R00026 & RD0008 & F00026 & C00017 & + & 3 \\
R00026 & RD0008 & F00026 & C00009 & + & 4 \\
R00032 & RD0009 & F00032 & F00022 & - & 1 \\
R00032 & RD0009 & F00032 & F00023 & - & 2 \\
R00032 & RD0009 & F00032 & F00024 & - & 3 \\
R00032 & RD0009 & F00032 & F00025 & - & 4 \\
R00032 & RD0009 & F00032 & F00026 & - & 5 \\
R00037 & RD0006 & F00036 & C00108 & + & 1 \\
R00038 & RD0013 & F00022 & F00036 & & \\
R00039 & RD0006 & F00037 & C00078 & - & 1 \\
R00039 & RD0006 & F00037 & C00071 & + & 2 \\
R00039 & RD0006 & F00037 & C00102 & - & 3 \\
R00039 & RD0006 & F00037 & C00107 & + & 4 \\
R00040 & RD0010 & F00022 & F00037 & + & \\
& & & & &
\end{tabular}

The attribution of Mill Creek, by Attribute Assignment records, is as follows:

1. F00032 is named "Mill Creek" by S00177 assigning T00160.

2. Through S00140, S00144, and S00148, respectively, F00022, F00023, and F00024 are assigned V00141, which vilues "Hydrographic category" (AD0009) as "Perennial."

3. Through S00152 and S00156, F00025 and F00026 are assigned V00147, which values "Hydrographic category" (AD0009) as "Intermittent."

4. F00037, representing the shoreline of F00022, is assigned (by S00189) V00166, which values "Delineation Status" (AD0013) as "Definite."

Attribute Assignment Table (Stream/River, etc., example, in two columns):

$\begin{array}{llllll}\text { SKEY } & \text { EFID } & \text { AFID } & \text { SKEY } & \text { EFID } & \text { AFID } \\ \text { S00139 } & \text { F00022 } & \text { E00004 } & \text { S00152 } & \text { F00025 } & \text { V00147 } \\ \text { S00140 } & \text { F00022 } & \text { V00141 } & \text { S00155 } & \text { F00026 } & \text { E00004 } \\ \text { S00143 } & \text { F00023 } & \text { E00004 } & \text { S00156 } & \text { F00026 } & \text { V00147 } \\ \text { S00144 } & \text { F00023 } & \text { V00141 } & \text { S00176 } & \text { F00032 } & \text { E00001 } \\ \text { S00147 } & \text { F00024 } & \text { E00004 } & \text { S00177 } & \text { F00032 } & \text { T00160 } \\ \text { S00148 } & \text { F00024 } & \text { V00141 } & \text { S00187 } & \text { F00036 } & \text { E00009 } \\ \text { S00151 } & \text { F00025 } & \text { E00004 } & \text { S00188 } & \text { F00037 } & \text { E00008 } \\ & & & \text { S00189 } & \text { F00037 } & \text { V00166 }\end{array}$

\section{RESERVATION AND BOUNDARY LINE EXAMPLE}

Lane Spring State Park is a feature instance which illustrates some interesting cases. The park is composed of two separate areal parts (one area is in the middle of the map, and the second area, labeled "LS SP," is at the lower edg? of the map). These two areas are connected by a trail which is also part of the park (see the contrived field notes). The trail and the two areas are each represented by a "Reservation" (EKEY = "E00018") feature object. Lane Spring State Park as a whole is represented by a "Named Feature" (EKEY = "E00001") object composed of the three reservation objects. The trail is also represented by a separate "Trail" (EKEY = "E00022") object. It is debatable as to whethe- or not the additional reservation object was needed for the trail, or if Lane Spring State Park could be composed of the two areal reservation objects and the trail object directly. 
As represented per DLG-E specifications (section 3), a reservation feature instance is bounded by a "Boundary Line" $(E K E Y=$ "E00024") feature. In this case, the boundary of Lane Spring State Park is not represented by a sin?le feature object (either basic or higher level) because an attribute value changes, it is not contiguous, and there is no name attribute. The park is thus bounded by three boundary line feature objects.

The following eight feature object records are related to this example:

Feature Object Table (Reservation and Boundary Line example):

\begin{tabular}{|c|c|c|c|c|c|c|c|c|c|}
\hline FKEY & PEID & DIMN & COMP & CNTG & NREL & NRTR & NELB & NAVS & NNTS \\
\hline F00018 & $\mathrm{E} 00022$ & 1 & C & $Y$ & 1 & 1 & 1 & 2 & 1 \\
\hline F00048 & E00018 & 2 & A & Y & 2 & 12 & 1 & 2 & 0 \\
\hline F00049 & E00018 & 2 & A & $Y$ & 2 & 2 & 1 & 2 & 0 \\
\hline F00050 & $\mathrm{E} 00001$ & $\mathbf{M}$ & F & $Y$ & 1 & 3 & 1 & 0 & 1 \\
\hline F00061 & E00024 & 1 & C & $\mathrm{Y}$ & 1 & 5 & 1 & 1 & 0 \\
\hline F00066 & $\mathrm{E} 00024$ & 1 & $\mathrm{C}$ & $Y$ & 1 & 1 & 1 & 1 & 0 \\
\hline F00075 & E00018 & 1 & C & $\mathrm{Y}$ & 1 & 1 & 1 & 2 & 1 \\
\hline F00076 & E00024 & 1 & $\mathrm{C}$ & $Y$ & 1 & 16 & 1 & 1 & 0 \\
\hline
\end{tabular}

Feature object F00050 represents Lane Spring State Park. It is composed of a contiguous set of three reservation feature objects (F00048, F00049, and F00075). F00048 and F00049 are each composed of a contiguous set of DLG areas (ten areas for F00048 and only one for F00049). F00075 is composed of one chain. That same chain (C00075) conprises feature object F00018, representing a trail feature instance. F00048 is bounded by two boundary line objects (FN0066 and F00076), differentiated by the attribute "Delineation Status" (AD0013). F00049 is bounded by object F00061. Each boundary line object (F00061, F00066, and F00076) is composed of a contiguous ordered set of chains. Note that there is no ground significance to the composition order of the coordinates of the boundary objects (as defined by FLAG modified chain coordinate order), BUT when these objects participate in a "Bounded by/Bounds" (RD0010) relationship, the direction does have ground significance that indicates to which side of the boundary the bounded feature instance lies.

The following Relationship Tuple records relate to this example:

Relationship Tuple Table (Reservation and Boundary Line example):

$\begin{array}{llllll}\text { RKEY } & \text { RDID } & \text { E1ID } & \text { E2ID } & \text { FLAG } & \text { SEON } \\ \text { R00018 } & \text { RD0008 } & \text { F00018 } & \text { C00075 } & + & \\ \text { R00051 } & \text { RD0004 } & \text { F00048 } & \text { A00026 } & & 1 \\ \text { R00051 } & \text { RD0004 } & \text { F00048 } & \text { A00024 } & & 2 \\ \text { R00051 } & \text { RD0004 } & \text { F00048 } & \text { A00017 } & & 3 \\ \text { R00051 } & \text { RD0004 } & \text { F00048 } & \text { A00020 } & & 4 \\ \text { R00051 } & \text { RD0004 } & \text { F00048 } & \text { A00031 } & & 5 \\ \text { R00051 } & \text { RD0004 } & \text { F00048 } & \text { A00032 } & & 6 \\ \text { R00051 } & \text { RD0004 } & \text { F00048 } & \text { A00023 } & & 7 \\ \text { R00051 } & \text { RD0004 } & \text { F00048 } & \text { A00025 } & & 8 \\ 2 \text { R00051 } & \text { RD0004 } & \text { F00048 } & \text { A00029 } & & 9 \\ \text { R00051 } & \text { RD0004 } & \text { F00048 } & \text { A00028 } & & 10 \\ \text { R00052 } & \text { RD0004 } & \text { F00049 } & \text { A00039 } & & \\ \text { R00053 } & \text { RD0005 } & \text { F00050 } & \text { F00048 } & & 1 \\ \text { R00053 } & \text { RD0005 } & \text { F00050 } & \text { F00049 } & & 2 \\ \text { R00053 } & \text { RD0005 } & \text { F00050 } & \text { F00075 } & & 3 \\ \text { R00068 } & \text { RD0006 } & \text { F00061 } & \text { C00077 } & + & 1 \\ \text { R00068 } & \text { RD0006 } & \text { F00061 } & \text { C00076 } & + & 2 \\ \text { R00068 } & \text { RD0006 } & \text { F00061 } & \text { C00074 } & + & 3 \\ \text { R00068 } & \text { RD0006 } & \text { F00061 } & \text { C00072 } & - & 4 \\ \text { R00068 } & \text { RD0006 } & \text { F00061 } & \text { C00078 } & + & 5 \\ \text { R00073 } & \text { RD0006 } & \text { F00066 } & \text { C00063 } & + & \\ \text { R00081 } & \text { RD0010 } & \text { F00048 } & \text { F00066 } & + & 1 \\ \text { R00081 } & \text { RD0010 } & \text { F00048 } & \text { F00076 } & + & 2 \\ \text { R00082 } & \text { RD0010 } & \text { F00049 } & \text { F00061 } & + & \\ \text { R00088 } & \text { RD0003 } & \text { F00075 } & \text { C00075 } & & \\ \text { R00089 } & \text { RD0006 } & \text { F00076 } & \text { C00041 } & + & 1 \\ \text { R00089 } & \text { RD0006 } & \text { F00076 } & \text { C00039 } & - & 2\end{array}$




\begin{tabular}{llllcc} 
RKEY & RDID & E1ID & E2ID & FLAG & SEQN \\
\cline { 3 - 5 } R00089 & RD0006 & F00076 & C00033 & + & 3 \\
R00089 & RD0006 & F00076 & C00026 & + & 4 \\
R00089 & RD0006 & F00076 & C00029 & - & 5 \\
R00089 & RD0006 & F00076 & C00036 & + & 6 \\
R00089 & RD0006 & F00076 & C00044 & + & 7 \\
R00089 & RD0006 & F00076 & C00049 & - & 8 \\
R00089 & RD0006 & F00076 & C00055 & - & 9 \\
R00089 & RD0006 & F00076 & C00060 & - & 10 \\
R00089 & RD0006 & F00076 & C00068 & - & 11 \\
R00089 & RD0006 & F00076 & C00091 & - & 12 \\
R00089 & RD0006 & F00076 & C00090 & - & 13 \\
R00089 & RD0006 & F00076 & C00089 & - & 14 \\
R00089 & RD0006 & F00076 & C00066 & - & 15 \\
R00089 & RD0006 & F00076 & C00064 & - & 16
\end{tabular}

The attribution of F00050, the entire state park, is implemented as follows:

1. S00227 assigns T00010 (Name text = "Lane Spring State Park").

2. S00273 assigns a comment (T00017, "From Park Admin. Office: trail is part of the park") to R00088, the Relationship Tuple record which defines the composition of F00075, the trail part of F00050.

The attribution of the basic park feature instances (F00048, F00049, F00075) is implemented as follows:

1. S00224, S00296, S00298 assigns V00231, which values "Reservation Type" (AD0021) as "Park."

2. S00225, S00297, S00299 assigns V00190, which values "Reservation Use Status" (AD0022) as "State."

The attribution of the boundary line objects is implemented as follows:

1. S00253 and S00266 assign V00166, which values "Delineation Status" (AD0013) as "Definite," to F00061 and F00076 respectively.

2. S00255 assigns V00204, which values "Delineation Status" (AD0013) as "Indefinite," to F00061.

The following Attribute Assignment records relate to this example:

Attribute Assignment Table (Reservation and Boundary Line example):

$\begin{array}{lllllc}\text { SKEY } & \text { EFID } & \text { AFID } & \text { SKEY } & \text { EFID } & \text { AFID } \\ \text { S00104 } & \text { F00018 } & \text { E00022 } & \text { S00253 } & \text { F00061 } & \text { V00166 } \\ \text { S00105 } & \text { F00018 } & \text { T00002 } & \text { S00254 } & \text { F00066 } & \text { E00024 } \\ \text { S00106 } & \text { F00018 } & \text { V00121 } & \text { S00255 } & \text { F00066 } & \text { V00204 } \\ \text { S00107 } & \text { F00018 } & \text { V00006 } & \text { S00257 } & \text { F00075 } & \text { E00018 } \\ \text { S00218 } & \text { F00048 } & \text { E00018 } & \text { S00265 } & \text { F00076 } & \text { E00024 } \\ \text { S00222 } & \text { F00049 } & \text { E00018 } & \text { S00266 } & \text { F00076 } & \text { V00166 } \\ \text { S00224 } & \text { F00048 } & \text { V00231 } & \text { S00273 } & \text { R00088 } & \text { T00017 } \\ \text { S00225 } & \text { F00048 } & \text { V00190 } & \text { S00296 } & \text { F00049 } & \text { V00231 } \\ \text { S00226 } & \text { F00050 } & \text { E00001 } & \text { S00297 } & \text { F00049 } & \text { V00190 } \\ \text { S00227 } & \text { F00050 } & \text { T00010 } & \text { S00298 } & \text { F00075 } & \text { V00231 } \\ \text { S00252 } & \text { F00061 } & \text { E00024 } & \text { S00299 } & \text { F00075 } & \text { V00190 }\end{array}$




\section{APPENDIX C \\ DLG-E DATA MODEL IMPLEMENTED WITHIN THE SPATIAL DATA TRANSFER SPECIFICATION}

Section

1. Data model component mappings $\mathbf{C}-\mathbf{1}$

2. Mapping DLG-E to an SDTS data structure C-2 


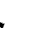




\section{APPENDIX C \\ DLG-E DATA MODEL IMPLEMENTED WITHIN THE SPATIAL DATA TRANSFER SPECIFICATION}

This appendix describes how the components of the DLG-E data model may be implemented within SDTS. Since SDT? is still undergoing review, several implementation issues are yet "to be resolved" (TBR). Therefore, the content of this appendix should not be considered to be final.

In the section of the main text entitled "A New Design," a framework for translating a set of data requirements into da+a model/structure/format constructs was presented. Levels were defined which can serve as steps in the translation procers. The first two levels, defining a data reality and a data model are covered in the section "Concepts of the DLG-E Design." This section, in conjunction with SDTS, is the next step in completing the translation process through the remaining two levels, data structure and file structures.

Before proceeding with the data structure step, the implementation of DLG-E within SDTS requires an initial "data mapping" step at the data model component level. This process must occur for any agency or user-defined data model or structure to conform to SDTS. SDTS has its own set of data model components. The components of DLG-E must first be mapped into SDTS model components. Only then can an SDTS data structure and file structure be selected.

\section{DATA MODEL COMPONENT MAPPINGS}

For the most part, DLG-E data model components have direct counterparts in SDTS. SDTS is more comprehensive in that it deals with graphic vector data and raster data, as well as topologically structured vector data. The DLG-E model is a clear topological vector data subset of SDTS. In only a few cases do the definitions of SDTS components need to be qualified to match DLG-E.

The data mappings outlined here do not include global (that is, header) data. The DLG-E data model does not explici ${ }^{\text {tly }}$ include them. Following the data model mappings, actual file structures will be outlined that will include SDTS globa! modules.

Summary of data mapping equivalence table, DLG-E and SDTS model components:

\section{DLG-E Objects}

Feature object

Linear graph/spatial objects
Node
Chain
Polygon

Point

\section{DLG-E Attributes}

Locational

Nonlocational of feature object of attribute value

\section{DLG-E Relationships}

Topological

Point-within-area

All others

\section{SDTS Objects}

Feature implemented as a composite object

Node

Chain

T-Polygon

Entity point (qualified as wholely contained within one area) - TBR

\section{SDTS Attributes}

Location coordinates (often termed spatial addresses)

Attribute related to composite object

Secondary attributes

\section{$\underline{\text { SDTS Components }}$}

Attribute with polygon foreign ID as attribute value - TBR

Included in node, chain, and t-polygon object definitions and defined relations 
Nontopological

Feature composed of element

All others
Composite-composed of-element relation; element ID's in the composite object record

TBR

\section{MAPPING DLG-E TO AN SDTS DATA STRUCTURE}

SDTS has two possible data structure forms from which to choose: vector and raster. Because the DLG-E model is fundamentally vector, that form will be outlined here.

\section{IMPLEMENTING DLG-E WITHIN THE SDTS VECTOR FORM}

The following table summarizes the modules and vector-based object representations that might be used in the DLG-E Implementation.

\begin{tabular}{lll} 
Module Type & Object Representation & Representation \\
\cline { 2 - 3 } Point-node & $\begin{array}{l}\text { Entity point } \\
\text { Area point } \\
\text { Node }\end{array}$ & PG (TBR) \\
Line & PA \\
Polygon & PN & LE \\
Composite & Composite chain & PC \\
Attribute primary & $\begin{array}{l}\text { Attribute primary module defines the primary } \\
\text { attributes associated with a spatial element }\end{array}$ & \\
or object. & FF \\
Attribute secondary & $\begin{array}{l}\text { Attribute secondary module defines the } \\
\text { secondary attributes associated with values } \\
\text { of primary atributes. }\end{array}$ &
\end{tabular}

The headings in the sections below have the following meaning:

MNEMONIC: Four-character mnemonic. The mnemonic will be left adjusted in the column for field name: and right adjusted for subfield names. Mnemonics for primary field names will be flagged with an "*."

FULL NAME: The full name of the field or subfield as used in the SDTS module specifications.

\section{DLG-E Point Within the SDTS Point-Node Module}

FIELD/SUBFIELD

$\begin{array}{cl}\text { MNEMONIC } & \text { FULL NAME (plus description if appropriate) } \\ \text { *PNTS } & \text { Point-node } \\ \text { OBRP } & \text { Object representation ("PG" Entity point - TBR) } \\ \text { OBID } & \text { Object ID } \\ \text { SADR } & \text { Spatial address (locational coordinates) } \\ \text { ARID } & \text { Area ID (TBR) }\end{array}$




\section{DLG-E Node Within the SDTS Point-Node Module}

FIELD/SUBFIELD

\section{MNEMONIC}

*PNTS

OBRP

OBID

SADR

LNID

FIELD/SUBFIELD

\section{MNEMONIC}

*LINE

OBRP

OBID

PIDL

PIDR

SNID

ENID

SADR

FIELD/SUBFIELD

MNEMONIC

*POLY

OBRP

OBID

LFID

FULL NAME (plus description if appropriate)

Point-node

Object representation ("PN" node)

Object ID

Spatial address (locational coordinates)

Line ID (This is a repeating field containing the ID's of the chains bounded by the node.)

\section{DLG-E Chain as Carried Within the SDTS Line Module}

\section{FULL NAME (plus description if appropriate)}

Line

Object representation ("LE" complete chain)

Object ID

Polygon ID left

Polygon ID right

Startnode ID

Endnode ID

Spatial address (This is a repeating field containing the coordinates of the chain. The order of the instances of this field indicates the construction of the line in terms of vertices.)

\section{DLG-E Polygon as Carried Within the SDTS Polygon Module}

FULL NAME (plus description if appropriate)

Polygon

Object representation ("PC" T-polygon)

Object ID

Chain foreign ID (This is a repeating field for carrying the chain ID's bounding the area.)

\section{DLG-E Feature Object as Carried Within the SDTS Composite Module}

FIELD/SUBFIELD

MNEMONIC

*COMP

OBRP

OBID

ATID

FRID

*ATPR
FULL NAME (plus description if appropriate)

Composite

Object representation ("FF")

Object ID

Attribute ID (This is a repeating field containing the ID's of the primary attribute records associated with this feature object.)

Foreign ID (This is a repeating field containing the ID's of the objects [other features, points, nodes, chains, and/or area] that are a part of this feature.)

Attribute Primary (This is a separate module defining the primary attributes associated with, in this case, a feature object.) 





\section{SELECTED SERIES OF U.S. GEOLOGICAL SURVEY PUBLICATIONS}

\section{Periodicals}

Earthquakes \& Volcanoes (issued bimonthly).

Preliminary Determination of Epicenters (issued monthly).

\section{Technical Books and Reports}

Professional Papers are mainly comprehensive scientific reports of wide and lasting interest and importance to professional scientists and engineers. Included are reports on the results of resource studies and of topographic. hydrologic, and geologic investigations. They also include collections of related papers addressing different aspects of a single scientific topic.

Bulletins contain significant data and interpretations that are of lasting scientific interest but are generally more limited in scope or geographic coverage than Professional Papers. They include the results of resource studies and of geologic and topographic investigations, as well as collections of short papers related to a specific topic.

Water-Supply Papers are comprehensive reports that present significant interpretive results of hydrologic investigations of wide interest to professional geologists, hydrologists, and enginecrs. The series covers investigations in all phases of hydrology, including hydrogeology, availability of water, quality of water. and use of water.

Circulars present administrative information or important scientific information of wide popular interest in a format designed for distribution at no cost to the public. Information is usually of short-term interest.

Water-Resources Investigations Reports are papers of an interpretive nature made available to the public outside the formal USGS publications series. Copies are reproduced on request unlike formal USGS publications, and they are also available for public inspection at depositories indicated in USGS catalogs.

Open-File Reports include unpublished manuscript reports, maps, and other material that are made available for public consultation at depositories. They are a nonpermanent form of publication that may be cited in other publications as sources of information.

\section{Maps}

Geologic Quadrangle Maps are multicolor geologic maps on topographic bases in 7.5- or 15-minute quadrangle formats (scales mainly $1: 24.000$ or $1: 62,500$ ) showing bedrock, surficial, or engineering geology. Maps generally include brief texts: some maps include structure and columnar sections only.

Geophysical Investigations Maps are on topographic or planimetric bases at various scales; they show results of surveys using geophysical techniques, such as gravity, magnetic, seismic, or radioactivity, which reflect subsurface structures that are of economic or geologic significance. Many maps include correlations with the geology.

Miscellaneous Investigations Series Maps are on planimetric or topographic bases of regular and irregular areas at various scales; they present a wide variety of format and subject matter. The series also includes 7.5-minute quadrangle photogeologic maps on planimetric bases that show geology as interpreted from aerial photographs. Series also includes maps of Mars and the Moon.
Coal Investigations Maps are geologic maps on topographic or planimetric bases at various scales showing bedrock or surficial geology, stratigraphy, and structural relations in certain coal-resource areas.

Oil and Gas Investigations Charts show stratigraphic information for certain oil and gas fields and other areas having petroleum potential.

Miscellaneous Field Studies Maps are milticolor or blackand-white maps on topographic or planimetric bases on quadrangle or irregular areas at various scales. Pre-1971 maps show bedrock geology in relation to specific mining or mineral-deposit problems; post-1971 maps are primarily black-and-white maps on vario'us subjects such as environmental studies or wilderness mineral investigations.

Hydrologic Investigations Atlases are multicolored or blackand-white maps on topographic or planimetric bases presenting a wide range of geohydrologic data of both regular and irregular areas; principal scale is 1:24.000, and regional studies are at 1:250.000 scale or smaller.

\section{Catalogs}

Permanent catalogs, as well as some others, giving comprehensive listings of U.S. Geological Survey publications are available under the conditions indicated below from the U.S. Geological Survey, Books and Open-File Reports Section, Federal Center, Box 25425. Denver, CO 80225. (See latest Price and Availability List.)

"Publications of the Geological Survey, 1879-1961" may be purchased by mail and over the counter in paperback book form and as a set of microfiche.

"Publications of the Geological Survey, 1962-1970" may be purchased by mail and over the counter in paperback book form and as a set of microfiche.

"Publications of the U.S. Geological Survey, 1971-1981" may be purchased by mail and over the counter in papert ack book form (two volumes, publications listing and index) and as a set of microfiche.

Supplements for 1982, 1983, 1984, 1985, 1986, and for subsequent years since the last permanent catalog may be purchased by mail and over the counter in paperback book form.

State catalogs, "List of U.S. Geological Sirvey Geologic and Water-Supply Reports and Maps For (State)," may be purchased by mail and over the counter in paperback booklet form only.

"Price and Availability List of U.S. Geological Survey Publications," issued annually, is available free of charge in paperback booklet form only.

Selected copies of a monthly catalog "New Publications of the U.S. Geological Survey" are available free of charge by mail or may be obtained over the counter in paperback booklet form only. Those wishing a free subscription to the monthly catalog "New Publications of the U.S. Geological Survey" should write to the U.S. Geological Survey, 582 National Center, Reston, VA 22092.

Note. - Prices of Government publications listed in older catalogs, announcements, and publications may be incorrect. Therefore. the prices charged may differ from the prices in catalogs, announcements, and publications. 
